\title{
Breast implant illness in silicone breast implant patients
}

Citation for published version (APA):

Colaris, M. J. L. (2022). Breast implant illness in silicone breast implant patients. [Doctoral Thesis, Maastricht University]. ProefschriftMaken. https://doi.org/10.26481/dis.20220211mc

Document status and date:

Published: 01/01/2022

DOI:

10.26481/dis.20220211mc

Document Version:

Publisher's PDF, also known as Version of record

\section{Please check the document version of this publication:}

- A submitted manuscript is the version of the article upon submission and before peer-review. There can be important differences between the submitted version and the official published version of record.

People interested in the research are advised to contact the author for the final version of the publication, or visit the DOI to the publisher's website.

- The final author version and the galley proof are versions of the publication after peer review.

- The final published version features the final layout of the paper including the volume, issue and page numbers.

Link to publication

\footnotetext{
General rights rights.

- You may freely distribute the URL identifying the publication in the public portal. please follow below link for the End User Agreement:

www.umlib.nl/taverne-license

Take down policy

If you believe that this document breaches copyright please contact us at:

repository@maastrichtuniversity.nl

providing details and we will investigate your claim.
}

Copyright and moral rights for the publications made accessible in the public portal are retained by the authors and/or other copyright owners and it is a condition of accessing publications that users recognise and abide by the legal requirements associated with these

- Users may download and print one copy of any publication from the public portal for the purpose of private study or research.

- You may not further distribute the material or use it for any profit-making activity or commercial gain

If the publication is distributed under the terms of Article $25 \mathrm{fa}$ of the Dutch Copyright Act, indicated by the "Taverne" license above, 


\section{Breast Implant Illness in \\ Silicone Breast Implant patients}

Maartje Josephine Lambertina Colaris 
All rights reserved. No part of this thesis may be reproduced, distributed, or transmitted in any form of by any means, including photocopying, recording, or other electronic or mechanical methods, without permission in writing of the author or from the publisher of the publication.

Illustrations by: Femke Colaris | www.femkecolaris.com

Final design: Jean Scheijen

Layout: Tiny Wouters

Printing: Proefschriftmaken.nl

ISBN: 978-94-6423-631-6

Printing of this thesis was financially supported by Maastricht University, Netherlands Side Affects Fund (Nederlandse Bijwerkingen Fonds) and Nederlandse Vereniging voor Plastische Chirurgie (NVPC).

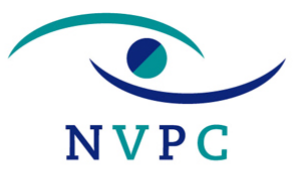

Nederlandse Vereniging voor Plastische Chirurgie handchirurgie, reconstructieve en esthetische chirurgie

\section{Nederlands Bilwerkingen Fonds}

\section{Maastricht University}




\title{
Breast Implant Illness in \\ Silicone Breast Implant patients
}

\author{
PROEFSCHRIFT
}

ter verkrijging van de graad van doctor aan de Universiteit Maastricht, op gezag van de Rector Magnificus, Prof. dr. Pamela Habibović, volgens het besluit van het College van Decanen,

in het openbaar te verdedigen

op vrijdag 11 februari 2022 om 13.00 uur

door

Maartje Josephine Lambertina Colaris geboren op 14 mei 1987 te Meerssen 


\section{Promoteres:}

Prof. dr. R.R.W.J. van der Hulst

Prof. dr. J.W. Cohen Tervaert

\section{Beoordelingscommissie:}

Prof. dr. V. Tjan-Heijnen (voorzitter)

Dr. J. van Bastelaar, Zuyderland Medisch Centrum

Prof. dr. A. Boonen

Prof. dr. G.A. van Koeveringe, Universiteit Maastricht

Dr. H. Rakhorst, Medisch Spectrum Twente 
Voor papa 



\section{TABLE OF CONTENTS}

Chapter 1 Introduction and overview of Silicone Breast Implant IIIness (SBII)

General Introduction and outline of the thesis

Overview of Silicone Breast Implant IIIness (SBII)

Chapter 2 Two hundreds cases of ASIA syndrome following silicone implants:

Chapter 3 Vitamin D deficiency as a risk factor for the development of autoantibodies In patients with ASIA and silicone breast implants: a cohort study and review of the literature

Chapter 4 Is explantation of silicone breast implants useful in patients with complaints?

Chapter 5 Subjective cognitive functioning in silicone breast implant patients: 108 A cohort study

Chapter 6 Summary, general discussion and future perspectives 


\section{CHAPTER 1}

Introduction and overview of

Silicone Breast Implant IIIness (SBII) 


\section{General Introduction and outline of the thesis}





\section{GENERAL INTRODUCTION}

\section{The female breast}

The female breast, composed of breast epithelium consists of glandular structures (acini) connected to a branched ductal system, has a naturally determined shape. ${ }^{1}$ It represents a woman's femininity and sensuality. Anatomical variations in shape, size, volume, and position of the female breasts on the chest, made them an unmistakable dignity in woman's self-image and self-esteem as well as a valuable part of the body in perception by society.

The individual and societal interest make aesthetic and reconstructive surgery of the female breast for plastic surgeons challenging, especially fitting to the many different expectations. The ideal size and shape of the female breast is not only subjective, but also influenced by cultural environment.

Breast implants are medical devices designed for surgical implantation to modify the size and shape of the breast in women. ${ }^{2}$ Breast implant surgery is the most common plastic surgery procedure performed globally of which the silicone-filled devices are used most commonly. ${ }^{2}$ Millions of women have had breast implantation surgery since the introduction of silicone gel-filled breast implants. Silicone implants were used in $85 \%$, and saline implants in $15 \%$, of all breast augmentations in $2019 .{ }^{3}$ An estimated $1-3 \%$ of all Dutch women have breast implants and it is estimated that around 30.000 implants are annually inserted. ${ }^{10}$

\section{History of Silicone Breast Implants}

Silicone Breast Implants (SBI), devices containing silicone gel within a silicone elastomer shell, were firstly introduced and implanted in a patient by Cronin and Gerow in 1962. ${ }^{4}$ Initially, these implants were accepted as being inert and considered as moderate risk devices (Class II). In the early 1980's, concerns arose about the safety of SBI resulting from local complications and other adverse outcomes as reported by new surveillance systems of The Food and Drug Administrations (FDA). ${ }^{5}$ Experiences with capsular contractures, reoperations and high rates of ruptured implants were issues of concern. At the same time, implants improved creating low-bleed devices with more durable shells that would decrease rupture rates. In June 1988, the FDA reclassified SBI into higher-risk devices (Class III), including products that needed premarket approval (PMA).5,6 April 10, 1991, 
the FDA asked manufacturers to provide data demonstrating safety and efficacy of the silicone breast implant devices and to submit PMA within 90 days. ${ }^{6}$ Meanwhile, patients had concerns regarding the safety of their implants, which were extensively reported in the laymen press. The American Society of Reconstructive and Plastic Surgery (ASRPS) independently reviewed the available data regarding the safety of silicone breast implants, as presented to the first FDA General \& Plastic Surgery Devices Panel meeting in November 1991. According to this review, problems associated with SBI were mainly local (e.g. rupture, capsular contracture) whereas no association between SBI and systemic disease was observed. ${ }^{6}$ The panel recommended that SBI could stay on the market for women undergoing breast reconstruction or a revision operation, but that additional safety data had to be collected. The $2^{\text {nd }}$ FDA General \& Plastic Surgery Devices Panel meeting in February 1992 classified SBI as investigational devices. ${ }^{6}$ Based on inadequately addressed safety concerns, the FDA restricted the use of SBI for reconstruction only in the context of scientific protocols in April 1992. SBI were no longer FDA approved for cosmetic purposes. This was accompanied with a call for studies on device performance and safety to improve surveillance of clinical outcomes. 5,7 From this moment on, the amount of scientific articles regarding a relation between connective tissue diseases (CTDS) and SBI increased. In July 1997, the Institute of Medicine (IOM) started to review all the past and current literature on the safety of SBI, commissioned by the Department of Health and Human Services (DHHS). The report was published in June 1999 and it was concluded that there was no link between SBI and CTDs and/or cancer. ${ }^{8}$ In May 2000, the manufacturers Inamed (previously McGhan) and Mentor got FDA approval to sell saline breast implants. In October 2003 and April 2005 the $3^{\text {th }}$ and $4^{\text {th }}$ FDA General \& Plastic Surgery Devices Panel meeting took place and advised approval of Mentor and Allergan (previous Inamed) SBI's. The implants were finally FDA approved on November 17, 2006 for reconstructive and aesthetic purposes. However, because of limited data on long-term outcomes, the FDA required the manufacturers to conduct post-approval studies.

\section{Epidemiology of Silicone Breast Implants}

After the introduction of SBI by Dow Corning in the 1960's, silicone became the mostly used implant filler for the next sixty years. Since the first presentation and use for application, a controversy has arisen on the safety and adverse effect of 
SBI. From the beginning on, SBI have been associated with certain clinical side effects, such as pain, capsular contracture, implant rupture and silicone leakage (,gel bleed'). The well-known Poly Implant Prothèse (PIP) Breast Implant Scandal from 2010 fuelled the local problems on SBI even more. The SBI by the French company PIP appeared to be made from cheaper industrial-grade silicone than normal and were found to have a higher risk of rupturing or leaking. ${ }^{9}$ On December 23, 2011 the French Government recommended for about 30.000 of woman to seek removal of the PIP breast implants. From this remarkable time point in the breast implant history, implants were once again examined more closely and once again questions arose on systemically and possible long-term side effects. ${ }^{10,11}$ Knowledge about breast implant prevalence is essential for assessing the absolute risk and public health impact of breast implant-related health problems. ${ }^{12}$ The PIP scandal clearly showed and highlighted the need for independent breast implant registry systems, not only to retrospectively detect affected patients, also to finish lack of clear epidemiological data. ${ }^{9}$ In the Netherlands, the Dutch Breast Implant Registry (DBIR) was introduced in 2015, a national opt-out and mandatory clinical registry that registers patients, surgery, and implant characteristics from all patients undergoing implantation and explantation of breast implants, and breast tissue expanders without the need for informed consent. ${ }^{13}$ The estimated national Dutch prevalence of breast implants among women between 20 and 70 years is $3.0 \%$, ranging from $1.7 \%$ at 21 to 30 years to $3.9 \%$ between 51 and 60 years. ${ }^{12}$ To study symptoms allocated by SBI patients to be due to SBI, requires an adequate duration of follow-up time. The FDA concluded that a study would need to collect data on hundreds of thousands of women for more than 10 years to confirm an association $^{5}$. Previous clinical studies on breast implant side effects were hampered by limitations such as under powering, selection bias, inadequately adjusting or not-adjusting for confounders, patient-reported symptoms which were not confirmed by a physician, lack on clarity of the existence of symptoms before the placement of breast implants and by lack of an adequate control group. ${ }^{15}$

\section{Silicone Breast Implants and systemic diseases}

A known extremely rare complication of $\mathrm{SBI}$ is breast implant-associated anaplastic large cell lymphoma (BIA-ALCL), firstly described by Keech and Creech. ${ }^{16} \mathrm{ALCL}$ is a 
rare form of T-cell non-Hodgkin lymphoma that may occur in the periprosthetic fluid or capsule of the SBI in women who undergo breast implantation. ${ }^{17,18}$

Whether SBI elicits inflammatory responses and/or autoimmune diseases/ reactions is still controversial. Autoimmune diseases that occur in SBI patients are rheumatoid arthritis (RA), Sjögren syndrome and other connective tissue diseases (CTD), vasculitis, granulomatous disease and others like multiple sclerosis and $\mathrm{M}$. Hashimoto. In a large meta-analysis by Balk et al., including 32 observational studies, concluded that there is no evidence for an association between SBI and any health outcomes. ${ }^{15}$ However, the authors observed a decreased risk for breast and endometrial cancer, and an increased risk for lung cancer, rheumatoid arthritis, Sjögren syndrome, and Raynaud syndrome. ${ }^{15}$ Limitations of the studies that were analysed were a general lack of adequate accounting for possible confounders (e.g., studies not specific to SBI). ${ }^{15}$ The most common risk of bias among studies was that analyses were mostly inadequately adjusted (4 studies) or not adjusted (27 studies) for potential confounders, whereas several studies reported adjusted analyses for some outcomes, but unadjusted analyses for other outcomes. ${ }^{15}$ Finally, there was no significant association between higher rates of suicide among SBI patients in comparison to the general population. ${ }^{15}$

In previous studies, it has been postulated that implant rupture and/or ageing can be important factors for eliciting an inflammatory response or for triggering the immune system upon silicone particles migrating throughout the body. ${ }^{19}$ All types of SBI are characterized by the phenomenon of gel bleed, which could lead to the spread of silicon material in organs. ${ }^{18}$ The migration of the silicone particles is accompanied by lymph node and thoracic silicone infiltration, with giant-cell granulomas and small silicone vacuoles found in lymph node biopsies. ${ }^{19,20}$

\section{Health complaints in silicone breast implant patients}

The typical clinical spectrum of systemically health complaints that SBI patients report, are myalgia, myositis or muscle weakness, arthralgia and/or arthritis, chronic fatigue, unrefreshing sleep or sleep disturbances, cognitive impairment (concentration problems, memory loss), pyrexia, dry eyes and/or dry mouth (sicca) as well as neurological manifestations (e.g. TIA, white matter lesions). ${ }^{10,21}$ Moreover, several other symptoms are frequently reported, such as Raynaud's phenomenon, recurrent respiratory tract infections, recurrent cystitis, livedo reticularis, headache, alopecia or hair loss, skin abnormalities, gastrointestinal 
symptoms (irritable bowel syndrome), night sweats, lymphadenopathy, and allergies. In a Dutch cohort study ( $n=32$ women with SBI and unexplained symptoms) patients were classified as having silicone implant incompatibility syndrome (SIIS) if they had systemic manifestations such as chronic fatigue, cognitive impairment, arthralgia, myalgias, sicca, and/or pyrexia. ${ }^{7}$ The median age at the time of evaluation was 49 years (range 18-64 years). ${ }^{7}$ Median time between start of complaints and time of breast implant was 10 years (2-24 years). ${ }^{7}$ Of the patients, 20\% reported signs and symptoms already within 2 years after operation; $33 \%$ developed signs and symptoms between 2 and 10 years after operation; 28\% between 10 and 20 years; and 19\% more than 20 years after the breast implant surgery. ${ }^{7}$ Of the $32 \mathrm{SBI}$ patients, 17 patients were classified as suffering from a systemic autoimmune disease, 7 patients from an organ-specific autoimmune disease and 15 had an immunodeficiency. ${ }^{7}$ In another descriptive Dutch cohort study ( $n=80$ women with SBI and unexplained systemic symptoms), 75\% of the women reported pre-existent allergy prior to implantation. ${ }^{11}$ The median age at time of diagnosis is around 47 years (range $22-78$ years). ${ }^{11}$ The median total exposure time to silicone breast implants was 14.5 years (range $2-42$ years). ${ }^{11}$ The most frequently reported symptoms include fatigue (89\%), neurasthenia (74\%), joint pain (69\%), muscle pain (65\%), morning stiffness (65\%), night sweats (63\%), and dyspnoea (45\%) and cognitive problems (35\%). ${ }^{11}$ The development of the symptoms after implantation of SBI begins after a symptom-free period of years with a median of 4.5 years (range 1 month to 30 years). ${ }^{11}$ While being exposed to $\mathrm{SBI}, 14 \%$ of patients developed a confirmed autoimmune disease at a median time of seven years after first implantation (range 3-30 years). ${ }^{11}$

These clinical findings in patients with SBI mimic the clinical picture of fibromyalgia, which is why it has been postulated that Breast Implant Illness is not a new disease. ${ }^{22}$ It has been postulated that in fibromyalgia, nociceptive signals (often psychological traumas) cause the development of symptoms via disturbed pain processing. ${ }^{23}$ The breast implant might trigger the nociceptors, which causes a disturbed pain signaling pathway and excessive stimulation of neurotransmitters in the central nervous system, and leads subsequently to systemic complaints. A major difference between idiopathic fibromyalgia and silicone-induced fibromyalgia, however, might be the co-occurrence of immune deficiency and/or autoimmunity. ${ }^{10}$ 


\section{Nomenclature}

During the years, a variety of terms have been applied to this clinical spectrum of SBI patient concerns; 'adjuvant breast disease' and 'human adjuvant disease' (1964), 'autoimmune/inflammatory syndrome induced by adjuvants (ASIA)' introduced by Shoenfeld $(2011)^{21}$, further specified as 'Silicone Implant Incompatibility Syndrome' (SIIS) $(2013)^{10}$ and the more well-known and most recently name 'Breast Implant IIIness' (2020). ${ }^{24,25}$

\section{OBJECTIVES OF THESIS}

Current evidence on the safety and adverse effects of SBI, "Breast Implant IIIness" (BII), remains still controversial. The aim of the thesis is to determine insight in the (systemically) health complaints that silicone breast implant patients are complaining about as well as to determine insight in which and how many SBI patients experience these health complaints. Moreover, the prevalence of health complaints in SBI patients in comparison to the general population and identifying other subgroups of SBI patients without complaints has been investigated, to determine if SBI patients are at higher risk for developing complaints.

\section{OUTLINE OF THE THESIS}

Chapter one: Starting with an introduction to the thesis, we first describe the evidence that is available to support the existence of Silicone Breast Implant IIIness (SBII), before describing the new data addressed in this thesis.

Chapter two: What is the spectrum of health complaints in a cohort of one hundred silicone breast implant patients diagnosed with ASIA (Maastricht, the Netherlands) and what are the differences and similarities in comparison with a cohort of one hundred patients diagnosed with adjuvant breast disease (Houston, USA) 30 years ago?

Chapter three: Is vitamin D deficiency or - insufficiency a risk factor for the development of autoantibodies in SBI patients with health complaints and what is the effect of vitamin D levels on the presence and/or titer levels of autoantibodies in different other autoimmune diseases? 
Chapter four: Which health complaints (including auto-immune diseases) improve after explantation of silicone breast implants and what is the course of these complaints after explantation as well as the effect on laboratory findings?

Chapter five: What is the prevalence and severity of subjective cognitive impairment in silicone breast implant patients with complaints compared to SBI patients without complaints and healthy controls? Is a possible relation to other symptoms as well as the duration of SBI exposure existing and what is the effect of ruptures and re-interventions on cognitive failure severity?

A summary and discussion as well as future perspectives is presented in the last chapter. 


\section{REFERENCES}

1. Vidi PA, Bissell MJ, Lelièvre SA. Three-dimensional culture of human breast epithelial cells: the how and the why. Methods Mol Biol. 2013;945:193-219.

2. Pirjavec Mahic A, Grebic D, Cargonja P, Kustic D. Silicone Gel Breast Implants: Past, Present, and Future. Acta Med Hist Adriat. 2020;18(1):165-176.

3. The American Society for Aesthetic Plastic Surgery (ASAPS). National Data Bank: Statistics 2019. Aesthet Surg J. 2020;40:1-26.

4. Cronin TD, Gerow FJ. Augmentation mammoplasty: A new "natural feel" prosthesis. In: Transactions of the third international congress of Plastic Surgery. Excerpta Medica Foundation, Amsterdam. 1963;66:41-49.

5. Center for Devices and Radiological Health and U.S. Food and Drug Administration. FDA Update on the Safety of Silicone Gel-Filled Breast Implants. June 2011. In. Accessed at The FDA Breast Implant website, www.fda.gov/breastimplants on 28 July 2020.

6. Spear SL, Parikh PM, Goldstein JA. History of breast implants and the food and drug administration. Clin Plast Surg. 2009;36(1):15-21, v.

7. Kessler, DA. The basis of the FDA's decision on breast implants. N Engl J Med. 1992;326:1713-1715.

8. Bondurant S, Ernster V, Herdman R. Institute of Medicine (US) Committee on the Safety of Silicone Breast Implants. Safety of Silicone Breast Implants. Washington, DC: The National Academies Press. 1999.

9. Wazir U, Kasem A, Mokbel K. The clinical implications of poly implant prothese breast implants: an overview. Arch Plast Surg. 2015;42(1):4-10.

10. Cohen Tervaert JW, Kappel RM. Silicone implant incompatibility syndrome (SIIS): a frequent cause of ASIA (Shoenfeld's syndrome). Immunol Res. 2013;56(2-3):293-298.

11. Maijers MC, de Blok CJ, Niessen FB, et al. Women with silicone breast implants and unexplained systemic symptoms: a descriptive cohort study. Neth J Med. 2013;71(10):534-540.

12. de Boer M, van Middelkoop M, Hauptmann M, et al. Breast Implant Prevalence in the Dutch Female Population Assessed by Chest Radiographs. Aesthet Surg J. 2020;40(2):156-164.

13. Rakhorst HA, Mureau MAM, Cooter RD, et al. The new opt-out Dutch National Breast Implant Registry Lessons learnt from the road to implementation. J Plast Reconstr Aesthet Surg. 2017;70(10):13541360.

14. Center for Devices and Radiological Health; U.S. Food and Drug Administration. Anaplastic large cell lymphoma (ALCL) in women with breast implants: preliminary FDA findings and analyses. 2011. Accessed www.fda.gov/MedicalDevices/ProductsandMedicalProcedures/ImplantsandProsthetics/BreastImplants /ucm239996.

15. Balk EM, Earley A, Avendano EA, Raman G. Long-Term Health Outcomes in Women With Silicone Gel Breast Implants: A Systematic Review. Ann Intern Med. 2016;164(3):164-175.

16. Keech JA, Jr., Creech BJ. Anaplastic T-cell lymphoma in proximity to a saline-filled breast implant. Plast Reconstr Surg. 1997;100(2):554-555.

17. de Boer M, van Leeuwen FE, Hauptmann M, et al. Breast Implants and the Risk of Anaplastic Large-Cell Lymphoma in the Breast. JAMA Oncol. 2018;4(3):335-341.

18. Leberfinger AN, Behar BJ, Williams NC, et al. Breast Implant-Associated Anaplastic Large Cell Lymphoma: A Systematic Review. JAMA Surg. 2017;152(12):1161-1168.

19. Nesher G, Soriano A, Shlomai G, et al. Severe ASIA syndrome associated with lymph node, thoracic, and pulmonary silicone infiltration following breast implant rupture: experience with four cases. Lupus. 2015;24(4-5):463-468.

20. Kappel RM, Boer LL, Dijkman H. Gel Bleed and Rupture of Silicone Breast Implants Investigated by Light-, Electron Microscopy and Energy Dispersive X-ray Analysis of Internal Organs and Nervous Tissue. Clin Med Rev Case Rep. 2016;3(1):1-9.

21. Shoenfeld Y, Agmon-Levin N. 'ASIA' - autoimmune/inflammatory syndrome induced by adjuvants. J Autoimmun. 2011;36(1):4-8. 
22. Wolfe F. "Silicone related symptoms" are common in patients with fibromyalgia: no evidence for a new disease. J Rheumatol. 1999;26(5):1172-1175.

23. Clauw DJ, Arnold LM, McCarberg BH, FibroCollaborative. The science of fibromyalgia. Mayo Clin Proc. 2011;86(9):907-911.

24. Mcguire PA, Haws MJ, Nahai F. Breast Implant Illness: How Can We Help? Aesthet Surg J. 2019;39(11):1260-1263.

25. Magnusson MR, Cooter RD, Rakhorst H, McGuire PA, Adams WP, Jr., Deva AK. Breast Implant IIlness: A Way Forward. Plast Reconstr Surg. 2019;143(3S A Review of Breast Implant-Associated Anaplastic Large Cell Lymphoma):74S-81S. 


\section{Overview of Silicone Breast Implant IIIness (SBII)}


Published as:

Silicone breast implants and autoimmune rheumatic diseases: myth or reality

\author{
Jan Willem Cohen Tervaert \\ Maartje JL Colaris \\ René RWJ van der Hulst
}

Curr Opin Rheumatol. 2017 Jul;29(4):348-354. 



\section{INTRODUCTION}

The first silicone breast implants (SBIs) were performed by Cronin and Gerow in 1962. ${ }^{1}$ Silicone gel was wrapped in an impermeable silicone envelope developed by Dow Corning. The SBI implantation procedure was considered a success, and since then, millions of women received SBI either as a cosmetic procedure or because of postmastectomy reconstruction. Soon thereafter, local and distant complications of the SBI procedure were reported and the first case reports were published with women developing arthralgias and fatigue and sometimes an autoimmune disease. ${ }^{2-5}$ Over the next 50 years, hundreds of patients are reported with similar symptoms and signs. ${ }^{6}$ Both patients and doctors suspect that these complaints are caused by the implants. Indeed, removal of the SBI results in an amelioration of symptoms in $60-80 \%$ of the patients. ${ }^{7}$ During recent years, we have seen over 200 patients with clinical signs and symptoms of this so-called siliconeincompatibility syndrome. In the current review, we describe signs and symptoms, and discuss potential pathophysiological mechanisms and disease management.

\section{SYMPTOMS AND SIGNS}

Typically, patients develop chronic fatigue and are already tired when they wake up, whereas the fatigue is not alleviated by rest. Patients have a substantial reduction in the ability to engage levels of occupational, educational, social and/or personal activities as before the illness started. Sleep disturbances such as problems falling asleep and/or staying asleep are often present. In addition, most patients report postexertional malaise. Probably related to these symptoms are the symptoms of cognitive impairment resulting in memory deficits ('Alzheimer-light'), absent-mindedness, word-finding difficulties and difficulty paying attention. Another early symptom is the occurrence of arthralgias or arthritis that is present in more than $90 \%$ of the patients. Most patients fulfill the 2016 criteria for fibromyalgia (see Table 1.1). ${ }^{8}$ Most (70-80\%) patients also suffer from morning stiffness that sometimes may last more than an hour. Patients, however, may also present with a symmetric polyarthritis compatible with a diagnosis of rheumatoid arthritis. ${ }^{9-10}$ 
Table 1.1 Fibromyalgia 2016 criteria.

A patient satisfies modified 2016 fibromyalgia criteria if the following 3 conditions are met:

(1) Widespread pain index (WPI) $\geq 7$ \& symptom severity scale (SSS) score $\geq 5$ OR WPI of 4-6 \& SSS score $\geq 9$

(2) Generalized pain, defined as pain in at least four of five regions, must be present. Jaw, chest and abdominal pain are not included in generalized pain definition.

(3) Symptoms must have been present for at least 3 months.

A diagnosis of fibromyalgia is valid irrespective of other diagnoses. A diagnosis of fibromyalgia does not exclude the presence of other clinically important illnesses.

Notes

(1) WPI: note the number of areas in which the patient has had pain over the last week. In how many areas has the patient had pain? Score will be between 0 and 19.

(2) Symptom severity scale (SSS) score Fatigue, Waking unrefreshed, Cognitive symptoms

For the each of the 3 symptoms above, indicate the level of severity over the past week using the

following scale:

0. No problem

1. Slight or mild problems, generally mild or intermittent

2. Moderate, considerable problems, often present and/or at a moderate level

3. Severe: pervasive, continuous, life-disturbing problems

The symptom severity scale (SSS) score is the sum of the severity scores of the three symptoms (fatigue, waking unrefreshed and cognitive symptoms) (0-9) and the sum (0-3) of the number of the following symptoms the patient has been bothered by that occurred during the previous 6 months:

(1) Headaches (0-1)

(2) Pain or cramps in lower abdomen (0-1)

(3) Depression (0-1)

The final symptom severity score (SSS) is between 0 and 12 .

Adapted from ${ }^{8}$

In addition, up to $90 \%$ of the patients have myalgias and/or muscle weakness. Weakness can be severe and may render the patient to be bedridden. In one study, an electromyography (EMG) was performed in 93 patients. The EMG was abnormal in $53 \%$ of the patients. ${ }^{11}$ Most often, a 'myopathic' pattern was found in these patients. ${ }^{11}$

Furthermore, two-third of the patients report pyrexia, whereas night sweats are common. Some patients additionally have strongly elevated ferritin levels and fulfill the diagnostic criteria for (silicone-induced) Still's disease. ${ }^{12}$ Importantly, 75\% of patients have dry eyes and/or a dry mouth. Symptoms of the dry eyes are often severe and may result in blurred vision and/or a keratitis sicca if left untreated. Sjogren syndrome A/Sjogren syndrome B (SSA/SSB) antibodies are only present in a minority of patients ${ }^{5}$, whereas salivary gland biopsies disclose mononuclear cell infiltrates different from what can be found in Sjogren's syndrome. ${ }^{13-14}$

Furthermore, 30-50\% of the patients develop new-onset Raynaud's phenomenon sometimes with nailfold abnormalities as demonstrated by capillaroscopy suggestive of systemic sclerosis. 
Another important manifestation that is present in $30-40 \%$ of patients is the occurrence of ischemic cerebral disease or a multiple sclerosis-like syndrome. ${ }^{5,11}$ Anticardiolipin antibodies and/or lupus anticoagulant are detected in only a minority of the patients. As patients without these antibodies lack traditional risk factors for a cerebro-vascular accident, a diagnosis of seronegative antiphospholipid syndrome is often considered. ${ }^{15-16}$

Allergies are reported in $50-80 \%$ of the patients. ${ }^{17}$ In most patients, these allergies are preexistent. In many cases, however, the patient report that allergic complaints had disappeared before the SBI operation and returned thereafter. Allergic complaints include sneezing, itching of the nose and eyes, red eyes, rhinorrhea, nasal congestion and postnasal drip. Furthermore, asthmatic patients may suffer from cough, wheeze and shortness of breath. Food allergies also occur and about $10-20 \%$ of the patients develop new-onset urticarial and/or quincke's oedema. A remarkable frequent finding (about $50 \%$ of patients) is metal-allergy with nickelinduced dermatitis. Furthermore, some patients present with episodic symptoms suggesting a diagnosis of mast cell activation syndrome. ${ }^{18-19}$

Finally, some patients present with a multiple chemical sensitivity syndrome. ${ }^{20}$ Dyspnoea in SBI patients can be a result of severe asthma, pulmonary nodules, interstitial lung disease and/or pulmonary silicone embolism. ${ }^{21-23}$ Furthermore, 20-40\% of patients suffer from severe and/or recurrent (upper respiratory tract) infections. Breast pain, tenderness and burning sensations are occasionally present. In addition, changes in breast shape, breast asymmetry, firmness of the breasts and breast enlargement may be noticed. Lymph nodes (axillary, cervical and inguinal) are often enlarged and tender (70-80\% of patients). Cardiovascular complaints include signs of orthostatic intolerance such as dizziness, disturbed balance, irregular heartbeat and sometimes chest pain. A mitral valve prolapse and/or joint hypermobility is found in about half of the patients. ${ }^{24}$ Twenty to forty percent of patients suffer from gastrointestinal symptoms such as abdominal pain with changes in bowel movement patterns such as found in irritable bowel syndrome. Swallowing difficulties and/or dysphagia are in most cases related to the sicca complaints.

A substantial amount of patients (10-20\%) have interstitial cystitis. The skin may be painful and burning sensations ('pins and needles') suggest that (atypical) small fiber neuropathy is present. ${ }^{25} \mathrm{~A}$ prominent livedo reticularis can be found in about $20-30 \%$ of patients, whereas mild livedo reticularis is present in another $30-40 \%$ 
of patients. Occasionally, tender subcutaneous nodules can be observed in the arms, legs, abdominal wall and/or elsewhere in the body. Histologically, these nodules demonstrate granulomatous inflammation (i.e. migratory silicone granulomas). ${ }^{22,26}$ Finally, 20-40\% of patients have ill-defined skin rashes, unexplained (sometimes severe) pruritus and/or alopecia. Laboratory findings are often nonspecific. Generally, C-reactive protein levels are normal. Angiotensinconverting enzyme and soluble interleukin-2 receptor levels are, however, in up to $50 \%$ of patients elevated. Antinuclear antibodies are present in $20 \%$ of patients, whereas various other antibodies such as SSA/SSB, anti-dsDNA, anti-Scl-70, anticardiolipin, anti-cyclic citrullinated peptide antibodies, IgM rheumatoid factor, antineutrophil cytoplasmic antibodies and/or cryoglobulins may be found.5,6 Furthermore, antipolymer antibodies have been described, but their diagnostic value is at present uncertain. ${ }^{27}$ Vitamin $D$ insufficiency and/or deficiency is a frequent finding and $20-50 \%$ of patients have decreased levels of IgG and/or IgG subclasses. ${ }^{5,6}$

\section{AUTOIMMUNE/INFLAMMATORY SYNDROME INDUCED BY ADJUVANTS, AUTOIMMUNE DISEASES AND ANAPLASTIC LARGE T-CELL LYMPHOMA}

The symptoms described above received during the last 50 years several different names: human adjuvant disease, siliconosis, silicone incompatibility syndrome and - more recently - autoimmune/inflammatory syndrome induced by adjuvants $(A S I A)^{6,28}$; Table 1.2. Others, however, state that these patients do not suffer from a separate disease, but are merely suffering from idiopathic chronic fatigue syndrome/mylagic encephalomyelitis (CFS/ME), fibromyalgia or mass somatization. ${ }^{29-31}$ We hypothesize that as a consequence of the immune activation, ASIA, allergies, autoantibodies, autoimmune diseases, IgG and/or IgG subclass deficiencies and finally lymphomas may develop.

ASIA was firstly described by Shoenfeld and Agmon-Levin in 2011. This syndrome assembles a spectrum of immune-mediated diseases triggered by adjuvants in persons who are genetically predisposed to it. ${ }^{28}$ Potential triggers are silicones, injection of mineral oil or other foreign substances and/or vaccines. In 2013, we reported 32 patients with ASIA due to silicone incompatibility syndrome. ${ }^{5}$ Median time between start of complaints and time of breast implant was 10 years 
(2-24 years). Fifty-three percent of the ASIA patients had an established systemic autoimmune disease, $22 \%$ of patients had an organ-specific autoimmune disease and $47 \%$ of patients a humoral immunodeficiency (either hypogammaglobulinemia or a IgG subclass deficiency). Subsequently, many patients with selfreported symptoms were evaluated in the Netherlands. ${ }^{6,17}$ From these, about 95\% fulfilled the criteria for ASIA (Table 1.2). These patients all had fatigue and/or cognitive symptoms, arthralgias and/or myalgias, and sicca complaints and/or pyrexia. Seventy to eighty percent of these ASIA patients had cosmetic breast augmentation, whereas $20-30 \%$ of these patients had breast reconstruction after mastectomy for breast cancer. More than $99 \%$ of the patients were women, the remaining being (transgender) males. At present, there are no epidemiologic studies performed to calculate the risk of ASIA in SBI patients. In the Netherlands, more than 4700 women with $\mathrm{SBI}$ and health issues registered themselves at a Dutch foundation for women with illness due to breast implants. Unfortunately, it is not known how many Dutch women have SBI. Importantly, however, since April 2015, data about all new patients with SBI are being collected, independently and prospectively, in the Dutch Breast Implant Registry. Clearly, more epidemiological studies on the association between ASIA and SBI are needed.

Many patients also fulfill the criteria for $\mathrm{CFS} / \mathrm{ME}^{32}$, fibromyalgia ${ }^{9}$, sarcoidosis ${ }^{5,33}$ and/or undifferentiated connective tissue disease. Furthermore, a substantial number of patients have well defined systemic autoimmune diseases such as Sjogren syndrome, antiphospholipid syndrome, rheumatoid arthritis, systemic sclerosis, systemic lupus erythematosus, eosinophilic granulomatosis with polyangiitis and different other forms of vasculitis. .,6,21 $^{2}$

Epidemiologic evidence for an increased occurrence of these autoimmune diseases is, however, sparse. ${ }^{10}$ In a recent meta-analysis, increased risks for rheumatoid arthritis and Sjogren syndrome were found. Importantly, the systematic review concluded that studies still do not provide conclusive evidence regarding safety of $\mathrm{SBI}$. Further investigations are required to determine whether increased occurrences exist between silicone gel implants and autoimmune diseases. ${ }^{10} \mathrm{SBI}$ patients, however, clearly have an increased risk to develop lymphomas. ${ }^{34-36}$ Especially, the risk to develop an anaplastic large T-cell lymphoma (ALCL) of the breast negative for anaplastic lymphoma kinase-1 (ALK-1) but positive for CD30 is strongly increased (odds ratio of 18.2). 
Table 1.2 Criteria for the diagnosis of autoimmune/inflammatory syndrome induced by adjuvants.

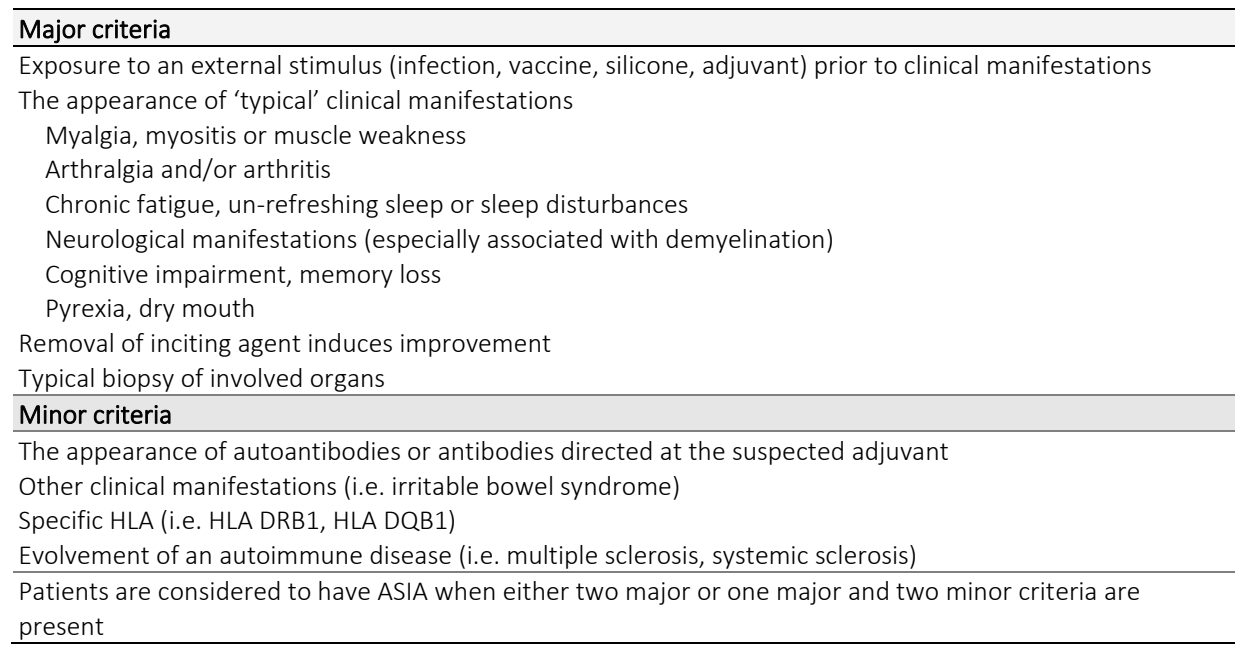

$H L A=$ human leukocyte antigen.

Adapted from ${ }^{28}$.

\section{PATHOPHYSIOLOGY OF SILICONE BREAST IMPLANTS RELATED DISEASE(S)}

In the late 1940s and in the 1950s, silicones were directly injected in the breast for augmentation purposes. Injected silicones, however, did not remain at the injection site and spread through the body and induced a foreign body reaction resulting in granulomatous inflammation. ${ }^{37}$ Furthermore, autoimmune/ inflammatory phenomena may occur. Silicone-gel can migrate outside the outer shell after SBI rupture. Migration through an intact shell has also been demonstrated (so-called 'gel bleed'). Recently, silicone material was found in multiple organs, nervous tissue and the brain in a patient at autopsy. ${ }^{38}$

The association between SBI and ASIA may result in the following scenario ${ }^{39-41}$ : Silicon-containing particles are captured by macrophages, resulting in entrapment within lysosomes. Subsequently, inflammasomes are activated, resulting in the production of cytokines such as interleukin-1 $\beta$. Also, reactive oxygen species (ROS) and reactive nitrogen species are produced. Subsequently, apoptosis of macrophages occurs resulting in the release of silicon-containing particles that can be taken up once again by other macrophages. Exposure to silicon- containing particles also leads to a massive production of interleukin-17 resulting in an influx 
of neutrophils that are activated and produce ROS and release enzymes such as myeloperoxidase. In addition, silicon-containing particles are transported to the regional lymph nodes, resulting in a pronounced adjuvant effect.

In animal models, it has been shown that SBI induces an adjuvant effect ${ }^{42-44}$ and increase the susceptibility to and/or exacerbate autoimmune diseases. ${ }^{45-47}$ In nonsusceptible animals, however, autoimmunity could not be induced. ${ }^{45}$ Which women susceptible are for development of SBI-related disease is at present unknown. However, several factors have been postulated. ${ }^{48}$ Firstly, patients who are known to have (a history of) allergy and/or an established autoimmune disease are at risk. Furthermore, those who have a familial predisposition for autoimmune disease are also prone to develop symptoms after SBI. It is important to realize that not only immunogenetic (i.e. human leukocyte antigen) factors play a role in the development of SBI-induced ASIA but probably also environmental factors such as smoking and obesity. ${ }^{48-50}$

Finally, in women with SBI, it is found that the capsule around these SBIs contain inflammatory cells that are predominantly Th1/Th17 cells, whereas regulatory T cells in the capsules are defective in suppressing these intracapsular T cells. ${ }^{51}$ These findings suggest that the Th17/Treg balance is disturbed that may result in the development of inflammatory/autoimmune diseases. ${ }^{52}$ Importantly, many patients with ASIA due to SBI have a humoral immune-deficiency ${ }^{5}$ and a vitamin D deficiency. ${ }^{53}$ These two factors also increase the risk to develop an autoimmune disease in susceptible patients. ${ }^{5,53}$ Furthermore, the chronic inflammation by the $\mathrm{SBI}$ in the capsule may result in progression from polyclonal lymphocyte stimulation to monoclonal lymphocyte stimulation, which in turn will result in lymphoma formation such as ALCL. ${ }^{35}$

\section{DISEASE MANAGEMENT}

Unfortunately, there are no randomized clinical trials performed on the management of women with SBI-related diseases. Also, there are no (inter)national guidelines formulated. However, on the basis of our personal experience, some therapeutic considerations should be considered. Firstly, vitamin $D$ deficiency and/or insufficiency should be corrected. As vitamin D may act as a regulatory agent of the immune system ${ }^{53-55}$, we prescribe vitamin $D$ 
supplementation to our patients. ${ }^{55-56}$ Secondly, triggers of immune activation should be avoided and/or treated. The patient should try to quit smoking. Furthermore, antiallergic medication should be prescribed to patients with allergic rhinosinusitis, whereas bacterial (respiratory) infections should be treated with antibiotics, especially when IgG levels and/or IgG subclasses are deficient. ${ }^{57}$ Furthermore, for eye symptoms, preservative-free tear supplements should be prescribed.

There is ample evidence that explantation of the SBI is an important first step in the management of women with SBI-related disorders. ${ }^{7,17}$ In our recent review, we found that 469 of 622 reported patients (75\%) improved after explantation. The shorter the period is that the SBI were in place, the better the amelioration of systemic symptoms and signs following removal. ${ }^{58}$ In patients who had already developed an established autoimmune disease, only $16 \%$ improved without additional immunosuppressive therapy. ${ }^{7}$

Unfortunately, several women still suffer from ASIA after explantation possibly because silicones are present throughout the body. ${ }^{38}$ There are no medications that can cure ASIA, but therapy can help reduce symptoms. Suggested medications include minocycline or doxycycline ${ }^{59-61}$, hydroxychloroquine or corticosteroids to dampen inflammation. In addition, medication may be prescribed for symptoms due to central sensitization ${ }^{62}$, gastrointestinal involvement ${ }^{63}$ and/or cardiovascular involvement. ${ }^{64}$ Finally, as in patients with fibromyalgia, a combination of drug, cognitive behavioural and exercise treatment should be considered. ${ }^{65-66}$ Also, some patients need psychiatric consultation. ${ }^{67}$

\section{CONCLUSION}

SBls are associated in a proportion of patients with complaints such as fatigue, cognitive impairment, arthralgias, myalgias, pyrexia, dry eyes and dry mouth. During the last few years, the concept that these symptoms are due to an adjuvant effect of migrated silicones has been further worked-out. Due to either SBI rupture or gel-bleed, silicones can migrate through the body into tissues and the central nervous system. Furthermore, these silicones can induce a chronic inflammatory process that may ultimately result in (an increase of) allergies, autoimmune diseases, immune deficiency and/or lymphomas. Explantation of SBI results in the 
majority of patients in an amelioration of the symptoms. There is an urgent need to start adequately adjusted epidemiological studies and creative postmarketing surveillance to obtain better evidence which percentage of patients does develop ASIA, immune deficiency, autoimmune diseases and/or ALCL. 


\section{REFERENCES}

1. Cronin TD, Gerow FJ. Augmentation mammoplasty: A new "natural feel" prosthesis. In: Transactions of the third international congress of Plastic Surgery. Excerpta Medica Foundation, Amsterdam. 1963;66:41-49.

2. Miyoshi K, Miyamura T, Kobayashi Y, et al. Hypergammaglobulinemia by prolonged adjuvanticity in man: disorders developed after augmentation mammaplasty. Jpn Med J. 1964;2122:9-14.

3. Ashley FL, Braley S, Rees TD, et al. The present status of silicone fluid in soft tissue augmentation. Plast Reconstr Surg. 1967;39(4):411-418.

4. van Nunen SA, Gatenby PA, Basten A. Post-mammoplasty connective tissue disease. Arthritis Rheum. 1982;25(6):694-697.

5. Cohen Tervaert JW, Kappel RM. Silicone implant incompatibility syndrome (SIIS): a frequent cause of ASIA (Shoenfeld's syndrome). Immunol Res. 2013;56(2-3):293-298.

6. Colaris MJL, de Boer M, van der Hulst RR, Cohen Tervaert JW. Two hundreds cases of ASIA syndrome following silicone implants: a comparative study of 30 years and a review of current literature. Immunol Res. 2017;65(1):120-128.

7. de Boer M, Colaris M, van der Hulst RR, Cohen Tervaert JW. Is explantation of silicone breast implants useful in patients with complaints? Immunol Res. 2017;65(1):25-36.

8. Wolfe F, Clauw DJ, Fitzcharles MA, et al. 2016 Revisions to the 2010/2011 fibromyalgia diagnostic criteria. Semin Arthritis Rheum. 2016;46(3):319-329.

9. Meier LG, Barthel HR, Seidl C. Development of polyarthritis after insertion of silicone breast implants followed by remission after implant removal in 2 HLA-identical sisters bearing rheumatoid arthritis susceptibility genes. J Rheumatol. 1997; 24(9):1838-1841.

10. Balk EM, Earley A, Avendano EA, Raman G. Long-Term Health Outcomes in Women With Silicone Gel Breast Implants: A Systematic Review. Ann Intern Med. 2016;164(3):164-175.

11. Shoaib BO, Patten BM, Calkins DS. Adjuvant breast disease: an evaluation of 100 symptomatic women with breast implants or silicone fluid injections. Keio J Med. 1994; 43(2):79-87.

12. Dagan A, Kogan M, Shoenfeld Y, Segal G. When uncommon and common coalesce: adult onset Still's disease associated with breast augmentation as part of autoimmune syndrome induced by adjuvants (ASIA). Clin Rheumatol. 2016; 35(6):1643-1648.

13. Freundlich B, Altman C, Snadorfi N, et al. A profile of symptomatic patients with silicone breast implants: a Sjo" grens-like syndrome. Semin Arthritis Rheum. 1994;24(1 Suppl 1):44-53.

14. Mavromatis BH, Tzioufas AG, Moutsopoulos HM. Sjogren-like disease and silicone implants: a Greek experience. J Clin Rheumatol. 1998;4(3):147-150.

15. Hughes GR, Khamashta MA. Seronegative antiphospholipid syndrome. Ann Rheum Dis. 2003;62(12):1127.

16. Nayfe R, Uthman I, Aoun J, et al. Seronegative antiphospholipid syndrome. Rheumatology (Oxford). 2013;52(8):1358-1367.

17. Maijers MC, de Blok CJ, Niessen FB, et al. Women with silicone breast implants and unexplained systemic symptoms: a descriptive cohort study. Neth J Med. 2013;71(10):534-540.

18. Frieri M, Patel R, Celestin J. Mast cell activation syndrome: a review. Curr Allergy Asthma Rep. 2013;13(1):27-32.

19. Maharaj S. An atypical immune-inflammatory disorder secondary to breast implant exposure. J Long Term Eff Med Implants. 2012;22(1):33-48.

20. Spencer TR, Schur PM. The challenge of multiple chemical sensitivity. J Environ Health. 2008;70(10):2427.

21. David PR, Dagan A, Colaris M, et al. Churg-Strauss syndrome: singulair or silicone (or both?). Isr Med Assoc J. 2016;18(3-4):168-170.

22. Dragu A, Theegarten $D$, Bach $A D$, et al. Intrapulmonary and cutaneous siliconomas after silent silicone breast implant failure. Breast J. 2009;15(5):496-499.

23. Gopinath PP, Ali A, Van Tornout F, et al. Chronic silicone embolism syndrome due to PIP breast implant leakage: a new entity? Histopathology. 2015;66(6):904-906. 
24. Grahame R, Bird HA, Child A. The revised (Brighton 1998) criteria for the diagnosis of benign joint hypermobility syndrome (BJHS). J Rheumatol. 2000;27(7):1777-1779.

25. Clauw DJ. What is the meaning of 'small fiber neuropathy' in fibromyalgia? Pain. 2015;156(11):21152116.

26. Teuber SS, Reilly DA, Howell L, et al. Severe migratory granulomatous reactions to silicone gel in 3 patients. J Rheumatol. 1999;26(3):699-704.

27. Wolfram D, Oberreiter B, Mayerl C, et al. Altered systemic serologic parameters in patients with silicone mammary implants. Immunol Lett. 2008;118(1):96-100.

28. Shoenfeld Y, Agmon-Levin N. 'ASIA' - autoimmune/inflammatory syndrome induced by adjuvants. J Autoimmun. 2011;36(1):4-8.

29. Fenske TK, Davis P, Aaron SL. Human adjuvant disease revisited: a review of eleven postaugmentation mammoplasty patients. Clin Exp Rheumatol. 1994;12(5):477-481.

30. Wolfe F. "Silicone related symptoms" are common in patients with fibromyalgia: no evidence for a new disease. J Rheumatol. 1999;26(5):1172-1175.

31. Dush DM. Breast implants and illness: a model of psychological factors. Ann Rheum Dis 2001;60(7):653-657.

32. Clayton EW. Beyond myalgic encephalomyelitis/chronic fatigue syndrome: an IOM report on redefining an illness. JAMA. 2015;313(11):1101-1102.

33. Teuber SS, Howell LP, Yoshida SH, Gershwin ME. Remission of Sarcoidosis following removal of silicone gel breast implants. Int Arch Allergy Immunol. 1994;105(4):404-407.

34. de Jong D, Vasmel WL, de Boer JP, et al. Anaplastic large-cell lymphoma in women with breast implants. JAMA. 2008;300(17):2030-2035.

35. Bizjak M, Selmi C, Praprotnik S, et al. Silicone implants and lymphoma: the role of inflammation. J Autoimmun. 2015;65:64-73.

36. Clemens MW, Miranda RN, Butler CE. Breast implant informed consent should include the risk of anaplastic large cell lymphoma. Plast Reconstr Surg. 2016; 137(4):1117-1122.

37. Barilaro G, Spaziani Testa C, Cacciani A, et al. ASIA syndrome, calcinosis cutis and chronic kidney disease following silicone injections. A case-based review. Immunol Res. 2016;64(5-6):1142-1149.

38. Kappel RM, Boer LL, Dijkman H. Gel Bleed and Rupture of Silicone Breast Implants Investigated by Light-, Electron Microscopy and Energy Dispersive X-ray Analysis of Internal Organs and Nervous Tissue. Clin Med Rev Case Rep. 2016;3(1):1-9.

39. Cohen Tervaert JW. Silicon exposure and vasculitis. In: Uversky VN, Kretsinger RH, Permyakov EA, editors. Encyclopedia of metalloproteins. Berlin: Springer Science. Business Media, LLC; 2012. pp. 1983-1988.

40. Lee $\mathrm{S}$, Hayashi $\mathrm{H}$, Maeda M, et al. Environmental factors producing autoimmune dysregulation: chronic activation of T cells caused by silica exposure. Immunobiology. 2012;217(7):743-748.

41. Yoshida SH, Chang CC, Teuber SS, Gershwin ME. Silicon and silicone: theoretical and clinical implications of breast implants. Regul Toxicol Pharmacol. 1993;17(1):3-18.

42. Narins RS, Beer K. Liquid injectable silicone: a review of its history, immunology, technical considerations, complications, and potential. Plast Reconstr Surg. 2006;118(3 Suppl):S77-S84.

43. Naim JO, Lanzafame RJ, van Oss CJ. The adjuvant effect of silicone-gel on antibody formation in rats. Immunol Invest. 1993;22(2):151-161.

44. Nicholson JJ3rd, Hill SL, Frondoza CG, Rose NR. Silicone gel and octamethylcyclotetrasiloxane (D4) enhances antibody production to bovine serum albumin in mice. J Biomed Mater Res. 1996;31(3):345353.

45. McDonald AH, Weir K, Schneider $M$, et al. Silicone gel enhances the development of autoimmune disease in New Zealand black mice but fails to induce it in BALB/cAnPt mice. Clin Immunol Immunopathol. 1998;87(3):248-255.

46. Schaefer CJ, Lawrence WD, Wooley PH. Influence of long term silicone implantation on type II collagen induced arthritis in mice. Ann Rheum Dis. 1999;58(8):503-509.

47. Schaefer CJ, Wooley PH. The influence of silicone implantation on murine lupus in MRL Ipr/lpr mice. J Rheumatol. 1999;26(10):2215-2221. 
48. Goren I, Segal G, Shoenfeld Y. Autoimmune/inflammatory syndrome induced by adjuvant (ASIA) evolution after silicone implants. Who is at risk? Clin Rheumatol. 2015; 34(10):1661-1666.

49. Kappel RM, Cohen Tervaert JW, Pruijn GJ. Autoimmune/inflammatory syndrome induced by adjuvants (ASIA) due to silicone implant incompatibility syndrome in three sisters. Clin Exp Rheumatol. 2014;32(2):256-258.

50. Watad A, Quaresma M, Brown S, et al. Autoimmune/inflammatory syndrome induced by adjuvants (Shoenfeld's syndrome): an update. Lupus. 2017;26(7):675-681.

51. Wolfram D, Rabensteiner E, Grundtman C, et al. T regulatory cells and TH17 cells in peri-silicone implant capsular fibrosis. Plast Reconstr Surg. 2012;129(2):327e-337e.

52. Noack $M$, Miossec $P$. Th17 and regulatory $T$ cell balance in autoimmune and inflammatory diseases. Autoimmun Rev. 2014;13(6):668-677.

53. Colaris MJL, van der Hulst RR, Cohen Tervaert JW. Vitamin D deficiency as a risk factor for the development of autoantibodies in patients with ASIA and silicone breast implants: a cohort study and review of the literature. Clin Rheumatol. 2017;36(5):981-993.

54. Peelen E, Knippenberg S, Muris AH, et al. Effects of vitamin D on the peripheral adaptive immune system: a review. Autoimmun Rev. 2011;10(12):733-743.

55. Smolders J, Peelen E, Thewissen M, et al. Safety and T cell modulating effects of high dose vitamin D3 supplementation in multiple sclerosis. PLoS One. 2010;5(12):e15235.

56. Vieth R. Implications for 25-hydroxyvitamin D testing of public health policies about the benefits and risks of vitamin D fortification and supplementation. Scand J Clin Lab Invest Suppl. 2012;243:144-153.

57. Jolles S, Chapel H, Litzman J. When to initiate immunoglobulin replacement therapy (IGRT) in antibody deficiency: a practical approach. Clin Exp Immunol. 2016;188(3):333-341.

58. Brawer AE. Amelioration of systemic disease after removal of silicone gel-filled breast implants. J Nutr Environ Med. 2009;10(2):125-132.

59. Crocco E, Pascini M, Suzuki N, et al. Minocycline for the treatment of cutaneous silicone granulomas: a case report. J Cosmet Laser Ther. 2016;18(1):48-49.

60. Rieger UM, Mesina J, Kalbermatten DF, et al. Bacterial biofilms and capsular contracture in patients with breast implants. Br J Surg. 2013;100(6):768-774.

61. Cohen JB, Carroll C, Tenenbaum MM, Myckatyn TM. Breast implant-associated infections: the role of the National Surgical Quality Improvement Program and the Local Microbiome. Plast Reconstr Surg. 2015;136(5):921-929.

62. Clauw DJ. Fibromyalgia and related conditions. Mayo Clin Proc. 2015;90(5):680-692.

63. Schoenfeld PS. Advances in IBS 2016: a review of current and emerging data. Gastroenterol Hepatol (N Y). 2016;12(8 Suppl 3):1-11.

64. Arnold AC, Okamoto LE, Diedrich A, et al. Low-dose propranolol and exercise capacity in postural tachycardia syndrome: a randomized study. Neurology. 2013;80(21):1927-1933.

65. Sarzi-Puttini P, Atzeni F, Salaffi F, et al. Multidisciplinary approach to fibromyalgia: what is the teaching? Best Pract Res Clin Rheumatol. 2011;25(2):311-319.

66. Borchers AT, Gershwin ME. Fibromyalgia: a critical and comprehensive review. Clin Rev Allergy Immunol. 2015;49(2):100-151.

67. Manoloudakis N, Labiris G, Karakitsou N, et al. Characteristics of women who have had cosmetic breast implants that could be associated with increased suicide risk: a systematic review, proposing a suicide prevention model. Arch Plast Surg. 2015;42(2):131-142. 



\section{CHAPTER 2}

Two hundreds cases of ASIA syndrome following silicone implants: a comparative study of 30 years and a review of current literature 


\section{Maartje JL Colaris* Mintsje de Boer* René RWJ van der Hulst Jan Willem Cohen Tervaert}

*Contributed equally

Immunol Res. $2017 \mathrm{Feb} ; 65(1)$ : 120-128. 


\section{ABSTRACT}

In this study, we compared one hundred patients with autoimmune/inflammatory syndrome induced by adjuvants (ASIA) due to silicone implant incompatibility syndrome diagnosed in 2014 in Maastricht, the Netherlands, with one hundred historical patients with adjuvant breast disease diagnosed in the Baylor College of Medicine, Houston, USA, between 1985 and 1992. Similarities and differences between these two cohorts were identified to determine whether the spectrum of silicone-related disease changed during the last 30 years. Patients with complaints possibly due to silicone-filled breast implants were prospectively examined in the Reinaert Clinic, Maastricht, the Netherlands between January 2014 and October 2014. All patients were evaluated for the fulfilment of ASIA criteria. Results were compared to results of the Baylor College cohort and 18 other reviewed historical cohorts. Clinical manifestations between the Maastricht and Baylor College cohorts were comparable. Fatigue was observed in 98 current patients and in 95 historical patients. Arthralgia was observed in 91 versus 81 historical patients. Myalgia was observed in 54 versus 91 patients. Cognitive impairment was observed in 78 versus 81 patients, pyrexia was observed in 64 versus 52 patients, sicca complaints in 73 versus 72 patients and severe neurological manifestations in 20 versus 32 patients. From the 54 patients who underwent removal of their silicone breast implant, 50\% $(n=27)$ of the patients experienced improvement of complaints after explantation of the implant. Also, in the 18 reviewed historical cohorts, similar clinical manifestations were described. Our findings suggest that no major changes were present in the observed clinical manifestations between the Maastricht and Baylor College cohorts. Also, despite changes in the principal constituents of the silicone implants during the past fifty years, silicone remained an adjuvant that may 'bleed' and subsequently may be a chronic stimulus to the immune system resulting in similar clinical manifestations as observed in the Maastricht cohort, the Baylor College cohort and 18 other large cohorts of patients. We therefore conclude that silicone-related disease has not changed during the last 30 years. 


\section{INTRODUCTION}

The safety of silicone-containing breast implants has been challenged since their introduction ${ }^{1,2}$, even though the principal constituents of implants have changed during the last fifty years. Well-known local complications of silicone-filled implants are capsular contracture, allergic reaction and autoimmune diseases. ${ }^{3-8}$ In addition, there is evidence for an increased occurrence of a rare form of non-Hodgkin lymphoma, i.e. anaplastic large $T$ cell lymphoma. ${ }^{9-11}$ Furthermore, we recently described the increased occurrence of a deficient humoral immune system in patients exposed to silicone-filled breast implants. ${ }^{3}$ Interestingly, it is at present still controversial whether silicone-filled breast implants increase the risk of autoimmunity. $3,12,13$ Nearly five decades after the first description of a syndrome called 'adjuvant breast disease'1,2 it was recognized that patients develop a specific disease that cannot be classified as a classic connective tissue disease (CTD) and it was proposed to label these patients as suffering from 'autoimmune/inflammatory syndrome induced by adjuvants' (ASIA) due to 'Silicone Implant Incompatibility Syndrome' (SIIS). ${ }^{3,14}$ Whether ASIA due to SIIS 3,15 is actually the same disease as the previously described adjuvant breast disease is at present still uncertain. ${ }^{2,16}$ To study this, we compared 100 consecutively diagnosed patients with ASIA due to SIIS with 100 historical patients described as suffering from 'adjuvant breast disease'.

\section{MATERIALS AND METHODS}

Two groups of patients with complaints due to silicone-containing breast implants are compared. A cohort of one hundred patients analysed for silicone breast implant-related complaints in 2014 in the Netherlands ('Maastricht cohort') and a cohort of one hundred patients diagnosed at Baylor College, Houston, Texas, USA, with 'Adjuvant Breast disease' due to silicone breast implants or silicone fluid injections between 1985 and 1992 as described in 1994 by Shoaib et al. ('Baylor College cohort'). ${ }^{16}$

Matching criteria between the two cohorts are Shoenfeld's criteria for the diagnosis of ASIA (Table 2.1). Patients who developed complaints after receiving silicone breast implants were referred to and evaluated by JWCT between January 2014 and October 2014 for prospective analysis ('Maastricht cohort'). All patients 
received a careful evaluation of their complaints, their medical history and a physical examination. ${ }^{3,17}$ A diagnosis of ASIA was made when Shoenfeld's criteria for this syndrome were fulfilled. ${ }^{14}$ Explicit four major and four minor criteria were evaluated; the patient was considered having ASIA when either two major or one major and two minor criteria were present (Table 2.1). The first consecutive hundred patients who fulfilled Shoenfeld's criteria for the diagnosis of ASIA were included in this study. Patients underwent laboratory measurements of immunoglobulins, antinuclear antibodies (ANA) and IgM rheumatoid factor (RF). 3,18 In addition, extractable nuclear antigen (ENA), antineutrophil cytoplasmic antibodies (ANCA), anticyclic citrullinated peptide (anti-CCP) were measured and several other autoantibodies (e.g. anticardiolipin antibodies) were measured in patients clinically suspected of suffering from specific autoimmune diseases. ${ }^{3}$ Immunoglobulins IgG, IgA and IgM were tested by latex-enhanced homogenous immunoassay by antigen-antibody complex with spectrophotometry by Turbidimetry, Roche Cobas, Roche, Basel, Switzerland. Antinuclear antibodies were tested by indirect immunofluorescence on HEp-2000 cells (Immuno Concepts, Sacramento, CA). ${ }^{17}$ Serum samples were screened in a dilution of 1:80. ${ }^{19} \mathrm{lgM}$ rheumatoid factor was tested by FEIA (Phadia ImmunoCAP 250, ThermoFisher Scientific, Freiburg, Germany). ${ }^{20}$ If explantation of silicone implants was performed, patients were reassessed by JWCT to document whether changes of complaints had occurred after explantation. Also, this assessment focussed on the different clinical manifestations of Shoenfeld's ASIA criteria. The comparative group of patients, described by Shoaib et al. ${ }^{16}$ in 1994 was composed of 100 symptomatic women with human adjuvant breast disease due to silicone incompatibility. These patients were evaluated for their symptoms primarily by an outside plastic surgeon and secondly by a neurologist in the Baylor College of Medicine ('Baylor College Cohort').

\section{Statistics}

For statistical analysis of results, a two-group Chi-square test with a 0.05 two-sided significance level was used (SPSS 22.0 software, IBM Corp, Armonk, NY). 
Table 2.1 Criteria for the diagnosis of ASIA.

\section{Major criteria}

- Exposure to an external stimulus (infection, vaccine, silicone, adjuvant) prior to clinical manifestations

- The appearance of 'typical' clinical manifestations:

- Myalgia, Myositis or muscle weakness

- Arthralgia and/or arthritis

- Chronic fatigue, un-refreshing sleep or sleep disturbances

- Neurological manifestations (especially associated with demyelination)

- Cognitive impairment, memory loss

- Pyrexia, dry mouth

- Removal of inciting agent induces improvement

- Typical biopsy of involved organs

\section{Minor criteria}

- The appearance of autoantibodies or antibodies directed at the suspected adjuvant

- Other clinical manifestations (i.e. irritable bowel syndrome)

- Specific HLA (i.e. HLA DRB1, HLA DQB1)

- Evolvement of an autoimmune disease (i.e. multiple sclerosis, systemic sclerosis)

$A S I A=$ autoimmune/inflammatory syndrome induced by adjuvants.

\section{Review}

We performed a literature search in PubMed, MEDLINE, EMBASE and the Cochrane Database of Systematic Reviews in February 2016. Additional citations were solicited from references in selected articles. The searches combined the following main terms: silicone breast implant, silicone adverse effects and the terms silicone-related symptom complex, adjuvant breast disease, human adjuvant disease, ASIA syndrome were separately added to the main two search terms.

We included articles focussing on patients with breast implants who were experiencing complaints that were ascribed to their silicone breast implants. Articles focussing on well-defined diseases, such as autoimmune or connective tissue diseases, were excluded. Articles in the period from January 1960 to the present time, in English were included. For all the included studies, the clinical manifestations in patients with silicone-related complaints were collected. Only case series (minimal 30 patients) were included, and no case reports were included. Studies focussing on malignancies in the breast (diagnostics, therapy or reconstruction) and implant failure (rupture, infection, capsular formation) were excluded. 


\section{RESULTS}

\section{Patient demographics}

The Maastricht cohort consists of 99 female patients and 1 transgender. All patients are exposed to silicone gel-filled breast implants. The median age at time of implantation was 33 years (14-56 years), and the median age at onset of clinical symptoms was 41 years (20-68 years). The median latency period from time of implant until onset of clinical symptoms was 4 years (range 1-39 years). The median age at the time of diagnosis was 49 years ( $27-72$ years). The median time between implant and diagnosis was 13 years (2-43). The comparative group of patients, the Baylor College cohort described in 1994, existed of 100 symptomatic women with either silicone breast implants $(n=97)$ or silicone fluid injections $(n=3)$. Median age was comparable to the median age of the patients from the Maastricht cohort (Table 2.2).

In both cohorts, patients received various sorts of implants from different manufacturers. All implants, however, were silicone gel-filled breast implants.

In both cohorts, approximately $70-80 \%$ of the patients received silicone breast implants for cosmetic reasons. Other reasons for implantation were reconstruction after benign or malignant tumour removal, or reconstruction after preventive ablation due to a BRCA mutation (Table 2.2).

Table 2.2 Patient demographics of both the cohorts including reasons for implantation.

\begin{tabular}{lcc}
\hline Variable & $\begin{array}{c}1994 \\
\text { Years (range) }\end{array}$ & $\begin{array}{c}2014 \\
\text { Years (range) }\end{array}$ \\
\hline Median age at time of evaluation & $\mathrm{NA}$ & $49(27-72)$ \\
Median age at time of implantation & $32(19-52)$ & $33(14-56)$ \\
Median age at onset of symptoms & $38(23-57)$ & $41(20-68)$ \\
Median age at time of diagnoses & $\mathrm{NA}$ & $49(27-72)$ \\
Median latency period & $6(0-24)$ & $4(1-39)$ \\
Median time between implant and diagnosis & $\mathrm{NA}$ & $13(2-43)$ \\
Median age at time of removal & $44(30-59)$ & $49(31-68)$ \\
\hline Reasons for implantation & 1994 & 2014 \\
& $\mathrm{~N}(\%)$ & $\mathrm{N}(\%)$ \\
\hline Cosmetic purposes & 68 & 80 \\
Malignant tumour & 4 & 14 \\
Benign tumour & 28 & 3 \\
BRCA positive & $\mathrm{NA}$ & 3 \\
\hline
\end{tabular}

$N A=$ not applicable. 


\section{Local manifestations and complications}

In the Maastricht cohort, local problems were frequently observed: capsular contracture $(n=29)$, sweating and/or leakage of the silicone implant $(n=13)$, implant rupture $(n=25)$, dislocation of the implant $(n=3)$ or local tenderness $(n=4)$. Furthermore, 70 patients had painful lymphadenopathy involving the axillary regions, often with cervical and/or inguinal lymphadenopathy as well.

In the Baylor College cohort of 1994, 76 patients suffered from local problems defined as capsular contracture, tenderness, soreness or pain of the breasts, burning and swollen breasts, infections, numbness of the nipples or discharge from the nipples. Fifty-eight patients had lymphadenopathy.

\section{Clinical symptoms}

In the Maastricht cohort, arthralgia $(n=91)$ and chronic fatigue $(n=98)$ are most often observed, followed closely by the other typical clinical manifestations of ASIA (Table 2.3). Other manifestations that were scored in the Maastricht cohort are Raynaud's phenomenon, irritable bowel syndrome (IBS), recurrent respiratory tract infections, recurrent cystitis, livedo reticularis and allergies (Table 2.4). In the Baylor College cohort, comparable numbers of clinical manifestations have been identified (Tables 2.3, 2.4).

Table 2.3 Presence of clinical manifestations in both cohorts.

\begin{tabular}{lccc}
\hline Symptom & 1994 & 2014 & $P$ value \\
& $\mathrm{N}(\%)$ & $\mathrm{N}(\%)$ & \\
\hline Myalgia, Myositis or muscle weakness & 91 & 54 & $<0.001$ \\
Arthralgia and/or arthritis & 81 & 91 & 0.04 \\
Chronic fatigue, un-refreshing sleep or sleep disturbances & 95 & 98 & 0.25 \\
Neurological manifestations (especially associated with demyelination) & 32 & 20 & 0.05 \\
Cognitive impairment, memory loss & 81 & 78 & 0.60 \\
Pyrexia & 52 & 64 & 0.09 \\
Dry eyes and/or dry mouth (sicca) & 72 & 73 & 0.87 \\
\hline
\end{tabular}

\section{Laboratory findings}

In the Maastricht cohort, fewer patients had antinuclear antibodies when compared to the cohort as described in 1994 (Table 2.5). In eight patients laboratory measurements for IgM rheumatoid factor could not be performed, and in two patients laboratory measurements for immunoglobulins could not be 
performed, due to an inadequate volume of serum. Herefore this data is reported as missing data.

Table 2.4 Presence of other clinical manifestations in both cohorts.

\begin{tabular}{lccc}
\hline Symptom & 1994 & 2014 & $P$ value \\
& $\mathrm{N}(\%)$ & $\mathrm{N}(\%)$ & \\
\hline Raynaud's phenomenon & 58 & 30 & $<0.001$ \\
Irritable bowel syndrome & $\mathrm{NA}$ & 17 & - \\
Recurrent respiratory tract infections & $\mathrm{NA}$ & 54 & - \\
Recurrent cystitis & $\mathrm{NA}$ & 36 & - \\
Livedo reticularis & 62 & 28 & $<0.001$ \\
Allergies & 52 & 52 & NS \\
\hline
\end{tabular}

NA = not applicable.

Table 2.5 Laboratory findings

\begin{tabular}{lcc}
\hline Measurement & 1994 & 2014 \\
& $\mathrm{~N}(\%)$ & $\mathrm{N}(\%)$ \\
\hline Increased immunoglobulins & $13 / 76(17)$ & $14 / 98(14)$ \\
Decreased immunoglobulins & $24 / 76(32)$ & $13 / 98(13)$ \\
ANA & $33 / 93(36)$ & $5 / 100(5)$ \\
RF & $10 / 90(11)$ & $4 / 92(4)$ \\
\hline
\end{tabular}

Immunoglobulins include total $\operatorname{lgG}, \lg$ and $\operatorname{lgM}$. $A N A=$ antinuclear antibodies; $R F=\operatorname{lgM}$ rheumatoid factor.

\section{Presence of autoimmune diseases}

In the Maastricht cohort, 34 patients were diagnosed with an autoimmune disease (Table 2.6). The presence of autoimmune diseases has not been described in the Baylor College cohort.

Table 2.6 Diagnostic findings in 100 patients with silicone-filled breast implants and ASIA in the 2014 cohort.

\begin{tabular}{lc}
\hline Symptom & $\mathrm{N}(\%)$ \\
\hline RA & 4 \\
CTD & 18 \\
Vasculitis & 5 \\
Granulomatous disease & 3 \\
Other & 7 \\
\hline
\end{tabular}

$R A=$ rheumatoid arthritis; $C T D=$ connective tissue disease. (systemic sclerosis $\mathrm{n}=2$, undifferentiated connective tissue disease $n=1$, Sjogren's syndrome $n=5$, antiphospholipid syndrome $n=7$, Systemic lupus erythematosus $n=3$ ); granulomatous disease (Crohn $n=1$, sarcoidosis $n=2$ ); Other autoimmune diseases (multiple sclerosis $n=1, M$. Hashimoto $n=2$, polychondritis recidivans $n=1$, pernicious anaemia $n=1$, lichen planus $n=1$ and neuralgic amyotrophy $n=1$ ). 


\section{Implant removal}

In the Maastricht cohort, 54 patients underwent removal of their silicone breast implant. Of these, $50 \%(n=27)$ of the patients experienced improvement of complaints after explantation of the implant. The median age at removal was 49 years (range 31-68). Symptoms such as fatigue, arthralgia, myalgia, sicca and pyrexia improved in most patients after explantation. In seven patients, however, the improvement was only observed temporarily, with a relapse of complaints after several weeks follow-up.

In the Baylor College cohort, 96 patients underwent explantation of the implant. The median age of the patients at explantation was 44 years (range 30-59). Whether these patients experienced improvement of their complaints after explantation was not described in the paper.

\section{Statistics}

We found significant differences between the two cohorts for the following clinical manifestations: myalgia, myositis or muscle weakness $(p<.001)$ and arthralgia and/or arthritis $(p=.04)$. Other clinical manifestations were not found to be significantly different: chronic fatigue $(p=.25)$, neurological manifestations $(p=.05)$, cognitive impairment $(p=.60)$, pyrexia $(p=.09)$ and sicca $(p=.87)$. Significant differences, however, were also observed between the two cohorts regarding livedo reticularis $(p<.001)$ and the occurrence of Raynaud's phenomenon $(p<.001)$ but not in the occurrence of allergies.

\section{DISCUSSION}

The objective of this study was to explore whether ASIA due to SIIS is the same disease as the previously described adjuvant breast disease. ${ }^{16}$ The results in this study show that clinical findings in patients with silicone breast implants in the current Maastricht cohort and the historical Baylor College cohort are more or less identical (Table 2.3). The typical clinical manifestations (major criterion 2 of the ASIA syndrome, Table 1) are clearly present in both cohorts. In the Maastricht cohort, almost all patients presented with fatigue, in combination with arthralgia 
and/or myalgia. These symptoms were nearly always accompanied with pyrexia, cognitive impairment and/or sicca complaints.

There are, however, differences between both cohorts. Myalgia was less frequently observed in the Maastricht cohort in comparison with the Baylor College cohort, whereas arthralgia/arthritis was more frequently observed in the Maastricht cohort. The difference could be due to the fact that arthralgia and myalgia are difficult to distinguish. Both symptoms have a musculoskeletal origin; the true origin of the pain is therefore sometimes difficult to establish. Another explanation might be that Shoaib et al. ${ }^{16}$ (a neurologist) did a more complete neurological work-up, whereas the auto-immunologist in Maastricht performed a more complete rheumatological work-up. ${ }^{3}$ Shoaib et al. have performed MRI's, muscle biopsies, electromyograms and specific measurements of autoantibodies (anti-GM1) to detect neurological diseases. These factors possibly explain why myalgia/myositis/muscular weakness and neurological manifestations scored higher in the Baylor College cohort.

Comparing the frequency of positive antinuclear antibodies and IgM rheumatoid factor between the two cohorts, less autoantibodies were detected in the Maastricht cohort compared to the Baylor College cohort. It could be that current silicone breast implants are less immunogenic, explaining fewer autoantibodies in the Maastricht cohort. Otherwise, the definitions of a positive ANA and/or positive rheumatoid factor may have been different. Unfortunately, from the Baylor College cohort, the exact description of ANA and rheumatoid factor measurement and interpretation is lacking and detailed information about cut-off values for ANA and IgM-RF are not described in the paper by Shoaib. ${ }^{16}$

In another study, in 156 women with adjuvant breast disease performed at the University of Missouri-Columbia in 1993, a positive ANA was found in $22 \%$ of the patients and a positive IgM-RF in $9 \%$ of patients. ${ }^{21}$ These results resemble more closely the results of autoantibody testing in the Maastricht cohort, suggesting that antigenicity of the breast implants did not change during the last 30 years. Finally, in the Maastricht cohort, the course of disease has been evaluated after explantation of the silicone breast implant. Improvement of complaints occurred in $50 \%$ of the patients. In another study, conducted by Peters et al. in 1997, a similar outcome was reported: $58 \%$ of their patients had fewer symptoms after explantation, whereas $74 \%$ of the patients declared that they 'felt better' and that their quality of life had improved. ${ }^{22}$ 


\section{REVIEW OF CURRENT LITERATURE}

Based on the similarities between the Maastricht and the Baylor College cohort, we decided to conduct a critical review of the literature, to study whether these similarities were also present in patients who have presented with silicone-related complaints in other studies. The results are presented in Table 2.7.

Our literature search yielded 390 citations. In total, 18 studies were included; 5 studies met eligibility criteria and were included. Thirteen studies were references in the previous included studies, met eligibility criteria and were included as well. Maijers et al. ${ }^{15}$ presented a cohort of 80 patients with silicone breast implants and unexplained symptoms such as fatigue, neurasthenia, myalgia, arthralgia, morning stiffness and night sweats in more than $60 \%$ of women. In addition, women experienced cognitive problems, dermatological symptoms, gastrointestinal symptoms, alopecia, sleeping disorders and depression.

Cohen Tervaert et al. ${ }^{3}$ presented a cohort of 32 patients with silicone breast implants. Patients presented with fatigue, arthralgia, myalgias, asthenia and/or fever. In addition, 50\% of patients had an immunodeficiency, whereas also 50\% had an autoimmune disease.

Contant et al. ${ }^{23}$ prospectively evaluated a cohort of 57 women with silicone-related symptom complex that were seen in an breast cancer centre between March 1995 and March 1997, who presented with sicca symptoms (dry eyes and dry mouth), arthralgias/arthritis, Raynaud's phenomenon, headache, dizziness, memory difficulties, palpitations, diarrhoea and transpiration.

In another study, Contant et al. evaluated the serology of 63 women with siliconerelated symptom complex who presented with complaints as described in the above mentioned study of Contant. These patients were examined between September 1990 and May 1995. ${ }^{24}$ They found that $16 \%$ of the patients were ANA positive, but there was no difference in symptoms between ANA-positive and ANAnegative patients.

Shoaib et al. presented 26 women with a systemic disease with central nervous system involvement after receiving silicone breast implants or silicone fluid injection, with symptoms suggesting a multiple sclerosis-like syndrome. Additional symptoms were myalgia, joint stiffness, arthralgia, sicca complex, headache, skin rash, joint swelling, Raynaud's phenomena, fever, hair loss, allergies, sensitivity to sunlight and lymphadenopathy. ${ }^{25}$ 


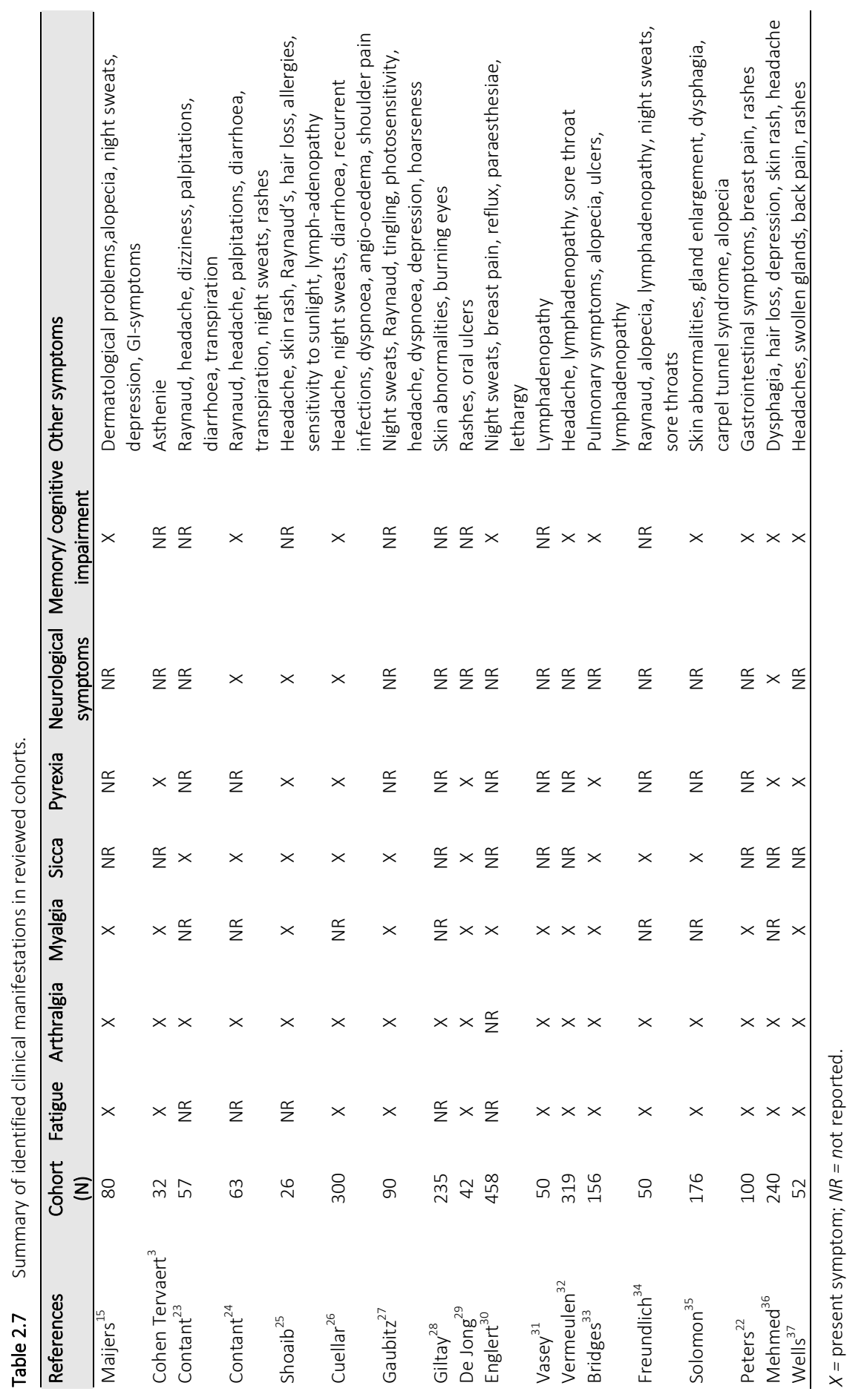


Cuellar et al. evaluated a cohort of 300 consecutive women seen in the Rheumatology department of the LSU Medical Center at New Orleans from January 1991 to November 1992 with silicone breast implants with musculoskeletal complaints: chronic fatigue, arthralgia, lowgrade fever, sicca, memory loss, multiple sclerosis-like syndrome, night sweats, headaches, chronic diarrhoea, recurrent infections, dyspnoea and angio-oedema. ${ }^{26}$

Gaubitz et al. ${ }^{27}$ presented 90 consecutive symptomatic women with silicone breast implants who underwent an MRI to detect implant rupture. These patients presented with a scala of symptoms: fatigue, arthralgia, myalgia, night sweats, dry eyes, swollen joints, Raynaud, tingling, photosensitivity, headache, dyspnoea, depression and hoarseness. Clinical symptoms in patients with ruptured SBI did not differ from patients with an intact SBI.

Giltay et al. presented a study in which 235 patients with silicone breast implants and 210 healthy controls filled in a questionnaire reflecting complaints such as painful or swollen joints, burning eyes, oral ulcers, Raynaud's phenomenon and/or skin abnormalities. Patients with silicone breast implant significantly reported more complaints after surgery than before surgery. Especially, more painful joints, burning eyes and skin abnormalities were reported compared to the control group. $^{28}$

De Jong et al. present a cohort of 42 symptomatic patients with silicone breast implants who were evaluated for antipolymer antibodies. These patients presented with symptoms as fatigue, arthralgia, morning stiffness, myalgia, sleep disturbance, rashes, dry eyes/mouth, oral ulcers, muscle weakness and fevers. ${ }^{29} \mathrm{SBI}$ exposure did not result in induction of polymer binding antibodies.

Englert et al. evaluated 458 female patients with silicone breast implants compared to a control group of 687 women who underwent plastic surgery but did not receive silicone breast implants. They found that patients with silicone breast implants more commonly had complaints such as night sweats, lethargy, breast pain, impaired mentation, reflux, paraesthesiae, hand muscle weakness and myalgia. ${ }^{30}$

Vasey et al. presented the clinical findings in a cohort of 50 symptomatic patients with silicone breast implants. The most common clinical findings included chronic fatigue, muscle pain, joint pain, joint swelling and lymphadenopathy. ${ }^{31}$

Vermeulen et al. studied the presence of symptoms of pain and fatigue in a cohort of 319 women with silicone breast implants. The four most frequent complaints in 
the women with implants were multi-joint pain, muscle pain, debilitating chronic fatigue and postexertional malaise. Fewer women had un-refreshing sleep, impaired cognition and headache, whereas one-third or fewer of the women with implants complained of painful lymph nodes and sore throat. ${ }^{32}$

Bridges et al. clinically and immunologically evaluated 156 women with silicone breast implants and symptoms of a rheumatic disease. These patients presented with fatigue, myalgia, arthralgia, sicca symptoms, mental confusion, pulmonary symptoms, alopecia, recurrent fever, lymphadenopathy and mucosal ulcerations. ${ }^{33}$ Freundlich et al. described typical sicca complaints in combination with a pattern of rheumatic symptoms (fatigue, generalized stiffness, poor sleep and arthralgias) in 50 female patients with silicone gel breast implants. They concluded that their patients did not fit into one single autoimmune, rheumatologic or neurological disease. Other problems in these patients included Raynaud's phenomenon, alopecia, lymphadenopathy, night sweats and frequent sore throats. ${ }^{34}$

Solomon et al. presented a clinical and laboratory profile of 176 symptomatic women with silicone breast implants. The most frequent symptoms seen in the women were chronic fatigue, cognitive dysfunction, arthralgia, dry mouth, dry eye, alopecia, dysphagia, telangiectasias, erythema of the chest wall, carpal tunnel syndrome, petechiae, lacrimal gland enlargement, thyroid tenderness, thyroid enlargement and parotid enlargement. ${ }^{35}$

Peters et al. reported 100 female patients who underwent explantation of their breast implants. Patients had systemic symptoms such as arthralgia, myalgia, fatigue, gastrointestinal symptoms, rashes, memory loss, sleep disturbances and breast pain. ${ }^{22}$

Mehmed et al. presented 240 patients undergoing explantation of their silicone breast implants. 196 patients underwent explantation with complaints such as chronic fatigue, memory loss, arthralgias, dysphagia, depression, altered sleep patterns, hair loss, skin rashes, headaches, flulike symptoms and atypical multiple sclerosis. $^{36}$

Finally, Wells et al. presented 52 women requesting removal of their silicone breast implants because they suspected a relation with complaints such as arthralgia, fatigue, myalgia, headaches, fevers, swollen glands, back pain, rashes, memory loss and swollen joints. ${ }^{37}$ 


\section{Summary of the reviewed literature}

A summary of the clinical manifestations identified in the cohorts is given in Table 2.7. The clinical manifestations of ASIA major criterion 2 are used as guideline (see Table 2.1); other symptoms are summarized under the heading 'other'.

After comparing the Maastricht cohort and the Baylor College cohort with the other identified studies, we concluded that a great similarity in clinical manifestations exists in all studies. Especially, the 7 typical clinical manifestations of ASIA (major criterion 2) are present throughout all identified cohorts. However, it should be noted that several other symptoms are frequently present, such as Raynaud's phenomenon, headache, alopecia or hair loss, skin abnormalities, gastrointestinal symptoms (irritable bowel syndrome), night sweats and lymphadenopathy. These clinical findings in patients with silicone breast implants resemble the clinical picture of fibromyalgia. ${ }^{38-40}$ It has been postulated that in fibromyalgia, nociceptive signals (often psychological traumas) cause the development of symptoms via disturbed pain processing. ${ }^{41}$ We propose that in patients with ASIA due to SIIS, the breast implant might be the nociceptive stimulus. The nociceptive stimulus (silicone) in combination with extensive worrying about the safety of the breast implant causes a disturbed pain signalling pathway and excessive stimulation of neurotransmitters in the central nervous system and subsequently the systemic complaints. ${ }^{41} \mathrm{~A}$ major difference between idiopathic fibromyalgia and silicone-induced fibromyalgia, however, is the cooccurrence of immune deficiency ${ }^{3}$ and/or autoimmunity $3,15,42$ during follow-up in patients with ASIA due to SIIS.

\section{CONCLUSION}

Are silicone breast implants safe? After half a century of worldwide usage, this is still a matter of debate. In 1992, the FDA restricted the use of silicone breast implant in the USA due to reports of fibromyalgia-like health complaints, systemic symptoms and autoimmunity. ${ }^{43}$ In 2000, Janowsky et al. ${ }^{12}$ performed a metaanalysis and concluded that silicone breast implants could be considered safe. However, in this meta-analysis a study of 10.830 patients was excluded, due to the fact that the complaints of these patients were 'selfreported'. ${ }^{44}$ If this study was not excluded, the relative risk for developing connective tissue disease would have 
increased from insignificant to significant with a value of 1.3. ${ }^{44}$ Furthermore, in the meta-analysis by Janowsky et al. ${ }^{12}$ only the development of well-defined connective tissue disease was addressed, and not the development of ASIA, adjuvant breast disease or other less well-defined conditions. This should imply that despite changes in the principal constituents of the silicone implants during the past fifty years, silicone remained an adjuvant that may 'bleed' and subsequently may be a chronic stimulus to the immune system resulting in similar clinical manifestations as observed in the Maastricht cohort, the Baylor College cohort and 18 other large cohorts of patients.

In conclusion, we report that there is a group of patients who develop complaints related to silicone breast implants. In the past thirty years, the character of silicone-related complaints has been similar. Whether silicone breast implants are safe, or if they are only safe in a subgroup of female patients, is however, after more than these thirty years, still not clear. This should be studied in future epidemiological and experimental studies. This research should be conducted, because the current evidence that silicone breast implants are safe is at present limited. 


\section{REFERENCES}

1. The American Society for Aesthetic Plastic Surgery. National Plastic Surgery Statistics Editor. California: The American Society for Aesthetic Plastic Surgery. 2009.

2. Miyoshi K, Miyamura T, Kobayashi Y, Itakura T, Nishijo K. Hyper-gammaglobulinemia by prolonged adjuvanticity in man: disorders developed after augmentation mammaplasty. Jpn Med J. 1964;2122: 9-14.

3. Cohen Tervaert JW, Kappel RM. Silicone implant incompatibility syndrome (SIIS): a frequent cause of ASIA (Shoenfeld's syndrome). Immunol Res. 2013;56:293-8.

4. Lidar M, Agmon-Levin N, Langevitz P, Shoenfeld Y. Silicone and scleroderma revisited. Lupus. 2012;21:121-7.

5. Levy $Y$, Rotman-Pikielny $P$, Ehrenfeld $M$, Shoenfeld $Y$. Silicone breast implantation-induced scleroderma: description of four patients and a critical review of the literature. Lupus. 2009;18: 1226-32.

6. Bar-Meir E, Eherenfeld M, Shoenfeld Y. Silicone gel breast implants and connective tissue disease: a comprehensive review. Autoimmunity. 2003;36:193-7.

7. Zandman-Goddard G, Ehrenfeld M, Shoenfeld Y. Silicone implants for breast augmentation and autoimmune diseases. Harefuah. 1993;125:360-4.

8. Ehrenfeld M, Shoenfeld Y. Breast silicone implant and autoimmunity: coincidence or cause and effect relationship? Harefuah. 1998;134:361-4.

9. Jewell M, Spear SL, Largent J, Oefelein MG, Adams WP Jr. Anaplastic large T-cell lymphoma and breast implants: a review of the literature. Plast Reconstr Surg. 2011;128:651-61.

10. Bizjak M, Selmi C, Praprotnik S, Bruck O, Perricone C, Ehrenfeld M, Shoenfeld Y. Silicone implants and Iymphoma: the role of inflammation. J Autoimmun. 2015;65:64.

11. Kadin ME, Deva A, Xu H, Morgan J, Khare P, MacLeod RA, van Natta BW, Adams WP Jr, Brody GS, Epstein AL. Biomarkers provide clues to early events in the pathogenesis of breast implant-associated anaplastic large cell lymphoma. Aesthet Surg J. 2016

12. Janowsky EC, Kupper LL, Hulka BS. Meta-analyses of the relation between silicone breast implants and the risk of connective-tissue diseases. N Engl J Med. 2000;342:781-90.

13. SCENIHR (Scientific Committee on Emerging and Newly Identified Health Risks). Preliminary opinion on the safety of Poly Implant Prothe'se (PIP) Silicone Breast Implants (2013 update). September 2013. http://ec.europa.eu/health/scientific_committees

14. Shoenfeld Y, Agmon-Levin N. 'ASIA'-autoimmune/inflammatory syndrome induced by adjuvants. J Autoimmun. 2011;36:4-8.

15. Maijers MC, de Blok CJ, Niessen FB, van der Veldt AA, Ritt MJ, Winters HA, et al. Women with silicone breast implants and unexplained systemic symptoms: a descriptive cohort study. Neth J Med. 2013;71:534-40.

16. Shoaib BO, Patten BM, Calkins DS. Adjuvant breast disease: an evaluation of 100 symptomatic women with breast implants or silicone fluid injections. Keio J Med. 1994;43:79-87.

17. Tervaert JW, Van Paassen P, Damoiseaux J. Type II cryoglobulinemia is not associated with hepatitis C infection: the Dutch experience. Ann N Y Acad Sci. 2007;1107:251-8.

18. Damoiseaux JG, Tervaert JW. From ANA to ENA: how to proceed? Autoimmun Rev. 2006;5:10-7.

19. Avery TY, van de Cruys M, Austen J, Stals F, Damoiseaux JG. Anti-nuclear antibodies in daily clinical practice: prevalence in primary, secondary, and tertiary care. J Immunol Res. 2014;2014:401739.

20. De Steenwinkel FD, Hokken-Koelega AC, de Ridder MA, Hazes JM, Dolhain RJ. Rheumatoid arthritis during pregnancy and postnatal catch-up growth in the offspring. Arthritis Rheumatol. 2014;66: 1705-11.

21. Bridges AJ, Conley C, Wang G, Burns DE, Vasey FB. A clinical and immunologic evaluation of women with silicone breast implants and symptoms of rheumatic disease. Ann Intern Med. 1993;118:929-36.

22. Peters W, Smith D, Fornasier V, Lugowski S, Ibanez D. An outcome analysis of 100 women after explantation of silicone gel breast implants. Ann Plast Surg. 1997;39:9-19. 
23. Contant CM, Swaak AJ, Obdeijn Al, van der Holt B, Tjong Joe Wai R, van Geel AN. A prospective study on silicone breast implants and the silicone-related symptom complex. Clin Rheumatol. 2002;21(3):215-9.

24. Contant CM, Swaak AJ, Wiggers T, Wai RT, van Geel AN. First evaluation study of the Dutch Working Party on silicone breast implants (SBI) and the silicone-related symptom complex (SRSC). Clin Rheumatol. 2000;19(6):458-63.

25. Shoaib BO, Patten BM. Human adjuvant disease: presentation as a multiple sclerosis-like syndrome. South Med J. 1996;89(2):179-88.

26. Cuellar ML, Gluck O, Molina JF, Gutierrez S, Garcia C, Espinoza R. Silicone breast implant-associated musculoskeletal manifestations. Clin Rheumatol. 1995;14(6):667-72.

27. Gaubitz M, Jackisch C, Domschke W, Heindel W, Pfleiderer B. Silicone breast implants: correlation between implant ruptures, magnetic resonance spectroscopically estimated silicone presence in the liver, antibody status and clinical symptoms. Rheumatol (Oxford). 2002;41(2):129-35.

28. Giltay EJ, Bernelot Moens HJ, Riley AH, Tan RG. Silicone breast prostheses and rheumatic symptoms: a retrospective follow up study. Ann Rheum Dis. 1994;53(3):194-6.

29. De Jong WH, Goldhoorn CA, Kallewaard M, Geertsma RE, Van Loveren H, Bijlsma JW, Schouten JS. Study to determine the presence of antipolymer antibodies in a group of Dutch women with a silicone breast implant. Clin Exp Rheumatol. 2002;20(2):151-60.

30. Englert H, Joyner E, Thompson M, Garcia H, Chambers P, Horner D, Hunt C, Makaroff J, O'Connor H, Russell N, March L. Augmentation mammoplasty and "silicone-osis". Intern Med J. 2004;34(12): 668-76.

31. Vasey FB, Havice DL, Bocanegra TS, Seleznick MJ, Bridgeford PH, Martinez-Osuna P, Espinoza LR. Clinical findings in symptomatic women with silicone breast implants. Semin Arthritis Rheum. 1994;24(1 Suppl 1):22-8.

32. Vermeulen RC, Scholte HR. Rupture of silicone gel breast implants and symptoms of pain and fatigue. J Rheumatol. 2003;30(10):2263-7.

33. Bridges AJ, Conley C, Wang G, Burns DE, Vasey FB. A clinical and immunologic evaluation of women with silicone breast implants and symptoms of rheumatic disease. Ann Intern Med. 1993;118(12): 929-36.

34. Freundlich B, Altman C, Snadorfi N, Greenberg M, Tomaszewski J. A profile of symptomatic patients with silicone breast implants: a Sjo"grens-like syndrome. Semin Arthritis Rheum. 1994;24((1 Suppl 1)):44-53.

35. Solomon G. A clinical and laboratory profile of symptomatic women with silicone breast implants. Semin Arthritis Rheum. 1994;24(1 Suppl 1):29-37.

36. Melmed EP. A review of explantation in 240 symptomatic women: a description of explantation and capsulectomy with reconstruction using a periareolar technique. Plast Reconstr Surg. 1998;101(5):1364-73.

37. Wells KE, Roberts C, Daniels SM, Kearney RE, Cox CE. Psychological and rheumatic symptoms of women requesting silicone breast implant removal. Ann Plast Surg. 1995;34(6):572-7.

38. Bennet RM, Jones J, Turk DC, Russel IJ, Matallana L. An internet survey of 2,596 people with fibromyalgia. BMC Musculoskelet Disord. 2007;9:8-27.

39. Rodriguez-Rodriguez L, Ramon Lamas J, Abasolo L, et al. The rs3771863 single nucleotide polymorphism of th TACR1gene is associated to a lower risk of sicca syndrome in fibromyalgia patients. Clin Exp Rheumatol Suppl. 2015;33(Suppl 88):S33-40.

40. Wolfe F. Silicone related symptoms" are common in patients with fibromyalgia: no evidence for a new disease. J Rheumatol. 1999;26(5):1172-5.

41. Clauw DJ, Arnold LM, McCarberg BH. The science of fibromyalgia. Mayo Clin Proc. 2011;86:907-11.

42. Agmon-Levin N, Shoenfeld Y. Chronic fatigue syndrome with autoantibodies - the result of an augmented adjuvant effect of hepatitis-B vaccine and silicone implant. Autoimmun Rev. 2008;8:52-5.

43. Kessler DA. The basis of the FDA's decision on breast implants. N Engl J Med. 1992;326:1713-5.

44. Soriano A, Butnaru D, Shoenfeld Y. Long-term inflammatory conditions following silicone exposure: the expanding spectrum of the autoimmune/inflammatory syndrome induced by adjuvants (ASIA). Clin Exp Rheumatol. 2014;32:151-4. 



\section{Maartje JL Colaris René RWJ van der Hulst Jan Willem Cohen Tervaert}

Clin Rheumatol. 2017 May;36(5):981-993. 


\section{ABSTRACT}

The development of autoimmunity and/or autoimmune diseases is multifactorial. Vitamin $D$ is one of the factors that might play a role. We postulated that both the presence of adjuvants and insufficient levels of vitamin D may result in the development of autoimmunity in patients with autoimmune/inflammatory syndrome induced by adjuvants (ASIA) in relation to silicone implant incompatibility. We measured vitamin D levels in 135 patients with ASIA in relation to silicone implant incompatibility and related findings to the presence of autoantibodies that are commonly used to diagnose systemic autoimmune diseases. Furthermore, we systematically reviewed the literature regarding vitamin $D$ deficiency as a risk factor for the development of autoantibodies. Vitamin D measurements were available for analysis in 131 of 135 patients with ASIA in relation to SIIS. Twenty-three patients (18\%) tested positive for autoantibodies, from which 18 patients (78\%) had either a vitamin D deficiency or insufficiency (median vitamin D level $60.5 \mathrm{mmol} / \mathrm{L}$ ), whereas five patients (22\%) had sufficient vitamin $\mathrm{D}$ levels. The risk to develop autoantibodies was significantly increased in vitamin $D$ deficient and/or insufficient patients $[R R 3.14 ; 95 \% \mathrm{Cl}, 1.24-7.95$; $p=0.009$ ]. Reviewed literature suggested an association between vitamin $\mathrm{D}$ levels and the presence and/or titer levels of autoantibodies in different autoimmune diseases. From our current study and from our review of the literature, we conclude that vitamin $D$ deficiency is related to the presence of autoantibodies. Whether vitamin $D$ supplementation results in a decrease of autoimmunity needs to be studied prospectively. 


\section{INTRODUCTION}

Silicone breast implants may be associated with nonspecific symptoms such as fatigue, myalgia, arthralgia, pyrexia, dry mouth, dry eyes, and cognitive impairment. ${ }^{1-3}$ Explantation of the breast implants results in improvement of the symptoms in $50-80 \%$ of the patients. ${ }^{1,4}$ At present, it is still controversial whether silicone-filled breast implants increase the risk of autoimmunity. ${ }^{3,5,6}$ Recently, however, it has been suggested that an increased prevalence of autoimmune diseases such as rheumatoid arthritis and Sjögren's syndrome exists in these patients. ${ }^{6}$ Moreover, immune deficiency may occur in these patients at an increased frequency. ${ }^{3}$ Finally, several autoantibodies have been reported to occur in silicone breast implant patients at an increased frequency. ${ }^{7-11}$ Also, these findings are, however, controversial. ${ }^{11,12}$

Vitamin $D$ is known to be a crucial factor in the calcium homeostasis. Vitamin D, however, is also essential for immunity. Importantly, vitamin D deficiency may represent a global health problem that has been underestimated for many years. ${ }^{13}$ Over the last decades, it has been shown that vitamin D deficiency is associated with an increased risk for infectious diseases. ${ }^{14}$ Moreover, a number of autoimmune diseases, including multiple sclerosis, type I diabetes, inflammatory bowel disease, systemic lupus erythematosus, and rheumatoid arthritis, are reported to be associated with vitamin D deficiency. ${ }^{15-17}$

Several mechanisms by which vitamin $D$ acts as a regulatory agent for the innate as well as the adaptive immune system have been described. ${ }^{18}$ Firstly, cells of the immune system have been shown to be direct targets of vitamin D metabolites. Secondly, many immune cells contain enzymes of the cytochrome P (CYP) family and are thus able to convert $25(\mathrm{OH}) \mathrm{D}$ into calcitriol, the biologically active form of vitamin D. ${ }^{18,19}$

Since vitamin $D$ is known to be a potent regulator of the immune system ${ }^{18}$ and vitamin $D$ deficiency is hypothesized to contribute to $B$ cell hyperactivity ${ }^{19}$, we postulate that vitamin $D$ deficiency is a risk factor for the development of autoantibodies in patients with autoimmune/inflammatory syndrome induced by adjuvants (ASIA) in relation to silicone implant incompatibility syndrome (SIIS). 3,20 To study this, we examined vitamin D levels in patients with ASIA in relation to SIIS and related findings to the presence of autoantibodies. Furthermore, we reviewed 
the effect of vitamin D deficiency as a risk factor for the development and/or production of autoantibodies.

\section{PATIENTS AND METHODS}

\section{Study population}

One hundred thirty-five consecutive ASIA in relation to SIIS patients were included in the current study. The patients were prospectively evaluated between January 2014 and September 2015 by one of us (JWCT). A diagnosis of ASIA was made based on criteria as previously described. ${ }^{2}$ In short, patients were diagnosed as suffering from ASIA when either two major or one major and two minor criteria were present. Criteria are summarized in Table 3.1.

Table 3.1 Criteria for the diagnosis of ASIA.

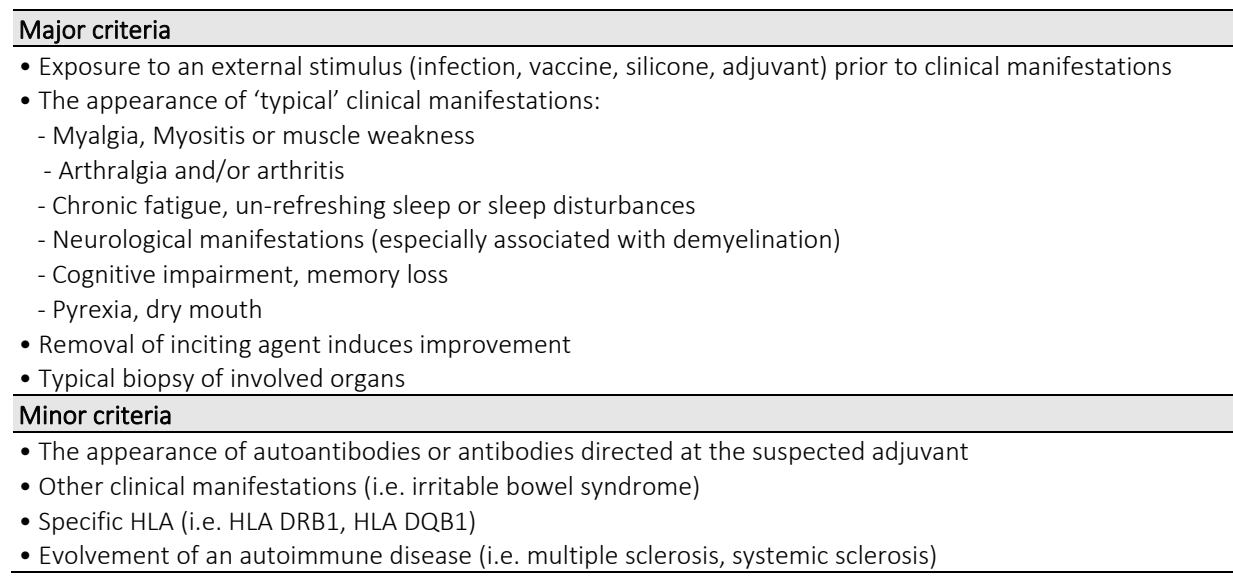

$A S I A$ = autoimmune/inflammatory syndrome induced by adjuvants.

\section{Laboratory investigation}

All patients underwent laboratory evaluations including measurements of vitamin $D$, antinuclear antibodies (ANA), antibodies to extractable nuclear antigens (ENA), anti-cardiolipin antibodies (anti-CL), anti- $\beta 2$ glycoprotein-1 antibodies, antineutrophil cytoplasmic antibodies (ANCA), IgM rheumatoid factor (RF), and anti-cyclic citrullinated peptide (anti-CCP) antibodies. ${ }^{21-27}$ If a positive ANA was found, serum was tested for anti-double-stranded DNA antibodies (anti-dsDNA) ${ }^{26}$, 
and if the ANCA test was positive, samples were additionally tested for PR3-ANCA and MPO-ANCA. ${ }^{25}$

Vitamin D status was evaluated by measurement of serum 25(OH)D levels with a chemiluminescent immunoassay method by Roche Cobas, Roche, Basel, Switzerland. Serum 25(OH)D levels below $50 \mathrm{nmol} / \mathrm{L}(20 \mathrm{ng} / \mathrm{mL})$ were considered as vitamin D deficiency. Vitamin D insufficiency was defined as $\geq 50$ and $<75 \mathrm{nmol} / \mathrm{L}(21-29 \mathrm{ng} / \mathrm{mL})$, whereas vitamin D sufficiency was defined as $\geq 75 \mathrm{nmol} / \mathrm{L}(30 \mathrm{ng} / \mathrm{mL}) .{ }^{28,29}$

\section{Statistical analysis}

For statistical analysis of the results, a chi-square test with a 0.05 two-sided significance level was used (SPSS 22.0 software, IBM Corp, Armonk, NY).

\section{REVIEW}

\section{Types of studies and outcome measures}

Type of studies and outcome measures All types of studies comparing vitamin D status and autoantibodies in patients with or without autoimmune diseases were included in this review. Meta-analysis and systematic review articles were excluded. Only articles published in English were used.

A full paper review was performed when abstracts described vitamin D levels in relation to the presence of autoantibodies and/or antibody titers. Exclusion of articles was based on the absence of (statistical) analysis of the (possible) association between serum vitamin $D$ levels and the presence of autoantibodies and/or antibody titers.

\section{Search methods}

A search in MEDLINE, PubMed, and the Cochrane database from their inception to February 2016 was performed. The used search terms in the PubMed NLM catalog Medical Subject Heading database relevant to this review were "Vitamin D," "Vitamin D [Mesh]," "Vitamin D deficiency [Mesh]," "Autoantibodies," and "Autoantibodies [Mesh]." Abstracts from 176 search hits were screened for eligibility. 


\section{Study selection}

Titles and abstracts were screened for eligibility according to the inclusion criteria by the first author. When included outcome measures were unclear after regarding the abstract, articles were retrieved in full text for additional assessment. After screening the 176 PubMed abstracts according to the inclusion criteria, 38 articles were retrieved for full paper review. Also, a manual search of the reference lists of the selected articles was performed, which resulted in 19 additional articles for the full paper review. Only published data were used. A total of 57 articles were retrieved for detailed full paper review. Criteria for exclusion were met in 10 articles, leaving 47 articles that were included in the final systematic review. A flow diagram of the selection process is shown in Figure 3.1.

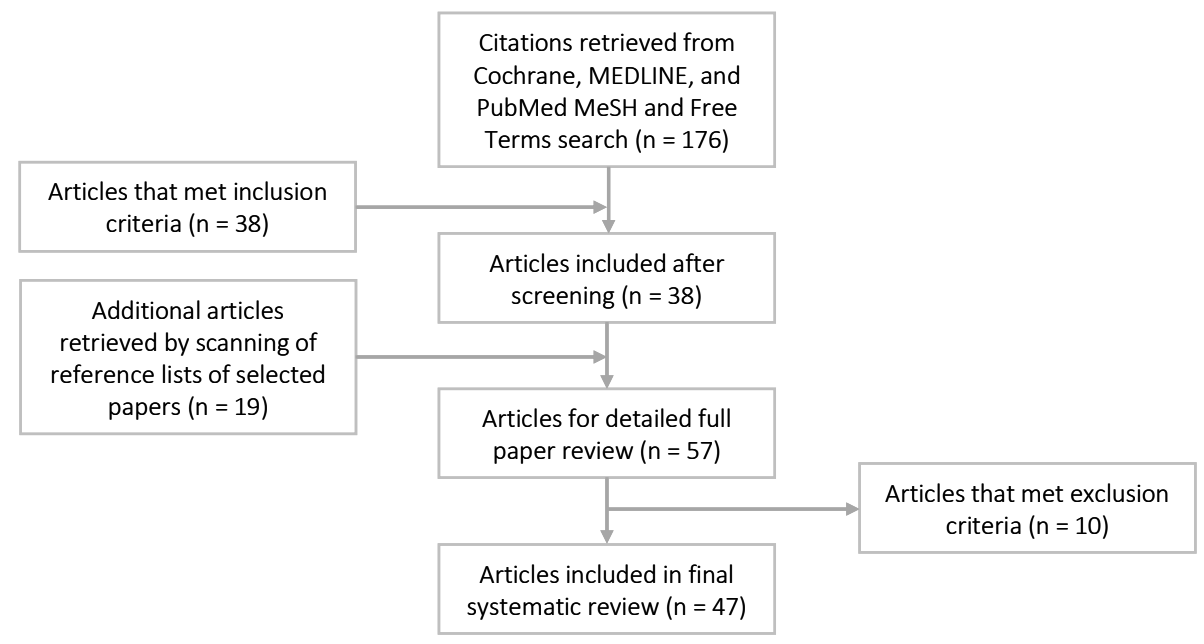

Figure 3.1 Flow diagram of study enrolment in this review.

\section{Data extraction}

Data relevant to the pre-stated outcome measures, the characteristics of the study, participants, and relevant statistical analysis of a (possible) association between the outcome measures were abstracted for this review. 


\section{RESULTS}

Vitamin D measurements were available for analysis in 131 of 135 patients with ASIA in relation to SIIS (Table 3.2). Thirtythree patients (25\%) presented with vitamin D deficiency ( $<50 \mathrm{nmol} / \mathrm{L}), 37$ (28\%) with vitamin D insufficiency ( $\geq 50$ and $<75 \mathrm{nmol} / \mathrm{L})$, and 61 (47\%) with vitamin D sufficiency ( $\geq 75 \mathrm{nmol} / \mathrm{L})$. No differences were observed in clinical characteristics between groups.

Twenty-three patients (18\%) tested positive for autoantibodies. In these 23 patients, one or more antibodies were detected (Table 3.3). Eighteen of these patients (78\%) had either a vitamin D deficiency or insufficiency (median vitamin D level $60.5 \mathrm{mmol} / \mathrm{L}$ ), whereas five patients (22\%) had sufficient vitamin D levels. The risk to develop autoantibodies was significantly increased in vitamin $D$ deficient and/or insufficient patients [RR 3.14; 95\% Cl, 1.24-7.95; $p=0.009$ ].

Table 3.2 The presence of clinical manifestations in vitamin D subgroups.

\begin{tabular}{|c|c|c|c|}
\hline \multirow[t]{2}{*}{ Symptom } & \multicolumn{3}{|c|}{ No. of patients } \\
\hline & $\begin{array}{c}\text { Vitamin D } \\
\text { deficiency } \\
\text { (<50 nmol/L) } \\
n=33\end{array}$ & $\begin{array}{c}\text { Vitamin D } \\
\text { insufficiency } \\
\text { ( } \geq 50-75 \mathrm{nmol} / \mathrm{L}) \\
\mathrm{n}=37\end{array}$ & $\begin{array}{c}\text { Vitamin D } \\
\text { sufficiency } \\
\text { ( } \geq 75 \mathrm{nmol} / \mathrm{L}) \\
\mathrm{n}=61\end{array}$ \\
\hline Myalgia, myositis, or muscle weakness & 18 & 17 & 41 \\
\hline Arthralgia and/or arthritis & 31 & 33 & 58 \\
\hline Fatigue, unrefreshing sleep or sleep disturbances & 32 & 37 & 60 \\
\hline Neurological manifestations ${ }^{a}$ & 7 & 7 & 16 \\
\hline Cognitive impairment, memory loss & 25 & 30 & 47 \\
\hline Pyrexia & 23 & 22 & 48 \\
\hline Dry eyes and/or dry mouth (sicca) & 27 & 24 & 47 \\
\hline
\end{tabular}

a Neurological manifestations: TIA/CVA or demyelination.

Table 3.3 Autoantibodies detected in $23^{\mathrm{b}}$ patients with ASIA in relation to SIIS.

\begin{tabular}{lc}
\hline Autoantibodies & No. of patients \\
\hline ANA/ENA & 6 \\
Anti-CL & 7 \\
ANCA & 4 \\
IgM-RF & 4 \\
Anti-CCP & 3 \\
\hline
\end{tabular}

ANA = antinuclear antibodies; anti-dsDNA = anti-double-stranded DNA antibodies; anti-SSA = anti-Sjögren's syndrome-related antigen $\mathrm{A} ;$ anti-SSB = anti-Sjögren's syndrome-related antigen $\mathrm{B}$; anti-CENPB = anticentromere protein $\mathrm{B}$; anti-SCl-70 = anti-topoisomerase I; anti-CL = anti-cardiolipin; $A N C A=$ anti-neutrophil cytoplasmic antibodies; IgM-RF = IgM rheumatoid factor; anti-CCP = anti-cyclic citrullinated peptide antibody.

${ }^{a}$ ANA specificities: anti-dsDNA $(n=1)$, anti-SSA $(n=2)$, anti-SSB $(n=1)$, anti-CENP-B $(n=1)$, anti-Scl70 $(n=1)$.

${ }^{b}$ One patient had two autoantibodies (anti-CCP and ANCA). 


\section{REVIEW}

Forty-seven studies were reviewed (17 case-control studies, 19 cross-sectional studies, 1 cross-sectional case-control study, 10 cohort studies). The selected articles will be presented according to five subcategories: autoimmune thyroid diseases, connective tissue diseases, inflammatory arthritides, multiple sclerosis, and other studies.

\section{Autoimmune thyroid diseases}

In several epidemiological studies, the association between vitamin D levels and the presence of autoimmune thyroid diseases (AITDs) has been investigated. ${ }^{30}$ Kivity et al. examined serum vitamin $D$ levels in relation to anti-thyroid peroxidase (anti-TPO) and anti-thyroglobulin (anti-TG) antibodies in 92 patients with thyroid diseases (28 patients with Hashimoto's thyroiditis, 22 patients with Graves' disease, 42 patients without evidence for autoimmunity) and 98 age-matched healthy control subjects. ${ }^{31}$ They documented a significantly higher prevalence of vitamin D deficiency $(<10 \mathrm{ng} / \mathrm{mL})$ in patients with thyroid diseases (58/92) compared to healthy controls $(30 / 98)(p<0.001)$. Vitamin D deficiency was present particularly in patients with Hashimoto's thyroiditis $(22 / 28 ; p=0.001)$ and in patients with Graves' disease $(14 / 22 ; p=0.01)$. As a consequence, vitamin D deficiency was found to be correlated with the presence of antithyroid antibodies $(p=0.01){ }^{31}$ Choi et al. observed in a crosssectional study that serum $25(\mathrm{OH}) \mathrm{D}$ levels were significantly lower in anti-TPO-positive (427/2793) compared to antiTPOnegative $(2366 / 2793)$ female euthyroid subjects $(p=0.03) .{ }^{32}$

In a subgroup analysis of pre- $(n=908)$ and postmenopausal $(n=1885)$ women, the serum $25(\mathrm{OH}) \mathrm{D}$ levels were significantly lower in pre-menopausal women with antiTPO antibodies $(p=0.049)$ but not in postmenopausal women with these antibodies $(p=0.186) .{ }^{32}$ Also, Goswami et al. found a significant inverse correlation between serum vitamin D levels and anti-TPO positivity $(p=0.04)$ in an Asian Indian population. ${ }^{33}$ Arslan et al. found anti-TPO positivity more frequently observed in healthy volunteers with severe $(<10 \mathrm{ng} / \mathrm{mL})$ and moderate $(10-20 \mathrm{ng} / \mathrm{mL})$ vitamin $D$ levels, compared to those with normal vitamin D levels ( $\geq 20 \mathrm{ng} / \mathrm{mL}$ ). ${ }^{34}$ Additionally, in antibodypositive patients, a significant inverse correlation between anti-TPO and anti-TG titers and 25(OH)D levels ( $p=0.017$ for anti-TPO and $p=0.05$ for anti-TG) was found. ${ }^{34}$ In a case-control study, Unal et al. found that anti-TG and anti-TPO 
titers were significantly higher in vitamin D-deficient AITD patients $(183 / 281)$ than in vitamin D-sufficient AITD patients (98/281) ( $p=0.02$ and $p=0.003$, respectively, for anti-TG and anti-TPO). ${ }^{35}$ In this study, the 281 AITD patients consist of 254 patients with Hashimoto thyroiditis and 27 patients with Graves' disease. Several other studies also found a negative correlation between serum vitamin $D$ levels and antithyroid antibody levels. ${ }^{36-40}$ Mazokopakis et al. found that anti-TPO levels were significantly higher in vitamin D-deficient patients with Hashimoto's thyroiditis (HT) ( $n=186)$ compared to HT patients with no vitamin D deficiency ( $n=32)(364 \pm 181$ vs. $115.8 \pm 37.1 \mathrm{IU} / \mathrm{mL}, p<0.0001)^{36}$, whereas Bozkurt et al. found that serum 25(OH)D levels were inversely correlated with anti-TPO $(p<0.001)$ and anti-TG levels $(p<0.001)$ in subjects with $\mathrm{HT}{ }^{36}$ Furthermore, Bozkurt observed that serum 25(OH)D levels in HT patients were significantly lower than in healthy controls. ${ }^{37}$ Shin et al. found that AITD patients (65 Hashimoto's thyroiditis and 46 Graves' disease) with antithyroid antibodies had lower levels of serum 25(OH)D than control patients without positive anti-thyroid antibodies $(12.6 \pm 5.5$ vs. $14.5 \pm 7.3 \mathrm{ng} / \mathrm{mL}$, respectively, $p<0.001) .{ }^{38}$ They also found that $25(\mathrm{OH}) \mathrm{D}$ levels were inversely correlated with the anti-TPO levels $(p<0.001)$ in the HT and Graves' patients. More recently, Wang et al. analyzed a total of 1714 Chinese healthy adults and reported that subjects that tested positive for anti-TG $(n=315)$ had lower serum 25(OH)D levels compared to subjects who were anti-TG negative $(p<0.01) .{ }^{39}$ Furthermore, they observed that higher anti-TG titers were associated with lower 25(OH)D levels independent of age, ethnicity, and TSH levels in females but not in males $(p=0.014)$. Finally, in non-lactating women with postpartum thyroiditis, anti-TPO and anti-TG titers were found to be inversely correlated with vitamin $D$ levels $(p<0.001) .40$

In contrast, D'Aurizio et al. did not observe statistically significant differences in vitamin $D$ levels between healthy controls and either patients with HT and/or Graves' disease $(n=100)$ and anti-TPO and/or anti-TSH receptor autoantibody positivity. ${ }^{41}$ Also, Ma et al. did not find serum 25(OH)D levels to be associated with anti-TPO or anti-TG levels in 70 patients with newly diagnosed HT. ${ }^{42}$ However, an association between serum 25(OH)D levels and anti-TSH receptor autoantibody levels was observed in their 70 patients $(p=0.036) .{ }^{42}$ Yasuda et al. evaluated 26 female patients with newly onset Graves' disease and found no association between serum 25(OH)D levels and anti-TSH receptor autoantibody levels. ${ }^{43}$ In women with polycystic ovary syndrome and positive anti-TPO and/or anti-TG 
antibody levels, no correlation between 25(OH)D levels and these antibodies was seen. ${ }^{44}$ Finally, Effraimidis et al. reported a longitudinal study with a 5-year followup period in which serum 25(OH)D levels of 521 euthyroid subjects were analyzed and related to the occurrence of thyroid peroxidase antibodies (anti-TPO). ${ }^{45}$ Subjects were euthyroid women who had first- or second-degree relatives with overt AITD who had normal TSH and no thyroid antibodies at baseline. Subjects that developed anti-TPO within a period of 5 years were compared to subjects who remained anti-TPO negative, matched for age, BMI, smoking status, estrogen use, month of blood sampling, and duration of follow-up. ${ }^{45}$ Sixty-seven subjects became positive for anti-TPO during follow-up, without developing abnormal TSH. No association with serum 25(OH)D levels was reported.

In conclusion, several studies suggested an association between the presence of anti-TPO and/or anti-TG and vitamin D levels and/or between autoantibody level and vitamin D level (Table 3.4). In a prospective study, however, vitamin D levels were not found to be a risk factor for the development of anti-TPO.

\section{Connective tissue diseases}

Low levels of vitamin $D$ are often found in systemic lupus erythematosus (SLE) patients. ${ }^{46,47}$ Vitamin $D$ levels are lower in postmenopausal SLE patients $(n=80)$ compared to pre-menopausal SLE patients $(n=80)(p=0.02) .{ }^{48}$ No association, however, could be observed between vitamin $D$ food intake and supplements and risk of the development of SLE. ${ }^{49}$ ANA-positive SLE patients are more likely to have vitamin $D$ deficiency $(\leq 20 \mathrm{ng} / \mathrm{mL})$ compared to ANAnegative SLE controls $(p=0.011) .{ }^{46}$ Also, anti-dsDNA autoantibody levels increased from normal vitamin D concentrations, to insufficient vitamin $D$ levels and from insufficient to vitamin D-deficient patient subsets as found in 177 Hungarian SLE patients $(p=0.021) .{ }^{48}$ In women with newly diagnosed SLE, Bonakdar et al. also found higher titers of antidsDNA antibodies with more severe vitamin D deficiency $(p<0.001) .{ }^{50}$ Also, Mok et al. showed a significant negative correlation between 25(OH)D levels and antidsDNA levels $(p=0.02)$ or anti-C1q levels $(p=0.02)$ in their SLE patients $(n=290) .{ }^{51}$ In contrast, Thudi et al. found higher levels of anti-dsDNA in a small group of female lupus patients with levels of vitamin $D$ that were greater than $47.7 \mathrm{nmol} / \mathrm{L}$ compared to subjects with $25(\mathrm{OH}) \mathrm{D}$ levels lower than $47.7 \mathrm{nmol} / \mathrm{L}(p=0.0069)$ $(n=37) .{ }^{52}$ Finally, in a small study performed in 28 Saudi children with SLE, levels of $25(\mathrm{OH}) \mathrm{D}$ tended to be inversely correlated with anti-dsDNA titers and ANA. ${ }^{53}$ 


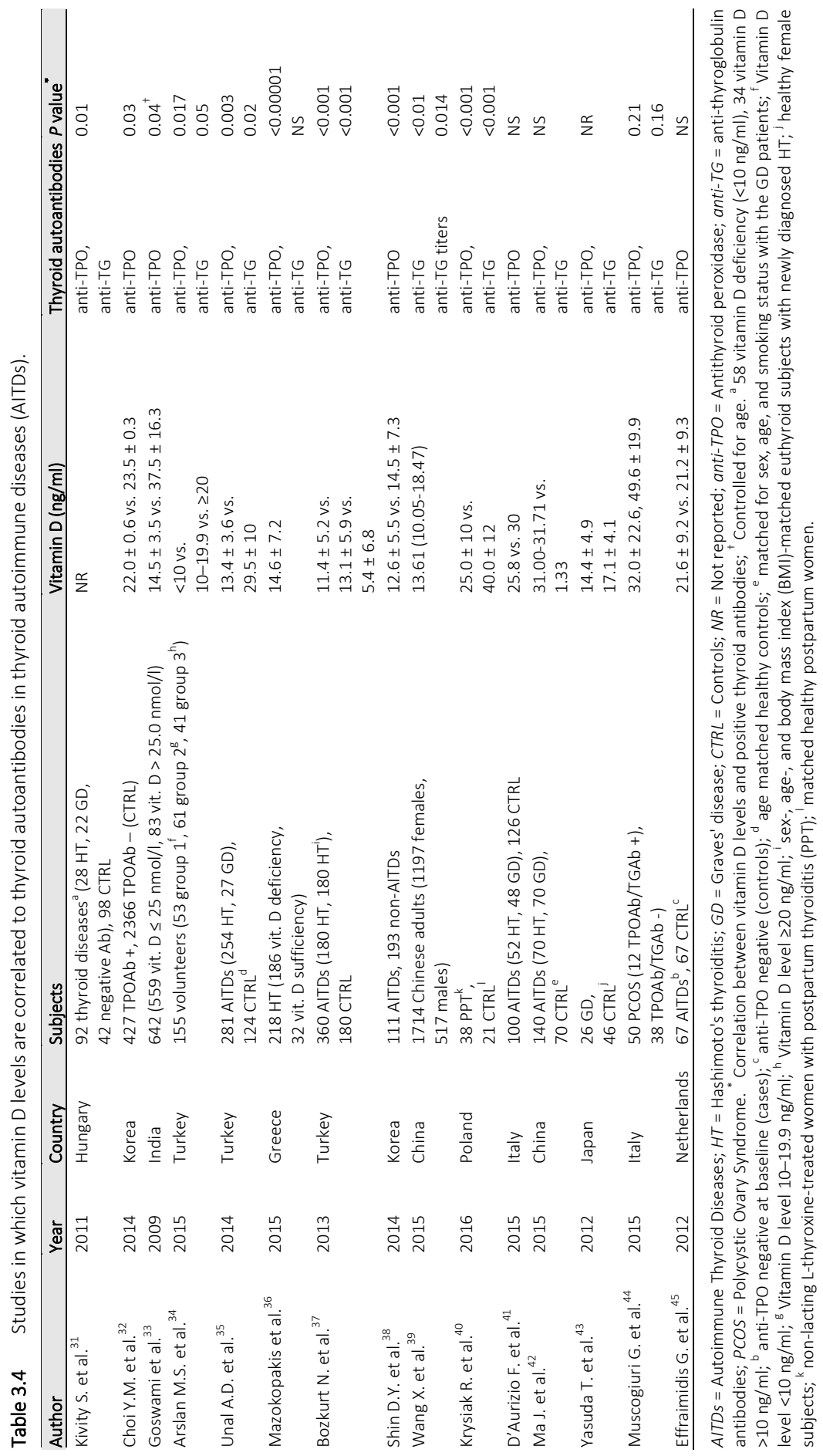


Also, in other connective tissue diseases, low levels of vitamin $D$ are found to be correlated with autoantibodies. In patients with Sjögren's syndrome, an inverse correlation between the concentrations of $25(\mathrm{OH}) \mathrm{D}$ and the titers of $\operatorname{lgM}$ rheumatoid factor were found $(n=25) .{ }^{54}$ In patients with mixed connective tissue disease (MCTD), higher serum levels of anti-U1-RNP (anti-ribonucleoprotein) antibodies were found in patients with low vitamin D levels $(p=0.022) .{ }^{55}$ Also, in 161 undifferentiated connective tissue disease (UCTD) patients, autoantibody profiles showed that serum levels of anti-U1-RNP, anti-SSA, and anti-CCP antibodies were inversely correlated to vitamin $\mathrm{D}$ levels $(p<0.05) .{ }^{56}$ During an average follow-up period of 2.3 years, 35/161 patients developed an established connective tissue disease. Vitamin D levels were lower in these patients compared to the vitamin D levels as found in the 126/161 UCTD patients that did not develop an established CTD $(14.7 \pm 6.45$ vs. $33.0 \pm 13.4 \mathrm{ng} / \mathrm{mL}, p=0.0001) .{ }^{56}$ In a crosssectional study in 23 pre-menopausal women with primary anti-phospholipid syndrome (APS), serum vitamin D levels and IgG and IgM anti-cardiolipin (anti-CL) antibodies were investigated and compared to vitamin D levels in 23 age- and racematched healthy controls. ${ }^{57}$ Lower serum levels of 25(OH)D [21.64 mg/dL (11.26) vs. $28.59 \mathrm{mg} / \mathrm{dL}$ (10.67), $p=0.039$ ] were found in the APS patients when compared to controls. No correlation, however, was found between vitamin D levels and IgG anti-CL levels ( $p=0.222$ ) and/or IgM anti-CL levels ( $p=0.535)$. In a large multinational study in patients with systemic sclerosis (SSc), vitamin D concentrations and the presence of anti-nuclear antibodies (ANA), anti-SCL70 antibodies, and RF were determined. ${ }^{58}$ Three hundred twentyseven serum samples of European patients with SSc and 141 samples of healthy controls were studied. Patients with SSc had significantly lower serum vitamin D concentrations compared to healthy controls $(p<0.001)$. An inverse relation between RF positivity and the vitamin $D$ concentration was found $(p<0.001)$. No association was found between vitamin D levels and the presence of ANA and/or anti-SCL70.

In conclusion, an inverse correlation between vitamin $D$ levels and the presence of autoantibodies in connective tissue diseases has been described (Table 3.5). In several studies, vitamin $D$ deficiency was found to be inversely correlated with autoantibody titers in connective tissue diseases, although findings are at present not conclusive. 


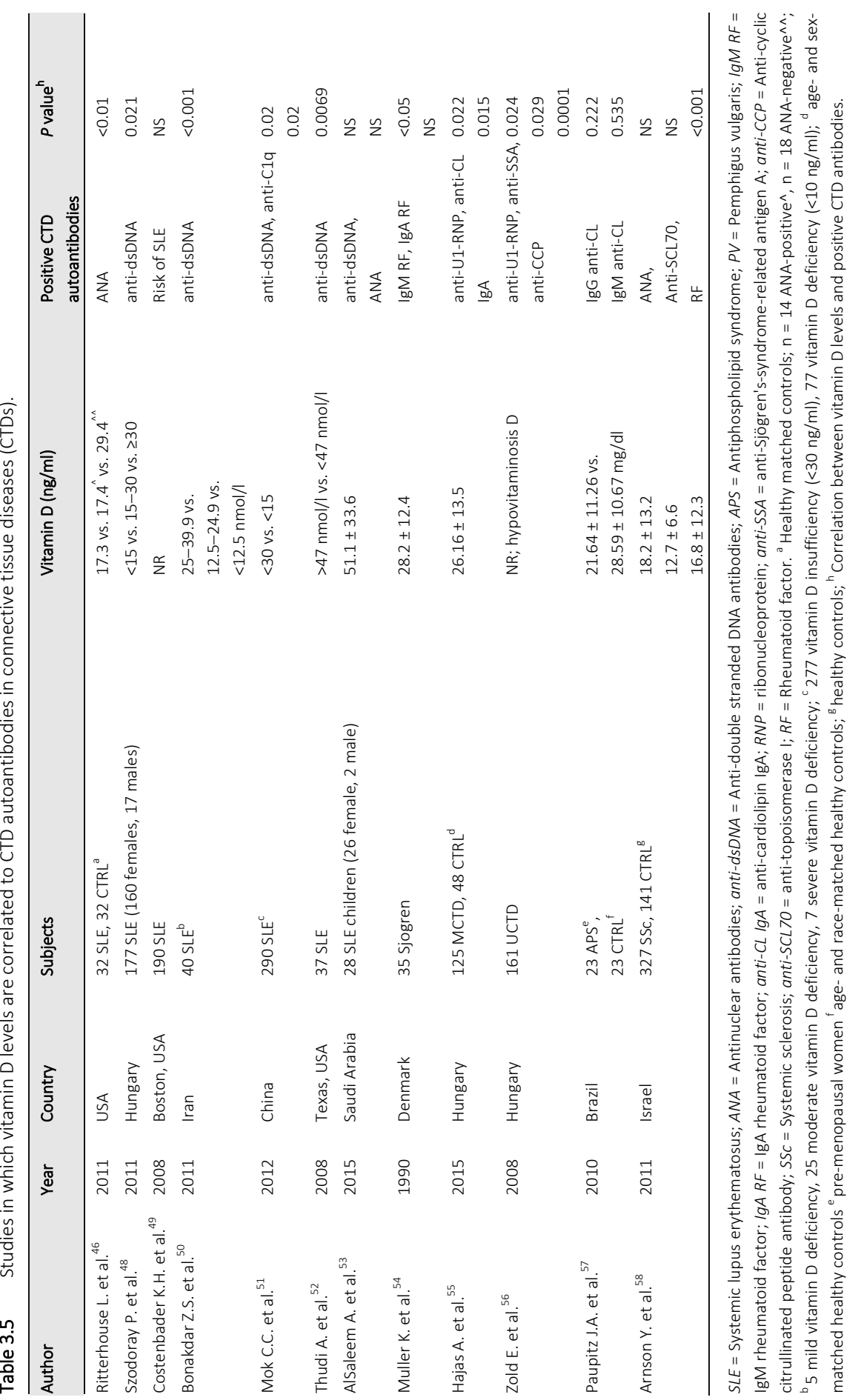




\section{Inflammatory arthritides}

In the Women's lowa Health Study, i.e., a prospective cohort of 29,368 women, it was demonstrated that vitamin $D$ food intake was inversely associated with the risk to develop rheumatoid arthritis (RA) $(n=152) .{ }^{59}$ However, in smaller studies, no association was found. Firstly, in 722 patients with RA from the Nurses' Health Study and Nurses' Health Study ${ }{ }^{49}$, and secondly, in the study by Nielen et al. $(n=79)$, no association between vitamin D deficiency and later development of RAwas observed. ${ }^{60}$ Feser et al. found in a healthy population at increased risk for RA that 25(OH)D levels were not associated with the presence of RA-related autoantibodies (76 subjects being positive for anti-CCP and/or RF) ( $p=0.15$ ). ${ }^{61}$ In contrast, RA patients with severe vitamin D deficiency (serum levels $\leq 15 \mathrm{nmol} / \mathrm{L}$ ) $(n=15)$ were shown to test more frequently positive for RF (100\%) when compared to RA patients with normal vitamin D serum levels ( $n=200$ ) $(77.5 \%)$ $(p=0.05) .{ }^{62}$ In a 10-year prospective cohort study of 775 RA, 738 ankylosing spondylitis (SPA), and 721 psoriatic arthritis (PsA) patients, 25(OH)D levels, RF, and anticyclic citrullinated peptide (anti-CCP) antibodies were measured. ${ }^{63}$ Levels were compared to 677 subjects without inflammatory rheumatic diseases. Five hundred twenty-eight RA patients (68.1\%) were found to be RF positive and 482 RA patients (62.2\%) anti-CCP positive. The prevalence of anti-CCP positivity was significantly higher in the $25(\mathrm{OH}) \mathrm{D}$ deficiency group $(<20 \mathrm{ng} / \mathrm{mL})(p<0.022)$ compared to patients with sufficient levels of vitamin D. ${ }^{63}$ Subclinical gut inflammationmay be present in patients with SPA. In a cross-sectional study by Teichman et al., 47/76 patients with SPA tested positive for human anti-tissue-transglutaminase-IgA (htTG) antibodies. These patients had significant lower 25(OH)D levels compared to SPA patients that tested negative for antihtTG antibodies (mean 17.4 vs. mean $41.5 \mathrm{ng} / \mathrm{mL} ; p<0.005) .{ }^{64}$

In conclusion, the relation between vitamin $D$ food intake and the risk of development of RA later in life is controversial. Furthermore, some studies suggest that there is an inverse correlation between vitamin $D$ levels and the presence of RA-related autoantibodies (RF and/or anti-CCP) in patients with RA (Table 3.6) and/or anti-TTG antibodies in SPA. 


\section{Multiple sclerosis}

Low levels of vitamin D are common in patients with multiple sclerosis (MS) and are associated with more severe disability and an increased risk for relapses of the disease. ${ }^{65}$ Also, the geographical distribution of MS suggests that people living in areas were vitamin D levels are low are more prone to develop MS. Furthermore, vitamin D supplementation may correct immunological abnormalities that are observed in MS. ${ }^{66,67}$ As a consequence, vitamin D supplementation is currently being studied for the prevention of disease relapses. ${ }^{68}$ An association between low vitamin D levels and MSrelated antibodies are, however, rarely reported. In a cross-sectional study of pediatric-onset MS, vitamin D status was found to be related to antibody levels to cytomegalovirus (CMV), while antibodies to other viruses (Epstein-Barr virus, herpes simplex virus 1 or 2) were not found to be associated with vitamin D levels. ${ }^{69}$ Epstein-Barr virus (EBV) is postulated to play an important role in the pathogenesis of MS by infecting B cells. ${ }^{70}$ Importantly, antibodies against the EBV antigens are associated with an increased risk of developing MS later in life. ${ }^{71}$ Salzer et al. showed an inverse association between vitamin D levels and antibody titers against EBV in MS patients. ${ }^{72}$ Décard et al. investigated serum 25(OH)D levels and EBV immunoreactivity in 25 individuals who donated blood prior to the first clinical MS manifestation. ${ }^{73}$ Cross-sectional analyses revealed a gradual decrease of vitamin $D$ levels and increase of antiEBNA-1 IgG titers before the first clinical manifestation of MS. Furthermore, Disanto et al. showed decreased anti-EBNA-1 IgG levels after 12 weeks of vitamin D supplementation in 15 relapsing-remitting MS (RRMS) patients $(p=0.016){ }^{74}$ Another study by Najafipoor et al. examined the effect of vitamin $D$ supplementation for 6 months on the anti-VCA IgG and anti-EBNA-1 IgG levels in 40 RRMS patients. ${ }^{75}$ They found six patients (15\%) with a decline in the level of anti-VCA titers and six patients (15\%) with a reduction in anti-EBNA1 titers in the supplemented group. There was, however, no significant relationship between the vitamin D levels and antibody levels (VCA IgG $p=0.420$; EBNA1 IgG $p=0.853$ ). In summary, both vitamin $D$ levels and autoantibodies against EBVare reported to be important in the pathogenesis of MS. A causal relation between these two etiological factors is suggested in several studies (Table 3.7). 


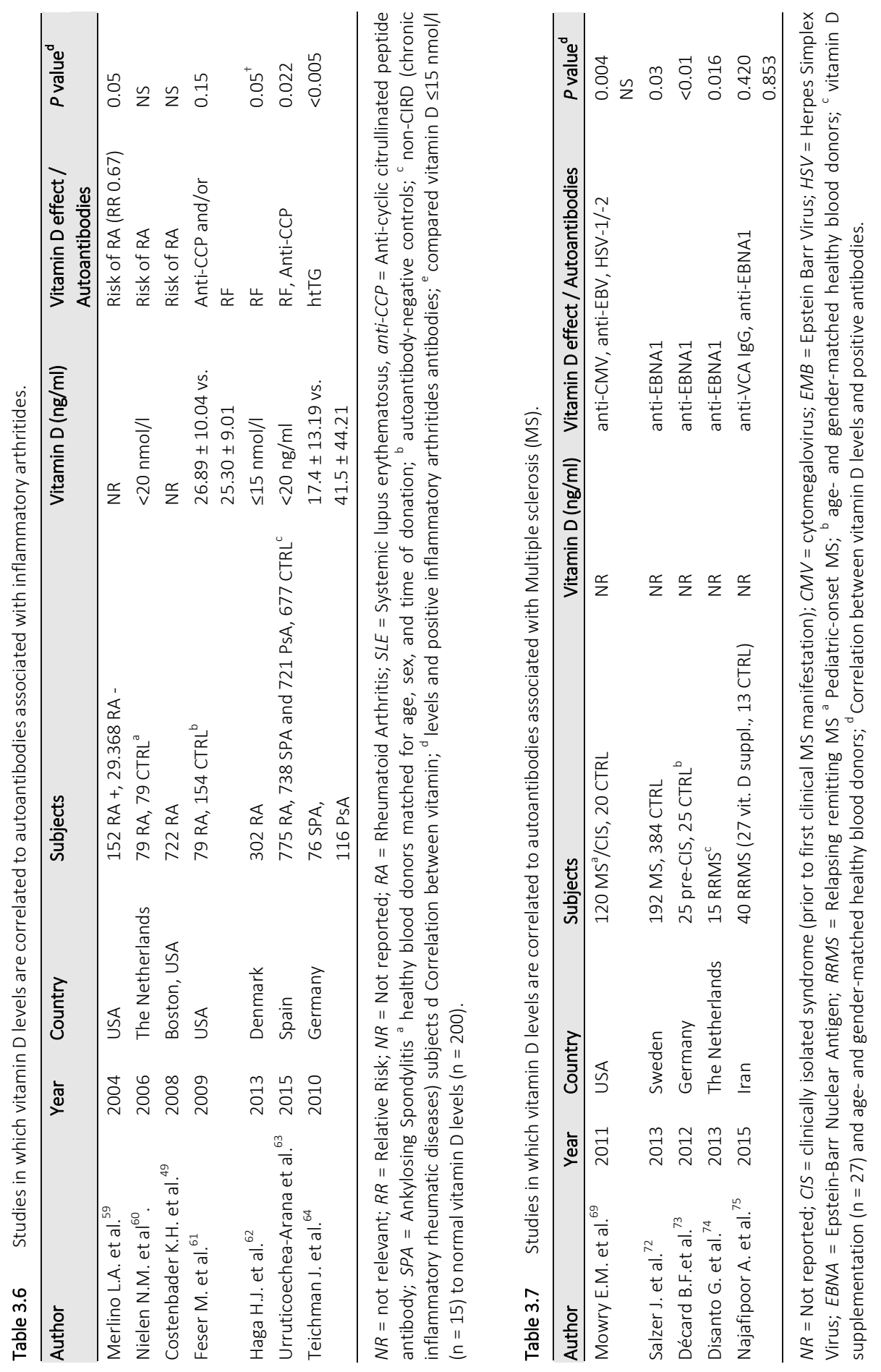




\section{Other studies}

Inflammatory bowel disease (IBD) is another disease that is linked to low vitamin D levels. ${ }^{17,76}$ A prospective study by Santos-Antunes et al. found an inverse relationship between vitamin $D$ levels and ANA positivity in IBD patients. ${ }^{77}$ The presence of ANA has also been shown to correlate with low serum vitamin D levels in patients with leprosy $(p<0.001) .{ }^{78}$ Ritterhouse et al. observed that ANApositive healthy controls are significantly more likely to be deficient in vitamin $D$ levels than ANA-negative healthy controls $(p=0.011) .{ }^{46}$ Nuti et al. found that 24 women with osteoporosis in the presence of coeliac disease and high levels of serum IgG antigliadin antibodies (IgG AGA) and tissue transglutaminase antibodies (anti-TTG) had lower serum 25(OH)D levels compared to 231 women with primary osteoporosis without coeliac disease $(p<0.01) .{ }^{79}$ They also found an inverse correlation between the serum 25(OH)D levels and the serum anti-TTG titers in these 24 women with primary osteoporosis and coeliac disease $(p<0.001)$. Karakan et al. investigated the presence of serum IgA anti-endomysial (IgA EMA) antibodies in relation to serum 25(OH)D levels in 135 patients with idiopathic osteoporosis and found that 13 patients (9.6\%) which tested positive for IgA EMA had lower serum 25(OH)D levels compared to IgA EMA-negative patients $(p<0.01) .{ }^{80}$ However, none of these 13 patients had findings consistent with coeliac disease. Furthermore, in a cross-sectional study by Ota et al. of 133 women with recurrent pregnancy losses, a significantly higher prevalence of anti-phospholipid antibodies and TPO antibodies was found in 63 patients with low vitamin D levels $(<30 \mathrm{ng} / \mathrm{mL}$ ) compared to 70 patients with normal vitamin D levels $\left(p<0.05\right.$ each). ${ }^{81} \mathrm{~A}$ prospective study by Njemini et al. investigated the prevalence of several organspecific and non-organspecific autoantibodies and serum 25(OH)D levels in 152 unselected Cameroonians. ${ }^{82}$ No association between the presence of autoantibodies and serum 25(OH)D levels could be found in this African population. Finally, Carvalho et al. observed anti-vitamin D antibodies in a subset of patients with several different autoimmune diseases ${ }^{83}$, but could not find a significant difference in serum 25(OH)D levels between the anti-vitamin D antibody-positive $(n=7)$ and anti-vitamin Dnegative $(n=164)$ patients.

In conclusion, an inverse correlation between serum vitamin $D$ levels and the presence of autoantibodies in several other conditions has been suggested as well (Table 3.8). 


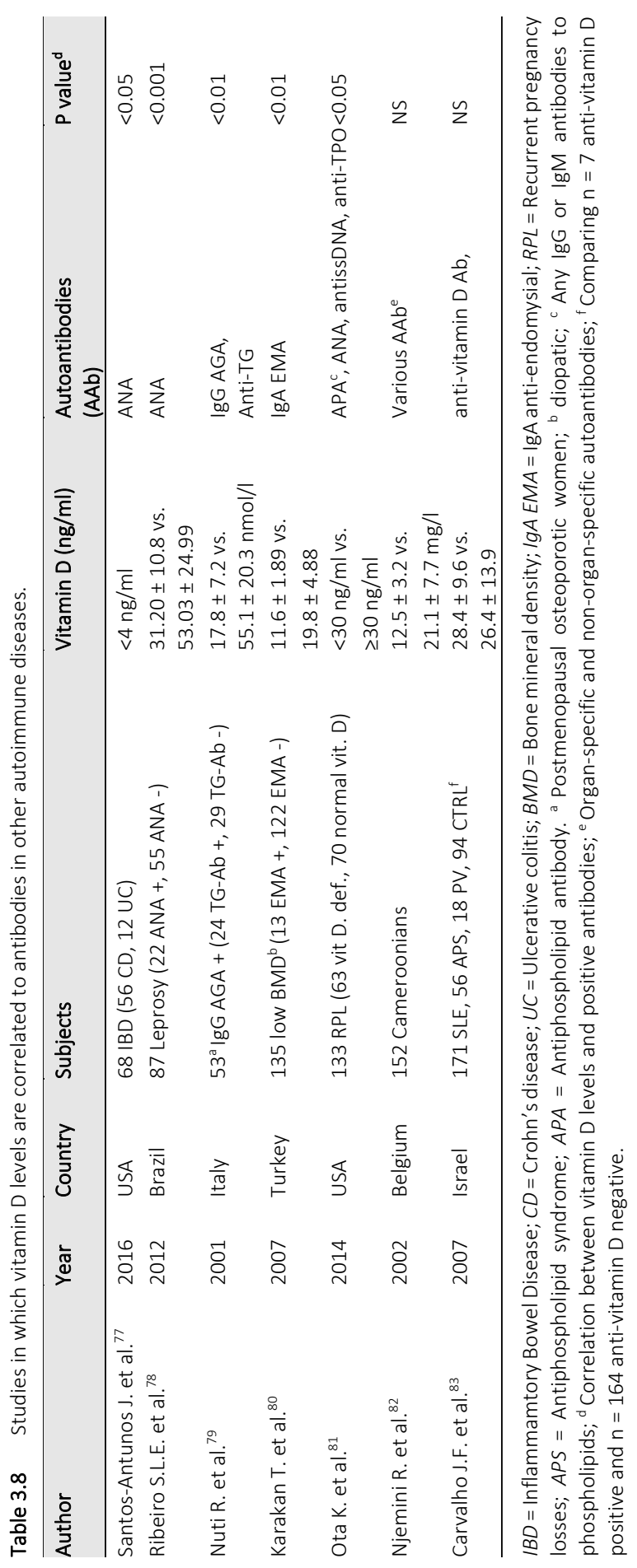




\section{DISCUSSION}

The aim of our study was to investigate the relation between vitamin D levels in patients with ASIA in relation to silicone implant incompatibility and the presence of autoantibodies. Vitamin D deficiency or insufficiency was found to be related to the presence of autoantibodies in our patients with silicone breast implants. A critical limitation to this finding is that we did not perform a study in control patients. Whether vitamin D deficiency is also related to the presence of autoantibodies in healthy control women remains therefore unknown. Furthermore, we reviewed the literature regarding an association between vitamin $D$ deficiency and the development of autoantibodies in several other (autoimmune) diseases. To our knowledge, this link has not been reviewed before. Conflicting data regarding the relation between vitamin $D$ levels and autoantibodies were found since low vitamin $D$ levels were linked to the presence of autoantibodies and/or the antibody titers in some, but not all studies. Thirty-one studies described a significant negative correlation between serum vitamin $D$ levels and autoantibodies: ten for antithyroid antibody levels ${ }^{31-40}$, nine for autoantibodies in connective tissue diseases $46,48,50-52,54-56,58$, two for RA-related autoantibodies (RF and/or anti-CCP $)^{62,63}$, one for anti-TTG antibodies ${ }^{64}$, four for autoantibodies against EBV in MS patients ${ }^{69,72-74}$, and five for autoantibodies in several other (autoimmune) diseases. ${ }^{77-81}$ Thirteen studies could, however, not confirm this correlation. ${ }^{41-45,49,53,57,60-61,75,82-83}$

Vitamin D deficiency has been underestimated for many years as a health problem. Importantly, the role of vitamin D insufficiency and/or deficiency in the development of different autoimmune diseases is at present increasingly studied. ${ }^{47,84}$ It has been demonstrated that many cells of the immune system express vitamin $D$ receptors (VDRs), e.g., monocytes and dendritic cells (DC). ${ }^{18}$ Whereas resting $T$ and $B$ cells express negligible VDR, activation of these cells results in upregulation of VDR expression. ${ }^{19}$ Furthermore, activated $B$ cells express CYP27B1 and CYP24A1 enzymes, which are responsible for the synthesis and breakdown of the active metabolite of vitamin $D$, thereby regulating vitamin $D$ activity in the microenvironment. ${ }^{19,68,85}$ Importantly, Chen et al. demonstrated that $1,25(\mathrm{OH})_{2} \mathrm{D}$ has potent direct effects on $\mathrm{B}$ cell responses, inhibiting proliferation, generation of class-switched memory $B$ cells, plasma cell differentiation, and Ig production. ${ }^{19}$ Furthermore, they demonstrated that $1,25(\mathrm{OH})_{2} \mathrm{D}$ induced increased 
apoptosis of proliferating B cells. ${ }^{19}$ Chen et al. therefore suggested that vitamin D deficiency could contribute to B cell hyperactivity, breakdown of B cell tolerance, and production of autoantibodies in SLE patients. ${ }^{19}$ Subsequently, it was demonstrated in in vitro experiments that synthesis of $\operatorname{lgM}, \lg G$, and $\lg A$ by various stimuli was inhibited in the presence of $1,25(\mathrm{OH})_{2} \mathrm{D} .{ }^{19}$ These in vitro inhibitory effects of vitamin D are, however, not confirmed in vivo. ${ }^{86-88}$ Ritterhouse et al. found that SLE patients with more pronounced B cell activation had lower mean 25(OH)D levels compared to SLE patients with less B cell activation. ${ }^{46}$ Importantly, they also found that patients with vitamin $D$ deficiency had higher mean serum IFN $\alpha$ activity than patients without a vitamin D deficiency. ${ }^{46}$ IFN $\alpha$ is produced in large amounts by activated dendritic cells (DCs) and has multiple pro-inflammatory effects on autoreactive cells and is therefore considered to be a central player in the progression to and maintenance of autoimmunity. ${ }^{89}$ Excessive dendritic cell activity could therefore be another hypothesis for the production of autoantibodies in vitamin D-deficient patients. Whether these pathophysiological hypotheses are relevant for the development of autoimmune diseases is, however, at present not clear.

\section{CONCLUSION}

Vitamin D may act as a regulatory agent of the immune system. Vitamin D deficiency is found to be related to the presence of autoantibodies in patients with silicone implant incompatibility syndrome. In line with our study, we found several reports that suggested that there is evidence that vitamin D levels are related to the presence and/or levels of autoantibodies in thyroid autoimmune diseases (AITDs), connective tissue diseases (CTDs), multiple sclerosis (MS), and several other (autoimmune) diseases. Randomized, controlled trials must be performed to elucidate whether vitamin D supplementation is beneficial as preventive therapy in patients with silicone breast implants to inhibit the development of autoantibodies. 


\section{REFERENCES}

1. Colaris MJL, de Boer M, van der Hulst RR, Cohen Tervaert JW. Two hundreds cases of ASIA syndrome following silicone implants-a comparative study of 30 years and a review of current literature. Immunol Res 2017;65(1):120-128.

2. Shoenfeld Y, Agmon-Levin N. 'ASIA'-autoimmune /inflammatory syndrome induced by adjuvants. J Autoimmun 2011;36:4-8.

3. Cohen Tervaert JW, Kappel RM. Silicone implant incompatibility syndrome (SIIS): a frequent cause of ASIA (Shoenfeld's syndrome). Immunol Res 2012;56:293-298.

4. De Boer M, Colaris M, van der Hulst RR, Cohen Tervaert JW. Is explantation of silicone breast implants useful in patients with complaints? Immunol Res 2017;65(1):25-36.

5. Janowsky EC, Kupper LL, Hulka BS. Meta-analyses of the relation between silicone breast implants and the risk of connectivetissue diseases. N Engl J Med 2000;342:781-790.

6. Balk EM, Earley A, Avendano EA, Raman G. Long-term health outcomes in women with silicone gel breast implants: a systematic review. Ann Intern Med 2016;164:164-175.

7. Shen GQ, Ojo-Amaize EA, Agopian MS, Peter JB. Silicate antibodies in women with silicone breast implants: development of an assay for detection of humoral immunity. Clin Diagn Lab Immunol 1996;3:162-166.

8. Kossovsky N, Gornbein JA, Zeidler M, Stassi J, Chun G, Papasian N, Nguyen R, Ly K, Rajguru S. Selfreported signs and symptoms in breast implant patients with novel antibodies to silicone surface associated antigens [anti-SSAA(x)]. J Appl Biomater 1995;6:153-160.

9. Zandman-Goddard G, Blank M, Ehrenfeld M, Gilburd B, Peter J, Shoenfeld Y. A comparison of autoantibody production in asymptomatic and symptomatic women with silicone breast implants. J Rheumatol 1999;26:73-77.

10. Tenenbaum SA, Rice JC, Espinoza LR, Cuéllar ML, Plymale DR, Sander DM, Williamson LL, Haislip AM, Gluck OS, Tesser JR. Use of antipolymer antibody assay in recipients of silicone breast implants. Lancet 1997;349:449-454.

11. Bar-Meir E, Teuber SS, Lin HC, Alosacie I, Goddard AG, Terybery J, Barka N, Shen B, Peter JB, Blank M, et al.) Multiple antibodies in patients with silicone breast implants. J Autoimmun 1995;8:267-277.

12. Wolfram D, Oberreiter B, Mayerl C, Soelder E, Ulmer H, PizaKatzer H, Wick G, Backovic A. Altered systemic serologic parameters in patients with silicone mammary implants. Immunol Lett 2008;118:96100.

13. Mithal A, Wahl DA, Bonjour JP, Burckhardt P, Dawson-Hughes B, Eisman JA, et al. Global vitamin D status and determinants of hypovitaminosis D. Osteoporos Int 2009;20:1807-1820.

14. Borella E, Nesher G, Israeli E, Shoenfeld Y. Vitamin D: a new anti-infective agent? Ann N Y Acad Sci 2014;1317:76-83.

15. Arnson $Y$, Amital $H$, Shoenfeld $Y$. Vitamin $D$ and autoimmunity: new aetiological and therapeutic considerations. Ann Rheum Dis 2007;66:1137-1142.

16. Rosen Y, Daich J, Soliman I, Brathwaite E, Shoenfeld Y. Vitamin D and autoimmunity. Scand J Rheumatol 2016;45:439-447.

17. Holick MF. Vitamin D deficiency. N Engl J Med 2007;357:266-281.

18. Peelen E, Knippenberg S, Muris AH, Thewissen M, Smolders J, Tervaert JW, Hupperts R, Damoiseaux J. Effects of vitamin $D$ on the peripheral adaptive immune system: a review. Autoimmun Rev 2011;10:733-743.

19. Chen S, Sims GP, Chen XX, Gu YY, Lipsky PE. Modulatory effects of 1,25-dihydroxyvitamin D3 on human B cell differentiation. J Immunol 2007;179:1634-1647.

20. Watad A, Quaresma M, Brown S, Cohen Tervaert JW, RodríguezPint I, Cervera R, Perricone C, Shoenfeld Y. Autoimmune/inflammatory syndrome induced by adjuvants (Shoenfeld's syndrome)-an update. Lupus 2017.

21. Damoiseaux JG, Tervaert JW. From ANA to ENA: how to proceed? Autoimmun Rev 2006;5:10-17. 
22. Tervaert JW, van der Woude FJ, Fauci AS, Ambrus JL, Velosa J, Keane WF, Meijer S, van der Griessen M, van der Hem GK, The TH, et al. Association between active Wegener's granulomatosis and anticytoplasmic antibodies. Arch Intern Med 1989;149:2461-2465.

23. Drijkoningen J, Damoiseaux J, van Paassen P, Tervaert JW. Clinical manifestations of the antiphospholipid syndrome as defined by the updated Sapporo classification criteria. Ann Rheum Dis 2007;66:1407-1408.

24. Tervaert JW, Van Paassen P, Damoiseaux J. Type II cryoglobulinemia is not associated with hepatitis C infection: the Dutch experience. Ann N Y Acad Sci 2007;1107:251-258.

25. Cohen Tervaert JW, Damoiseaux J. Antineutrophil cytoplasmic autoantibodies: how are they detected and what is their use for diagnosis, classification and follow-up? Clin Rev Allergy Immunol 2012;43: 211-219.

26. Avery TY, van de Cruys M, Austen J, Stals F, Damoiseaux JG Anti-nuclear antibodies in daily clinical practice: prevalence in primary, secondary, and tertiary care. J Immunol Res 2014:401739.

27. De Steenwinkel FD, Hokken-Koelega AC, de Ridder MA, Hazes JM, Dolhain RJ. Rheumatoid arthritis during pregnancy and postnatal catch-up growth in the offspring. Arthritis Rheumatol 2014;66: 1705-1711.

28. Holick MF, Binkley NC, Bisschoff-Ferrari HA, Gordon GM, Hanley DA, Heaney RP, Murad MH, Weaver $\mathrm{CM}$, Endocrine Society. Evaluation, treatment, and prevention of vitamin D deficiency: an endocrine society clinical practice guideline. J Clin Endocrin Metab 2011;96:1911-1930.

29. Cashman KD, Dowling KG, Skrabákova Z, Gonzales-Gross M, Valtueña J, De Henauw S, et al. Vitamin D deficiency in Europe: pandemic? Am J Clin Nutr 2016;103:1033-1044.

30. Wang J, Shishi LV, Chen G, He J, Zhong H, Xu Y. Metaanalysis of the association between vitamin D and autoimmune thyroid disease. Nutrients 2015;7:2485-2498.

31. Kivity S, Agmon-Levin N, Zisappl M, Shapira Y, Nagy EV, Dankó K, Szekanecz Z, Langevitz P, Shoenfeld Y. Vitamin D and autoimmune thyroid diseases. Cell Mol Immunol 2011;8:243-247.

32. Choi YM, Kim WG, Kim TY, Bae SJ, Kim HK, Jang EK, et al. Low levels of serum vitamin D3 are associated with autoimmune thyroid disease in pre-menopausal women. Thyroid 2014;24: 655-661.

33. Goswami R, Marwaha RK, Gupta N, Tandon N, Screenivas V, Tomar N, Ray D, Kanwar R, Agarwai R. Prevalence of vitamin $D$ deficiency and its relationship with thyroid autoimmunity in Asian Indians: a community-based survey. Br J Nutr 2009;102:382- 386.

34. Arslan MS, Topaloglu O, Ucan B, Karakose M, Karbek B, Tutal E, et al, Isolated vitamin D deficiency is not associated with nonthyroidal illness syndrome, but with thyroid autoimmunity. Scientific WorldJournal. 2015.

35. Unal AD, Tarcin O, Parildar H, Cigerli O, Eroglu H, Demirag NG. Vitamin D deficiency is related to thyroid antibodies in autoimmune thyroiditis. Cent Eur J Immunol 2014;39:493-497.

36. Mazokopakis EE, Papadomanolaki MG, Tsekouras KC, Evangelopoulos AD, Kotsiris DA, Tzortzinis AA. Is vitamin $D$ related to pathogenesis and treatment of Hashimoto's thyroiditis? Hell J Nucl Med 2015;18:222-227

37. Bozkurt NC, Karbek B, Ucan B, Sahin M, Cakal E, Ozbek M, Delibasi T. The association between severity of vitamin D deficiency and Hashimoto's thyroiditis. Endocr Pract 2013;19:479-484.

38. Shin DY, Kim KJ, Kim D, Hwang S, Lee EJ. Low serum vitamin D is associated with anti-thyroid peroxidase antibody in autoimmune thyroiditis. Yonsei Med J 2014;55:476-481.

39. Wang X, Zynat J, Osiman R, Tuhuti A, Abdunaimu M, Wang H, Jin X, Xing S. Low serum vitamin D is associated with antithyroid-globulin antibody in female individuals. Int J Endocrinol. 2015.

40. Krysiak R, Kowalcze K, Okopien B. The effect of vitamin D on thyroid autoimmunity in non-lactating women with postpartum thyroiditis. Eur J Clin Nutr 2016;70:637-639.

41. 41. D'Aurizio F, Villalta D, Metus P, Doretto P, Tozzoli R. Is vitamin D a player or not in the pathophysiology of autoimmune thyroid diseases? Autoimmun Rev 2015;14:363-369.

42. Ma J, Wu D, Li C, Fan C, Chao N, Liu J, Li Y, Wang R, et al. Lower serum 25-hydroxyvitamin D level is associated with 3 types of autoimmune thyroid diseases. Medicine (Baltimore). 2015.

43. Yasuda T, Okamoto Y, Hamada N, Miyashita K, Takahara M, Sakamoto F, et al. Serum vitamin D levels are decreased and associated with thyroid volume in female patients with newly onset Graves' disease. Endocrine 2012;42:739-741. 
44. Muscogiuri G, Palomba S, Caggiano M, Tafuri D, Colao A, Orio F. Low 25 (OH) vitamin D levels are associated with autoimmune thyroid disease in polycystic ovary syndrome. Endocrine 2016;53: 538-542.

45. Effraimidis G, Badenhoop K, Tijssen JG, Wiersinga WM. Vitamin D deficiency is not associated with early stages of thyroid autoimmunity. Eur J Endocrinol 2012;167:43-48.

46. 46. Ritterhouse LL, Crowe SR, Niewold TB, Kamen DL, Macwana SR, Roberts VC, et al. Vitamin D deficiency is associated with an increased autoimmune response in healthy individuals and in patients with systemic lupus erythematosus. Ann Rheum Dis 2011;70:1569-1574.

47. Schneider L, Dos Santos AS, Santos M, da Silva Chakr RM, Monticielo OA. Vitamin D and systemic lupus erythematosus: state of the art. Clin Rheumatol 2014;33:1033-1038.

48. Szodoray P, Tarr T, Bazco A, Poor G, Szegedi G, Kiss E. The immunopathological role of vitamin D in patients with SLE: data from a single centre registry in Hungary. Scand J Rheumatol 2011;40: 122-126.

49. Costenbader KH, Feskanich D, Holmes M, Karlson EW, Benito-Garcia E. Vitamin D intake and risks of systemic lupus erythematosus and rheumatoid arthritis in women. Ann Rheum Dis 2008; 67:530-535.

50. Bonakdar ZS, Jahanshahifar L, Jahanshahifar F, Gholamrezaei A. Vitamin D deficiency and its association with disease activity in new cases of systemic lupus erythematosus. Lupus 2011;20:1155- 1160.

51. Mok CC, Birmingham DJ, Ho LY, Hebert LA, Song H, Rovin BH. Vitamin D deficiency as marker for disease activity and damage in systemic lupus erythematosus: a comparison with anti-dsDNA and anti-C1q. Lupus 2012;21:36-42.

52. Thudi A, Yin S, Wandstrat AE, Li QZ, Olsen NJ. Vitamin D levels and disease status in Texas patients with systemic lupus erythematosus. Am J Med Sci 2008;335:99-104.

53. AlSaleem A, AlE'ed A, Alsaghier A, Al-Mayouf SM. Vitamin D status in children with systemic lupus erythematosus and its association with clinical and laboratory parameters. Clin Rheumatol 2015; 34:81-84.

54. Müller K, Oxholm P, Sorensen OH, Thymann M, Hoier-Madsen M, Bendtzen K. Abnormal vitamin D3 metabolism in patients with primary Sjögren's syndrome. Ann Rheum Dis 1990;49:682-684.

55. Hajas A, Sandor J, Csathy L, Csipo I, Barath S, Paragh G, Seres I, Szegedi G, Shoenfeld Y, Bodolay E. Vitamin D insufficiency in a large MCTD population. Autoimmun Rev 2011;10:317-324.

56. Zold E, Szodoray P, Gaal J, Kappelmayer J, Csathy L, Gyimesi E, Zeher M, Szegedi G, Bodolay E. Vitamin D deficiency in undifferentiated connective tissue disease. Arthritis Res Ther. 2008.

57. Paupitz JA, Freire de Carvalho J, Caparbo VF, Klack K, Pereira RM. Primary antiphospholipid syndrome in premenopausal women: low vitamin D, high fat mass, and maintained bone mineral mass. Lupus 2010;19:1302-1306.

58. Arnson Y, Amital H, Agmon-Levin N, Alon D, Sanchez-Castan M, Lopez-Hoyos M, et al. Serum 25-OH vitamin $D$ concentrations are linked with various clinical aspects in patients with systemic sclerosis: a retrospective cohort study and review of the literature. Autoimmun Rev 2011;10:490-494.

59. Merlino LA, Curtis J, Mikuls TR, Cerhan JR, Criswell LA, Saag KG. Vitamin D intake is inversely associated with lower risk of rheumatoid arthritis in older women: results from the lowa women's health study. Arthritis Rheum 2004;50:72-77.

60. Nielen NM, van Schaardenburg D, Lems WF, van de Stadt RJ, Reesink HW, Habibuw MR, van der HorstBruinsma IE, Twisk JW, Dijkmans BA. Vitamin D deficiency does not increase the risk of rheumatoid arthritis; comment on the article by Merlino et al. Arthritis Rheum 2006;54:3719-3720.

61. Feser M, Derber LA, Daene KD, Lezotte DC, Weisman MH, Buckner JH, et al. Plasma 25, OH vitamin D concentrations are not associated with rheumatoid arthritis (RA)-related autoantibodies in individuals at elevated risk for RA. J Rheumatol 2009;36:943-946.

62. Haga HJ, Schmedes A, Naderi Y, Moreno AM, Peen E. Severe deficiency of 25-hydroxyvitamin $D_{3}\left(25-\mathrm{OH}_{-}\right.$ $D_{3}$ ) is associated with high disease activity of rheumatoid arthritis. Clin Rheumatol 2013;32:629-633.

63. Urruticoechea-Arana A, Martín-Martínez MA, Castañeda S, Piedra CA, González-Juanatey C, Llorca J, Díaz-Gonzalez F, GonzálezGay MA, CARMA Project Collaborative Group. (2015) Vitamin D deficiency in chronic inflammatory rheumatic diseases: results of the cardiovascular in rheumatology [CARMA] study. Arthritis Res Ther 2015;17(1):211. 
64. Teichman J, Voglau MJ, Lange U. Antibodies to human tissue transglutaminase and alterations of vitamin D metabolism in ankylosing spondylitis and psoriatic arthritis. Rheumatol Int 2010l30: 1559-1563.

65. Salzer J, Hallmans G, Nyström M, Stenlund H, Wadell G, Sundström P. Vitamin D as a protective factor in multiple sclerosis. Neurology 2012;79:2140-2145.

66. Smolders J (2010) Vitamin D and multiple sclerosis: correlation, causality, and controversy. Autoimmune Dis 2010;2011:629538;

67. Smolders J, Peelen E, Thewissen M, Cohen Tervaert JW, Menheere P, Hupperts R, Damoiseaux J (2010) Safety and T cell modulating effects of high dose vitamin D3 supplementation in multiple sclerosis. PLoS One 2010;5(12):e15235..

68. Smolders J, Hupperts R, Barkhof F, Grimaldi LM, Holmoy T, Killesetin J, et al. Efficacy of vitamin D3 as add-on therapy in patients with relapsing-remitting multiple sclerosis receiving subcutaneous interferon $\beta$-1a: a phase II, multicenter, double-blind, randomized, placebo-controlled trial. J Neurol Sci 2011;311:44-49.

69. Mowry EM, James JA, Krupp LB, Waubant E. Vitamin D status and antibody levels to common viruses in pediatric-onset multiple sclerosis. Mult Scler 2011;17:666-671.

70. Rolf L, Muris AH, Hupperts R, Damoiseaux J. Iluminating vitamin D effects of B-cells-the multiple sclerosis perspective. Immunology 2016;147:275-284.

71. Levin LI, Munger KL, Rubertone MV, Peck CA, Lennette ET, Spiegelman D, Ascherio A. Temporal relationship between elevation of Epstein-Barr virus antibody titers and initial onset of neurological symptoms in multiple sclerosis. JAMA 2005;293:2496-2500

72. Salzer J, Nyström M, Hallmans G, Stenlund H, Wadell G, Sundström P. Epstein-Barr virus antibodies and vitamin D in prospective multiple sclerosis biobank samples. Mult Scler 2013;19: 1587-1591.

73. Décard BF, von Ahsen N, Grunwald T, Streit F, Stroet A, Niggemeier P, Schottstedt V, Riggert J, Gold R, Chan A. Low vitamin $D$ and elevated immunoreactivity against Epstein-Barr virus before first clinical manifestation of multiple sclerosis. J Neurol Neurosurg Psychiatry 2012;83:1170-1173.

74. Disanto G, Handel AE, Damoiseaux J, Hupperts R, Giovannoni G, Smolders J, Ramagopalan SV. Vitamin D supplementation and antibodies against the Epstein-Barr virus in multiple sclerosis patients. Mult Scler 2013;19:1679-1680.

75. Najafipoor A, Roghanian R, Zarkesh-Esfahani SH, Bouzari M, Etemadifar M. The beneficial effects of vitamin D3 on reducing antibody titers against Epstein-Barr virus in multiple sclerosis patients. Cell Immunol 2015;294:9-12.

76. Kabbani TA, Koutroubakis IE, Schoen RE, Ramos-Rivers C, Shah N, Swoger J, et al. Association of vitamin D level with clinical status in inflammatory bowel disease: a 5-year longitudinal study. Am J Gastroenterol 2016;111:712-719.

77. Santos-Antunes J, Nunes AC, Lopes S, Macedo G. The relevance of vitamin D and antinuclear antibodies in patients with inflammatory bowel disease under anti-TNF treatment: a prospective study. Inflamm Bowel Dis 2016;22:1101-1106.

78. Ribeiro SL, Pereira HL, Mangueira CL, Ferreira CE, Rosseto E, Scheinberg M. The development of arthritis and antinuclear antibodies correlate with serum 25-hydroxyvitamin D levels in patients with leprosy. Ann Rheum Dis 2012;71:2062-2063.

79. Nuti R, Martini G, Valenti R, Giovani S, Salvadori S, Avanzati A. Prevalence of undiagnosed coeliac syndrome in osteoporotic women. J Intern Med 2001;250:361-366.

80. Karakan T, Ozyemisci-taskiran O, Gunendi Z, Atalay F, Tuncer C. Prevalence of IgA-antiendomysial antibody in a patient cohort with idiopathic low bone mineral density. World J Gastroenterol 2007;13:2978-2982.

81. Ota K, Dambaeva S, Han AR, Beaman K, Gilman-Sachs A, KwakKim J. Vitamin D deficiency may be a risk factor for recurrent pregnancy losses by increasing cellular immunity and autoimmunity. Hum Reprod 2014;29:208-219.

82. Njemini R, Meyers I, Demanet C, Smitz J, Sosso M, Mets T. The prevalence of autoantibodies in an elderly sub-Saharan African population. Clin Exp Immunol 2002;127:99-106.

83. Carvalho JF, Blank M, Kiss E, Tarr T, Amital H, Shoenfeld Y. Anti-vitamin D, vitamin D in SLE: preliminary results. Ann N Y Acad Sci 2007;1109:550-557. 
84. Barrea L, Savanelli MC, Di Somma C, Napolitano M, Megna M, Colao A, Savastano S. Vitamin D and its role in psoriasis: an overview of the dermatologist and nutritionist. Rev Endocr Metab Disord 2017;18(2):195-205.

85. Rolf R, Muris AH, Hupperts R, Damoiseaux J. Vitamin D effects on B cell function in autoimmunity. Ann N U Acad Sci 2014;1317:84-91.

86. Holmoy T, Lossius A, Gundersen TE, Moen SM, Castellazzi M, Fainardi E, Casetta I. Intrathecal levels of vitamin D and IgG in multiple sclerosis. Acta Neurol Scand 2012;125:e28-e31.

87. Knippenberg S, Smolders J, Thewissen PE, Tervaert JW, Hupperts R, Damoiseaux J. Effect of vitamin D(3) supplementation on peripheral B cell differentiation and isotype switching in patients with multiple sclerosis. Mult Scler 2011;17:1418-1423.

88. Peelen E, Rijkers G, Meerveld-Eggink A, Meijvis S, Vogt M, Cohen Tervaert JW, Hupperts R, Damoiseaux J. Relatively high serum vitamin D levels do not impair the antibody response to encapsulated bacteria. Eur J Clin Microbiol Infect Dis 2013;32:61-69.

89. Ben-Zvi I, Aranow C, Mackay M, Stanevsky A, Kamen DL, Marinescu M, Collins CE, Gilkeson GS, Diamond $B$, Hardin JA. The impact of vitamin D on dendritic cell function in patients with systemic lupus erythematosus. PLoS One 2010;5(2):e9193. 


\section{CHAPTER 4 Is explantation of silicone breast implants useful in patients with complaints?}




\section{Mintsje de Boer Maartje JL Colaris René RWJ van der Hulst Jan Willem Cohen Tervaert}




\section{ABSTRACT}

In this review, we present a critical review of the existing literature reflecting the results of explantation of silicone breast implants in patients with silicone-related complaints and/or autoimmune diseases. A literature search was performed to discuss the following issues: which clinical manifestations and autoimmune diseases improve after explantation, and what is the course of these complaints after explantation. Next, we reviewed studies in which the effect of explantation on laboratory findings observed in patients with silicone breast implants was studied, and lastly, we reviewed studies that described the effect of reconstruction of the breast with a new implant or autologous tissue after explantation. We calculated from the literature that explantation of the silicone breast improved silicone-related complaints in 75\% of the patients (469 of 622). In patients with autoimmune diseases, however, improvement was only infrequently observed without additional therapy with immunosuppressive therapy, i.e., in $16 \%$ of the patients (3 of 18). The effect of explantation did not influence autoantibody testing such as ANA. We discuss several possibilities which could clarify why patients improve after explantation. Firstly, the inflammatory response could be reduced after explantation. Secondly, explantation of the implants may remove a nociceptive stimulus, which may be the causative factor for many complaints. Options for reconstruction of the explanted breast are autologous tissue and/or water-/hydrocellulose-filled breast implant. Unfortunately, in very few studies attention was paid to reconstructive possibilities. Therefore, no adequate conclusion regarding this issue could be drawn. In conclusion, explantation is useful for improvement of silicone-related complaints in $75 \%$ of the patients, whereas in patients who developed autoimmune diseases improvement is only observed when explantation is combined with immunosuppressive therapy. In a patient with silicone-related complaints in which explantation is considered, the patient should be counseled for the different options of reconstruction after explantation. 


\section{INTRODUCTION}

Since the introduction of silicone breast implants in the early 1960s, it has been postulated that patients may develop complaints related to silicone breast implants. Hence at present, there is still controversy whether breast implants are safe. $^{1,2}$

Patients with implants may develop nonspecific complaints such as arthralgia, myalgia and fatigue. In the past years, these complaints in patients with silicone breast implants have been named differently: human adjuvant disease or adjuvant breast disease, silicone-related symptom complex, siliconosis and more recently ASIA syndrome due to silicone implant incompatibility syndrome (SIIS). ${ }^{3-11}$ In these patients, it is postulated that silicone act as an adjuvant to the immune system, resulting in inflammation, autoimmune diseases, immunodeficiencies and/or allergies. ${ }^{10}$ In search of an effective therapy for these patients, it is the current practice to advise patients to undergo explantation of their implants. In this paper, we review the existing literature addressing the effectiveness of implant removal as treatment for patients with complaints that are possibly related to their silicone breast implants.

\section{METHODS}

\section{Study selection}

We performed a comprehensive literature search in PubMed, MEDLINE, EMBASE and the Cochrane Central Register of Controlled Trials, and the Cochrane Database of Systematic Reviews through the first quarter of 2016. Additional citations were solicited from references in selected articles. The searches combined the following terms: 'Breast implants [Mesh],' 'Silicone, adverse effect [Mesh],' for the period between January 1960 and the present time. An additional search to crossreference the outcome of the previous search was performed with the terms 'removal', 'explantation' and 'Device Removal Mesh.'

We included studies discussing patients with breast implants (silicone- or salinefilled) who reported or presented with silicone-related complaints (Table 4.1) after insertion of the breast implants and who underwent explantation of the breast implant. ${ }^{4,6-9}$ Studies of all type were included, meaning case reports, case series, case-control studies and descriptive cohort studies. We excluded studies that 
described explantation of breast implants that was performed because the implants were ruptured and/or were leaking and no description of silicone-related complaints was mentioned. We excluded also studies focussing on malignancies of the breast after silicone breast implantation. Also, studies focussing on silicone oil/gel injections were excluded.

We report on: (1) whether improvement of several silicone-related complaints (including autoimmune diseases) after explantation (Table 4.1) occurred; (2) what the course of improvement of complaints is after explantation; (3) what the effect of explantation is on laboratory findings; (4) whether patients underwent reconstruction of the breast after explantation or not.

Table 4.1 Silicone-related complaints and other silicone-related manifestations.

\begin{tabular}{ll}
\hline Silicone related complaints & Fatigue \\
& Myalgia \\
& Arthralgia \\
& Pyrexia \\
& Sicca (dry eyes/dry mouth) \\
& Memory, concentration and sleep disturbances \\
Neurological manifestations (TIA/CVA, demyelination) & Raynaud's phenomenon \\
Other & Irritable bowel syndrome \\
& Allergies \\
& Immunodeficiencies \\
& Autoimmune diseases \\
\hline
\end{tabular}

\section{Study extraction and assessment}

Data from each included study were extracted. Extracted data included study type, participants, implant characteristics (if available), silicone-related complaints (Table 4.1), laboratory findings (if available), explantation, status of silicone-related complaints/autoimmune disease after explantation, status of laboratory findings after explantation (if available), course of disease/symptoms after explantation, reconstruction of explanted breast (if available).

The literature search yielded 720 citations. Firstly, titles and abstracts were read. On the basis of titles and abstracts, 45 publications were provisionally accepted for review. After screening of the full text, 17 studies met eligibility criteria. Additionally, 6 studies were selected based on references in these 17 studies that also met eligibility criteria and were therefore retrieved and used as well (Figure 
4.1). Of the 23 included studies, 10 were case reports/case series (Table 4.2) and 13 studies were cohort studies (Table 4.3).

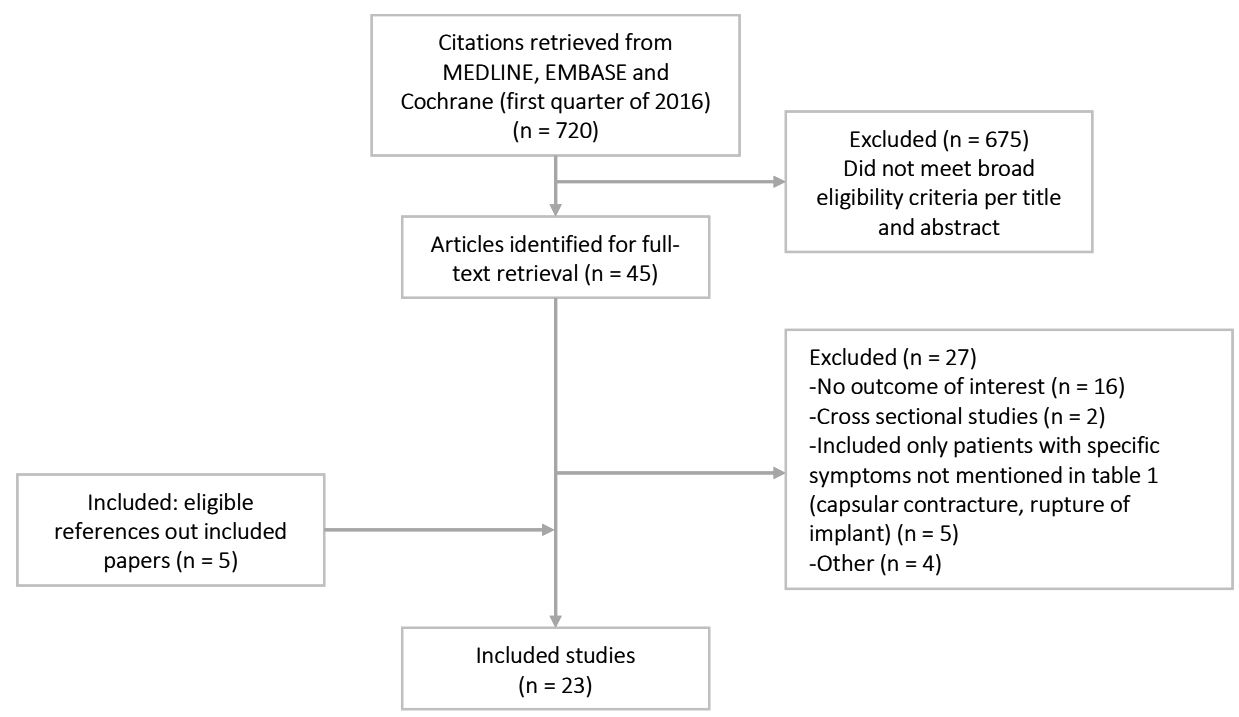

Figure 4.1 Summary of evidence search and selection.

\section{RESULTS}

\section{Improvement of complaints after explantation: case reports}

Teuber et al. described a 45-year-old woman who presented with Raynaud's phenomenon, myalgia, pyrexia, malaise, cutaneous lesions, uveitis, enlarged lymph nodes and shortness of breath, which developed 7 years after cosmetic mamma augmentation. A X-ray of the chest showed bilateral hilar lymphadenopathy and a transbronchial biopsy revealed noncaseating granulomas consistent with sarcoidosis. The course of the sarcoidosis was progressive and only minimal responsive to prednisone (minimal improvement in pulmonary, ocular and joint symptoms). However, cutaneous sarcoidosis and enlarged lymph nodes resolved after explantation, whereas symptoms and clinical condition improved dramatically as well. ${ }^{12}$ 


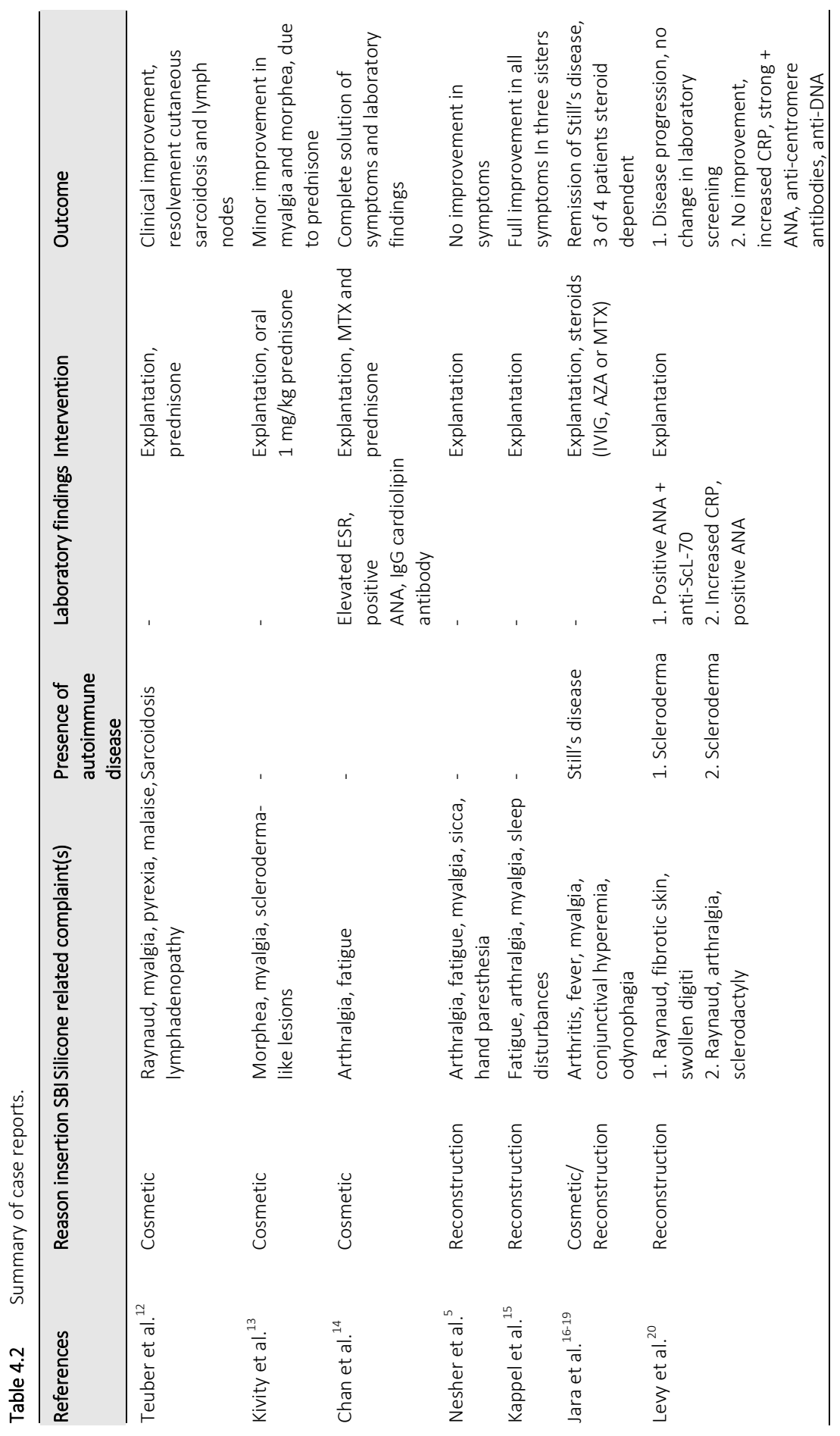




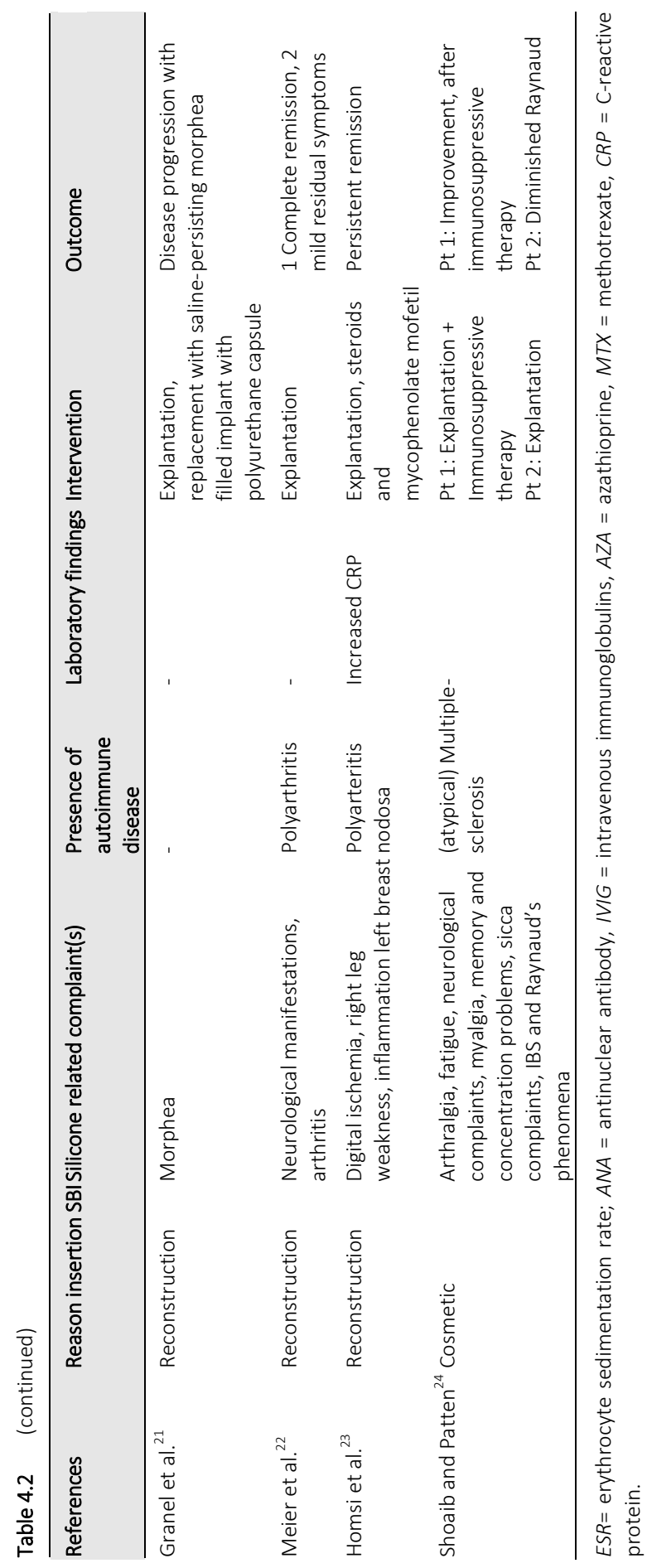




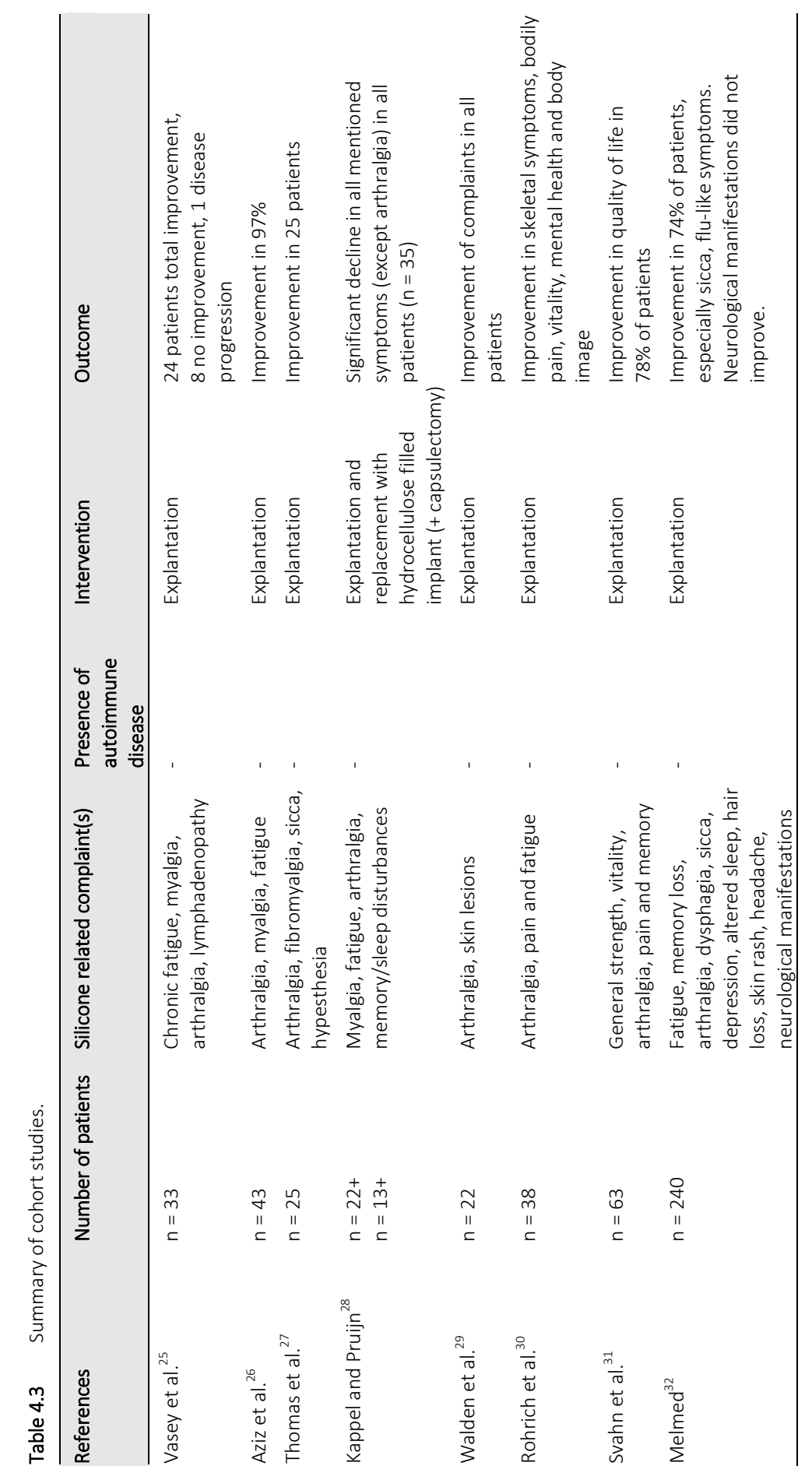




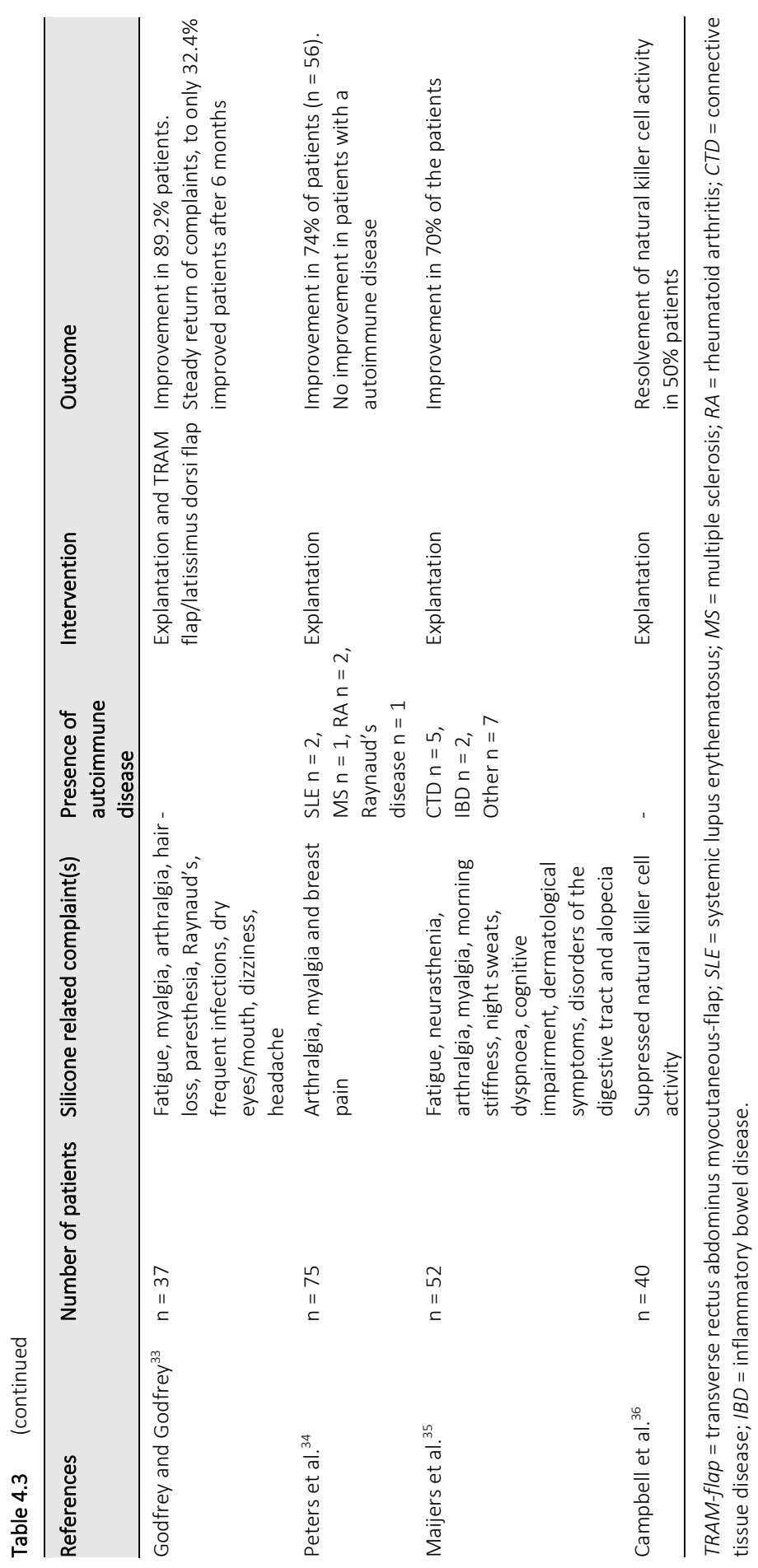


Kivity et al. presented a patient who developed myalgias and morphea after breast augmentation with silicone breast implants. Due to tightening of the skin around the implants and significant discomfort, the implants were surgically removed. The clinical symptoms (myalgia, morphea) did not improve after implant removal, whereas treatment with $1 \mathrm{mg} / \mathrm{kg}$ prednisone resulted in some improvement. ${ }^{13}$

Chan et al. described a patient with arthralgias and fatigue, which developed after mamma augmentation with silicone breast implants 7 years earlier. Laboratory screening showed increased inflammatory markers, such as elevated sedimentation rate, positive ANA and IgG anti-cardiolipin antibodies. A diagnosis of an unspecified inflammatory disease was made, and treatment with methotrexate and steroids was started. Ultrasound of the breast showed a ruptured left breast implant. The patient chooses to replace the breast implants by new silicone gelfilled implants. Soon after surgery, she developed a rash. Subsequently, her breast implants were removed. 10 weeks later, the methotrexate and prednisolone could be stopped and the patient showed complete resolution of her symptoms and the inflammatory response. ${ }^{14}$

Nesher et al. presented a patient with a silicone breast implant placed for reconstruction after a mastectomy. After implant rupture a revision with a new silicone implant was performed and subsequently, the patient developed fatigue, arthralgia, myalgia, dry eyes, cognitive impairment, intermittent abdominal pain, attacks of fainting, weight loss, headaches and hand paresthesias. ${ }^{5}$ An MRI showed enlarged supra-clavicular lymph nodes possibly due to silicone granuloma and enhancement of the chest wall after gadolinium injection. After explantation, the fibromyalgialike symptoms did not improve, whereas generalized weakness, fatigue and insomnia also persisted.

Kappel et al. described three sisters with a BRCA-1 gen mutation who underwent preventive mastectomy and reconstruction with silicone breast implants. All three women developed fatigue, arthralgias, myalgias and sleep disturbances within a period of four years after implantation. ${ }^{15}$ All complaints improved as evaluated 2.5 years after explantation of the implants.

Jara et al. presented a case report and discussed three other patients who developed Still's disease after silicone breast implantation. ${ }^{16-19}$ All four patients underwent implant removal and experienced improvement. However, all patients received additional therapy such as steroids, intravenous immunoglobulins, 
azathioprine or methotrexate. Three of the four patients remained steroid dependent during long-term follow-up.

Levy et al. presented two cases with silicone breast implants and systemic sclerosis who underwent explantation. ${ }^{20}$ Case 1 was a patient who underwent bilateral mamma reconstruction with silicone breast implants. 14 years later, she developed Raynaud's phenomenon, heartburn and swelling of fingers and toes, telangiectasia and fibrotic skin changes. Laboratory screening showed ANA and anti-SCL-70 autoantibodies. She underwent removal of the implants. Rupture occurred during removal and silicones entered into the blood stream. Several months later, she developed extreme dyspnea, severe restrictive lung disease with low CO diffusing capacity and interstitial lung disease. She died two years after implant removal from progressive systemic sclerosis. Case 2 comprises a 52-year-old patient who underwent mastectomy and 3 years later insertion of a silicone breast implant. Seven years later, she developed arthralgias, Raynaud's phenomenon, sclerodactyly and telangiectasia. Laboratory screening showed increased CRP and positive ANA. Due to gradual hardening of the implant associated with pain, the patient opted for replacement. Several months later, the replaced implant ruptured and was removed without further replacement. Clinical symptoms did not improve after explantation.

Granel et al. presented a 53-year-old woman who underwent mamma reconstruction with silicone breast implants. ${ }^{21}$ Localized morphea occured after 1 year. The implant was replaced by a saline-filled implant with a polyurethanecovered silicone capsule. Disease progression occurred with persisting morphea without signs of systemic sclerosis.

Meier et al. described two HLA identical sisters who both received silicone breast implants and subsequently developed polyarthritis and neurological symptoms. ${ }^{22}$ After removal of the implants, the rheumatic as well as neurological symptoms improved dramatically in both patients. One patient achieved complete remission. The other patient had mild residual symptoms.

Homsi et al. presented a 49-year-old woman who presented with necrotizing vasculitis following silicone breast implants because of congenital breast asymmetry. The patients suffered from digital ischemia, right leg paresis and inflammation of the inferior part of the left breast. Due to cutaneous necrosis of the breast, the patient underwent capsulotomy and removal of the implant. Histopathological examination showed necrotizing arteritis. Treatment with high 
dose prednisone and mycophenolate mofetil was initiated, and after one year of follow-up, a persistent remission was observed. ${ }^{23}$

Shoaib et al. described two patients with human adjuvant disease due to SBI who underwent implant removal. ${ }^{24}$ The first patient presented with arthralgia, fatigue and neurological manifestations six years after (cosmetic) augmentation. She was diagnosed with atypical multiple sclerosis. Explantation did not result in improvement, whereas intravenous cyclophosphamide and immunoglobulins did. The second patient presented two years after augmentation with the same clinical manifestations as patient 1 and additional symptoms such as myalgia, memory and concentration problems, sicca complaints, irritable bowel syndrome and Raynaud's phenomena. An MRI showed demyelinisation and she was diagnosed with atypical multiple sclerosis. She underwent explantation 3 years after the first symptoms and improvement was minimal, i.e., only observed in diminished Raynaud's phenomenon.

Case reports are summarized in Table 4.2.

\section{Improvement of complaints after explantation: Case series}

Vasey et al. presented 50 patients with silicone breast implants with findings such as fatigue, myalgias, arthralgias and lymphadenopathy. ${ }^{25}$ Thirty-three women underwent implant removal and 17 did not undergo implant removal. During an observation period of 14 months, the complaints did not change in the 17 patients without explantation, whereas in the patients with explantation, 24 women improved (no symptoms anymore), 8 did not change, and in only one patient, symptoms worsened after an average follow-up of 22 months.

Aziz et al. prospectively followed 95 women who had silicone gel-filled breast implants and rheumatologic symptoms (arthralgia, myalgia) and fatigue and found that the symptoms improved in 42 (97\%) of the 43 women who had their breast implants removed. ${ }^{26}$ In contrast, rheumatologic symptoms worsened in 50 (96\%) of 52 women who did not have their implants removed.

Thomas et al. presented 25 patients who underwent implant removal because of arthralgias, sicca complaints and hypesthesia. ${ }^{27}$ Improvement in patient-reported symptoms and signs occurred over the course of months postoperatively in all patients.

Kappel et al. presented a study in which they compared a group of patients with silicone breast implants with complaints such as fatigue, myalgias, arthralgias, 
memory and sleep disturbances who underwent removal, capsulectomy and subsequently insertion of a hydrocellulose-filled implant $(n=22$ ) to a group of patients with silicone breast implants with similar symptoms as the patients in the first group who underwent removal and insertion of a the hydrocellulose-filled implant, but no capsulotomy $(n=13) .{ }^{28}$ A questionnaire examining the presence of symptoms pre-operatively and post-operatively was filled in by patients of both groups. In both symptomatic groups, a significant decline of the presence of symptoms was observed. Only arthralgias, however, did not improve in the patients who underwent explantation without capsulectomy. Importantly, improvement appeared to be more pronounced when an additional capsulectomy was performed.

Walden et al. prospectively studied the outcome of explantation in a group of 22 patients with silicone implants with complains such as arthralgias using a questionnaire for health status and compared the results to a group of patients who underwent a cholecystectomy $(n=20) \cdot{ }^{29}$ In the explantation group, selfreported health rating scores improved from 2.64 to 4.89 , but did not change in the cholecystectomy group (7.57 to 8.07). Unfortunately, the exact number of patients who experienced improvement is not mentioned in this study.

Rohrich et al. prospectively assessed the efficacy of explantation of silicone breast implants in 38 women with complaints such as arthralgia and fatigue. Selfevaluation of the health status was done preoperatively and 6 weeks and 6 months postoperatively. In addition, the general practitioner evaluated the health status of the patients. $^{30}$ After explantation, patients showed an improvement in measurements of arthralgia and pain, as well as an increase in vitality, mental health and body area satisfaction when compared with preoperative measurements. Unfortunately, authors do not state what number of patients experienced improvement.

Svahn et al. retrospectively studied health improvement following removal of silicone gel-filled breast implants in 63 female patients. ${ }^{31}$ Quality of life was assessed by a questionnaire in which physical and cognitive function was studied. Improvement in symptoms occurred in 49 of the 63 (78\%) patients regarding quality of life.

In the largest study to date, Mehmed et al. described explantation in 240 women who presented with symptoms such as chronic fatigue, memory loss, arthralgia, dysphagia, depression, altered sleep patterns, hair loss, skin rashes, headaches, flu- 
like symptoms and atypical multiple sclerosis. ${ }^{32}$ After explantation, $74 \%$ of the patients reported that they felt much better. Especially, dry eyes and flu-like symptoms improved quickly. MS-like symptoms, however, did not improve.

Godfrey et al. presented 37 patients with silicone breast implants and complaints such as fatigue, myalgia, arthralgia, hair loss, paresthesia, Raynaud's phenomenon, dry eyes/mouth, dizziness and headache who underwent replacement of breast implants. ${ }^{33}$ Postoperatively, a major improvement in symptoms was observed in $89 \%$ of patients. However, at 6 months postoperatively, symptoms returned in most patients leaving only $32 \%$ of the patients asymptomatic during longer followup.

Peters et al. evaluated the outcome of removal of breast implants in 75 symptomatic patients after extensive evaluation preoperatively. ${ }^{34}$ Patients had complaints such as arthralgia, myalgia, fatigue, gastrointestinal symptoms, rashes, memory loss, sleep disturbances and breast pain. 2.7 years after explantation, 56 patients stated that their quality of life had improved. Six of 75 patients had a proven autoimmune disease (see Table 4.3). After follow-up, none of these patients had shown any improvement in clinical status or autoantibody levels.

Recently, Maijers et al. described a cohort of 80 patients presenting with complaints such as fatigue, arthralgias, myalgias, morning stiffness, night sweats, cognitive impairment, dermatological symptoms and/or alopecia. Fifty-two women underwent explantation. Thirty-six women reported a significant decrease in the symptoms, of which nine patients stated that they were completely without complaints. ${ }^{35}$ Eleven patients had an autoimmune disease such as Sjögren's syndrome or systemic sclerosis. Unfortunately, it is not described whether these patients did improve after explantation as well.

Case series are summarized in Table 4.3.

\section{Effect of explantation on laboratory findings}

Kivity et al. presented a patient with morphea undergoing explantation of the breast implant. ANA was found to be positive before removal. ${ }^{13} 4$ weeks after removal, ANA were still present.

Also in the case that was reported by Jara et al., positive ANA were found before and after implant removal. ${ }^{16}$ 
Levy et al. ${ }^{20}$ reported a case with positive ANA. After explantation, ANA remained strongly positive, and anti-centromere antibodies and anti-dsDNA became detectable.

In the study by Kappel et al. ${ }^{28}$, three sisters underwent explantation because of complaints. After explantation, IgG levels increased, whereas ANA remained positive in these patients.

Peters et al. presented 5 patients with autoimmune diseases and autoantibodies. After explantation (2.7 years) autoantibodies persisted.

Campbell et al. presented a study in which the NK cell function of 40 symptomatic patients with silicone breast implants was evaluated before and after explantation. ${ }^{36}$ After explantation, NK activity increased in $50 \%$ of the patients, whereas NK activity decreased in $26 \%$ of the patients and was unchanged in $24 \%$. Unfortunately, no control group was studied to compare NK activity during followup in healthy controls.

\section{Effect of reconstruction after explantation}

Few data are available with respect to the effect of reconstruction after explantation.

Granel et al. present a 53-year-old woman with morphea who underwent replacement of a silicone implant by a saline-filled implant with a polyurethane capsule. Disease progression occurred. ${ }^{21}$

Kappel et al. describe explantation of silicone breast implants in three symptomatic sisters and subsequently replacement of hydrocellulose-filled implants. ${ }^{15}$ Full recovery did occur.

In another study by Kappel et al. ${ }^{28}$, patients underwent explantation of the silicone implant (with or without capsulectomy) and immediate reconstruction with a hydrocellulose-filled implant. Significant improvement in symptoms did occur in these patients as well $(n=35)$.

Godfrey et al. present 37 patients who underwent replacement of breast implants due to systemic complaints and subsequently reconstruction with autologous tissue (TRAM flap or latissimus dorsi flap). ${ }^{33}$ At 6 months postoperatively, only $32.4 \%$ of the patients remained free of symptoms. 


\section{SUMMARY}

\section{Silicone-related complaints}

In this review, we have described 11 case reports with a total of 19 patients who underwent explantation. ${ }^{12-24}$ In these case reports, 12 of 19 patients (63\%) experienced improvement of their silicone-related complaints after explantation. Two of 17 patients experienced disease progression (12\%).

In the case series, we have 12 case series with a total of 703 patients who underwent explantation. ${ }^{25-36}$

For 603 patients, it was well described whether clinical status improved after explantation. ${ }^{25-28,31-35}$ of 603 patients, 457 (76\%) experienced improvement of silicone-related complaints after explantation. In one of 703 patients, evident disease progression after explanation was reported.

In total (case reports and case series), this implies that 469 of 622 patients (75\%) experienced improvement of silicone-related complaints after explantation.

\section{Autoimmune diseases}

If we only assess the improvement in autoimmune diseases after explantation, we see that in the case reports 10 of 12 patients with an autoimmune disease experienced some improvement after explantation. ${ }^{12,16-19,22-24}$ However, 7 of 10 patients who improved after explantation also received immunosuppressive or immunomodulatory therapy before, during or after implant removal. In the case series, only one author, Peters. ${ }^{33}$ closely described the presence of patients with an autoimmune disease in his cohort and whether these patients improved after explantation. None of the 6 patients with well-defined autoimmune disease improved after explantation. In total, this implies that only 3 of 18 patients (16\%) with a well-defined autoimmune disease did improve after explantation without additional therapy. Furthermore, 7 of 18 patients (39\%) with autoimmune diseases improved after explantation in combination with adjuvant immunosuppressive therapy. 


\section{DISCUSSION}

Whether silicone can elicit an inflammatory or autoimmune response has been subject of debate since the introduction of silicone breast implants. Up until the present, there is still no conclusive evidence that proves whether silicone implants are safe or unsafe. Furthermore, the exact prevalence of complaints in patients with silicone breast implants is unknown. ${ }^{1}$ Several studies implicate that there is no increased risk to develop autoimmune diseases after silicone breast implant insertion. ${ }^{2}$ Therefore, the FDA lifted the ban on these implants in 2004. Recently, it has been suggested that the methodological designs of the studies that influenced this decision were not correct and that more research, especially in larger prospective cohorts, is needed. ${ }^{3}$ In light of the recent developments, e.g., the uproar concerning the PIP and Silimed prosthesis, the description of ASIA and breast implant-associated anaplastic large cell lymphoma (BIA-ALCL) ${ }^{4,37}$, we agree that more attention should be paid to silicone-related problems. Fortunately, this is already occurring as can be seen by the representation of the articles that were included in this review. After a first wave of articles in the 1990s, a second wave of articles appeared during recent years.

Whether epidemiological studies do or do not demonstrate an increase in autoimmune diseases is, however, less relevant when one realizes that there are patients who present with complaints that might be attributed to silicone breast implants and that explantation of the implants is an important treatment strategy to resolve these complaints.

In this review, we have therefore investigated the effectivity of explantation of the silicone breast implant in improving complaints. We found that explantation of the silicone breast implant improved silicone-related complaints in approximately $75 \%$ of the patients (469 of 622). Autoimmune diseases improved in approximately $56 \%$ of the patients (10 of 18); however, explantation had to be combined with immunosuppressive therapy in most of these patients.

There are several possibilities why patients improve after explantation. Two possibilities that are not mutually exclusive may clarify why explantation of breast implants may result in improvement in symptoms: (1) explantation of the silicone breast implant results in reduction in the (auto-)immune response, (2) explantation of the silicone breast implant results in reduction in nociceptive signals. 


\section{Reduction in the immune response}

In different experimental models, it has been demonstrated that silicone can induce an autoimmune or inflammatory response. ${ }^{38-40}$ Moreover, in humans, adjacent to the periprosthetic space, chronic inflammation, characterized by proliferation of mesenchymal cells and collagen synthesis, is regularly observed. This chronic inflammation is morphologically classified as a foreign body reaction and well known as the periprosthetic capsule. ${ }^{41,42}$ In this periprosthetic and pericapsular space, silicone migrated from the shell of the implant can be captured by macrophages, which results in activation of these macrophages. ${ }^{43}$ Importantly, oxygen radicals released from this activated macrophage may result in oxidation of silicone, leading to the local formation of silica. ${ }^{43}$ In experimental studies, it is demonstrated that this results in the secretion of cytokines, promotion of fibroblast proliferation and collagen production. ${ }^{44}$ In addition, in vivo a significant lymphoplasmatic infiltration is observed. This can lead to continuous stimulation of the immune system, leading to formation of autoantibodies and the formation of anti-silicone antibodies. ${ }^{5,45-47}$ It is hypothesized that the autoimmune/inflammatory process will be reduced by removing the inducing agent of this process, i.e., the silicone breast implant, 4,10

We observed that patients with silicone-related complaints improved after explantation, but patients who have already developed autoimmune diseases immunosuppressive drugs were additionally needed to induce remission of the disease. This implies that explantation alone is not effective for resolution of the autoimmune diseases.

An explanation for this phenomenon could be that prior to explantation silicone particles have already been migrated into the periprosthetic tissue, lymph nodes and other tissues. ${ }^{48,49}$ This implies that the silicone particles remain present in the body after explantation and that the autoimmune/inflammatory response continues. This could also clarify the observation that autoantibodies remain detectable after explantation.

\section{Reduction in nociceptive signals}

Clinical findings in patients with ASIA due to SIIS resemble the clinical picture of fibromyalgia. ${ }^{50,51}$ Indeed, the type of complaints is more or less identical in these two diseases. It has been postulated that in fibromyalgia nociceptive signals (often 
psychological trauma) cause the development of symptoms via disturbed pain processing. ${ }^{52}$ Could it be that in patients with ASIA due to SIIS the breast implant is the nociceptive stimulus causing the symptoms? Could a disturbed pain signaling pathway due to the nociceptive stimulus (silicone), in combination with extensive worrying about the safety of the breast implant, cause excessive stimulation of neurotransmitters in the central nervous system and therefore cause the systemic complaints?52 This hypothesis may-at least partially-explain why patients experience improvement in symptoms when the silicone breast implant, and thus the nociceptive stimulus, is explanted and why improvement in the quality of life is reported. In this theory, self-evaluation after explantation/after removal of the nociceptive stimulus should improve, since there is no longer a reason for extensive worrying. More research whether the improvement after explantation is due to the removal of the nociceptive stimulus should be performed.

\section{Practical implications}

Silicone-related complaints have been labeled differently in the past decades (human adjuvant disease, adjuvant breast disease, ASIA syndrome). Symptoms, however, did not change during the last 30 years. ${ }^{11}$ General practitioners and other specialists should be aware that patients with silicone breast implants may present with these symptoms (Table 4.1). The symptoms, however, are not very specific. In making the decision that the complaints may be related to the silicone breast implants, it is therefore important to rule out other diseases. For the physician who advises the patient, it is valuable to inform the patients what the results of explantation of the breast implant might be. Importantly, explantation may results in body deformity and impaired body image, which may have a significant psychological impact. ${ }^{29}$ Therefore, patients should also be informed what alternative reconstruction possibilities are available after explantation. Alternatives can consist of reconstruction with autologous tissue such as free flaps (LTP or DIEP flap), lipofilling (with external preexpansion) or reconstruction with breast implants filled with saline or hydrocellulose. ${ }^{28,33,53-55}$ In this review, we have found that the effect of reconstruction after explantation in patients with silicone-related complaints has received extremely little attention up until the present time. Mamma reconstruction with autologous tissue instead of implants tends to be popular in this category of patients due to a higher long-term satisfaction, higher patient' satisfaction and a higher perception of naturalness. ${ }^{56}$ However, in the 
current reviewed literature, it is not yet clear whether autologous tissue is a good alternative. ${ }^{33}$ Reconstruction with a breast implant filled with hydrocellulose might be another alternative since exposure to silicone is diminished. ${ }^{15,28}$ However, the evidence for the use of hydrocellulose-filled implants as a safe alternative is at present also very limited and importantly, silicone-related complaints can also occur in patients with an implant filled with hydrocellulose or saline.

More research on which type of reconstruction could be used for patients with silicone breast implant-related complaints should be performed.

\section{CONCLUSION}

The objective of this review was to investigate whether explantation of silicone breast implants in patients with silicone-related complaints is useful. We have observed that in approximately $75 \%$ of the patients with silicone-related complaints improvement occurs. However, in patients with silicone breast implants who have developed an autoimmune disease explantation appears to be successful only when explantation is combined with immunosuppressive therapy. We postulate that both reduction in the immune response and reduction in nociceptive signals could explain why patients with silicone-related complaints experience improvement after explantation. Migration of silicone particles into the adjacent tissue could explain why explanation alone is not successful in all patients. Lastly, since very few studies dealt with the type of reconstruction for the explanted breast, we strongly suggest that more research should be done regarding this issue. 


\section{REFERENCES}

1. Balk EM, Earley A, Avendano EA, Raman G. Long-term health outcomes in women with silicone gel breast implants: a systematic review. Ann Intern Med. 2016;164(3):164-175.

2. Janowsky EC, Kupper LL, Hulka BS. Meta-analyses of the relation between silicone breast implants and the risk of connective-tissue diseases. N Engl J Med. 2000;342:781-790.

3. Soriano A, Butnaru D, Shoenfeld Y. Long-term inflammatory conditions following silicone exposure: the expanding spectrum of the autoimmune/inflammatory syndrome induced by adjuvants (ASIA). Clin Exp Rheumatol. 2014;32:151-154.

4. Shoenfeld Y, Agmon-Levin N. 'ASIA'-Autoimmune/inflammatory syndrome induced by adjuvants. J Autoimmun. 2011;36:4-8.

5. Nesher G, Soriano A, Shlomai G, ladgarov Y, Shulimzon TR, Borella E, Dicker D, Shoenfeld Y. Severe ASIA syndrome associated with lymph node, thoracic, and pulmonary silicone infiltration following breast implant rupture: experience with four cases. Lupus. 2015;24(4-5):463-468.

6. Shoaib BO, Patten BM, Calkins DS. Adjuvant breast disease: an evaluation of 100 symptomatic women with breast implants or silicone fluid injections. Keio J Med. 1994;43(2):79-87.

7. Brozena SJ, Fenske NA, Cruse CW, Espinoza CG, Vasey FB, Germain BF, Espinoza LR. Human adjuvant disease following augmentation mammoplasty. Arch Dermatol. 1988;124(9):1383-1386.

8. Shanklin DR, Smalley DL. The immunopathology of siliconosis. History, clinical presentation, and relation to silicosis and the chemistry of silicon and silicone. Immunol Res. 1998;18(3):125-173.

9. Contant CM, Swaak AJ, Obdeijn Al, van der Holt B, Tjong Joe Wai R, van Geel AN, Eggermont AM. A prospective study on silicone breast implants and the silicone-related symptom complex. Clin Rheumatol. 2002;21(3):215-219.

10. Cohen Tervaert JW, Kappel RM. Silicone implant incompatibility syndrome (SIIS): a frequent cause of ASIA (Shoenfeld's syndrome). Immunol Res. 2013;56:293-298.

11. Colaris MJL, de Boer M, van der Hulst RR, Cohen Tervaert JW. Two hundreds cases of ASIA syndrome following silicone implants-a comparative study of 30 years and a review of current literature. Immunol Res. 2017;65(1):120-128.

12. Teuber SS, Howell LP, Yoshida SH, Gershwin ME. Remission of sarcoidosis following removal of silicone gel breast implants. Int Arch Allergy Immunol. 1994;105(4):404-407.

13. Kivity S, Katz M, Langevitz P, Eshed I, Olchovski D, Barzilai A. Autoimmune syndrome induced by adjuvants (ASIA) in the Middle East: morphea following silicone implantation. Lupus. 2012;21(2):136139.

14. Chan SA, Malik F, Wharton S, Klocke R. Systemic inflammatory disease resolution following cosmetic silicone breast implant removal. BMJ Case Rep. 2015;2015:bcr2014207418.

15. Kappel RM, Cohen Tervaert JW, Pruijn GJ. Autoimmune/inflammatory syndrome induced by adjuvants (ASIA) due to silicone implant incompatibility syndrome in three sisters. Clin Exp Rheumatol. 2014;32(2):256-258.

16. Jara L, Medina G, Go'mez-Ban uelos E, Saavedra MA, Vera-Lastra O. Still's disease, lupus-like syndrome, and silicone breast implants. A case of 'ASIA' (Shoenfeld's syndrome). Lupus. 2012;21(2):140-145.

17. Katayama I, Umeda T, Nishioka K. Adult Still's-disease-like illness in a patient with silicone breast implants. Clin Rheumatol. 1998;17:81-82.

18. Cre'tel E, Richard MA, Jean R, Durand JM. Still's-like disease, breast prosthesis, and collagen implants. Rheumatol Int. 2001;20:129-131.

19. Blasiak A, Blachowicz A, Gietka A, Rell-Bakalarska M, Franek E. Still's disease in patient with silicone breast implants: case report. Pol Arch Med Wewn. 2008;118:65-67.

20. Levy $Y$, Rotman-Pikielny P, Ehrenfeld M, Shoenfeld Y. Silicone breast implantation-induced scleroderma: description of four patients and a critical review of the literature. Lupus. 2009;18(13):1226-1232.

21. Granel B, Serratrice J, Gaudy C, Weiller-Merli C, Bonerandi JJ, Lepidi H, Coulomb-Marchetti B, Disdier P. Weiller PJ.D Localized morphea after silicone-gel-filled breast implant. Dermatology. 2001;202(2):143144. 
22. Meier LG, Barthel HR, Seidl C. Development of polyarthritis after insertion of silicone breast implants followed by remission after implant removal in 2 HLA-identical sisters bearing rheumatoid arthritis susceptibility genes. J Rheumatol. 1997;24(9):1838-1841.

23. Homsi Y, Carlson JA, Homsi S. Polyarteritis nodosa presenting as digital gangrene and breast lesion following exposure to silicone breast implants. Case Rep Rheumatol. 2015;2015:765170.

24. Shoaib BO, Patten BM. Human adjuvant disease: presentation as a multiple sclerosis-like syndrome. South Med J. 1996;89(2):179-188.

25. Vasey FB, Havice DL, Bocanegra TS, Seleznick MJ, Bridgeford PH, Martinez-Osuna P, Espinoza LR. Clinical findings in symptomatic women with silicone breast implants. Semin Arthritis Rheum. 1994;24(1 Suppl 1):22-28.

26. Aziz NM, Vasey FB, Leaverton PE, Other E. Comparison of clinical status among women retaining or removing gel breast implants. Am J Epidemiol. 1997;145(11):191.

27. Thomas WO 3rd, Harper LL, Wong SW, Michalski JP, Harris CN, Moore JT, Rodning CB. Explantation of silicone breast implants. Am Surg. 1997;63(5):421-429.

28. Kappel RM, Pruijn GJ. The monobloc hydrogel breast implant, experiences and ideas. Eur J Plast Surg. 2012;35(3):229-233.

29. Walden KJ, Thompson JK, Wells KE. Body image and psychological sequelae of silicone breast explantation: preliminary findings. Plast Reconstr Surg. 1997;100(5):1299-1306.

30. Rohrich RJ, Kenkel JM, Adams WP, Beran S, Conner WC. A prospective analysis of patients undergoing silicone breast implant explantation. Plast Reconstr Surg. 2000;105(7):2529-2537 (discussion 25382543).

31. Svahn JK, Vastine VL, Landon BN, Dobke MK. Outcome of mammary prostheses explantation: a patient perspective. Ann Plast Surg. 1996;36(6):594-600.

32. Melmed EP. A review of explantation in 240 symptomatic women: a description of explantation and capsulectomy with reconstruction using a periareolar technique. Plast Reconstr Surg. 1998;101(5):1364-1373.

33. Godfrey PM, Godfrey NV. Response of locoregional and systemic symptoms to breast implant replacement with autologous tissues: experience in 37 consecutive patients. Plast Reconstr Surg. 1996;97(1):110-116.

34. Peters W, Smith D, Fornasier V, Lugowski S, Ibanez D. An outcome analysis of 100 women after explantation of silicone gel breast implants. Ann Plast Surg. 1997;39(1):9-19.

35. Maijers MC, de Blok CJ, Niessen FB, van der Veldt AA, Ritt MJ, Winters HA, et al. Women with silicone breast implants and unexplained systemic symptoms: a descriptive cohort study. Neth J Med. 2013;71:534-540.

36. Campbell A, Brautbar N, Vojdani A. Suppressed natural killer cell activity in patients with silicone breast implants: reversal upon explantation. Toxicol Ind Health. 1994;10(3):149-154.

37. Bizjak M, Selmi C, Praprotnik S, Bruck O, Perricone C, Ehrenfeld M, Shoenfeld Y. Silicone implants and lymphoma: the role of inflammation. J Autoimmun. 2015;65:64-73.

38. Schaefer CJ, Wooley PH. The influence of silicone implantation on murine lupus in MRL Ipr/lpr mice. J Rheumatol. 1999;26:2215-2221.

39. McDonald AH, Weir K, Schneider M, Gudenkauf L, Sanger JR. Silicone gel enhances the development of autoimmune disease in New Zealand black mice but fails to induce it in BALB/cAnPt mice. Clin Immunol Immunopathol. 1998;87:248-255.

40. Naim JO, Satoh M, Buehner NA, et al. Induction of hypergammaglobulinemia and macrophage activation by silicone gels and oils in female A.SW mice. Clin Diagn Lab Immunol. 2000;7:366-370.

41. Friemann J, Bauer M, Golz B, Rombeck N, Ho“hr D, Erbs G, Steinau HU, Olbrisch RR. Physiologic and pathologic patterns of reaction to silicone breast implants. Zentralbl Chir. 1997;122(7):551-564.

42. Alijotas-Reig J, Ferna'ndez-Figueras MT, Puig L. Late-onset inflammatory adverse reactions related to soft tissue filler injections. Clin Rev Allergy Immunol. 2013;45(1):97-108.

43. Narins RS, Beer K. Liquid injectable silicone: a review of its history, immunology, technical considerations, complications, and potential. Plast Reconstr Surg. 2006;118(3 Suppl):77S-84S.

44. Lugano EM, Dauber JH, Elias JA, Bashey RI, Jimenez SA, Daniele RP. The regulation of lung fibroblast proliferation by alveolar macrophages in experimental silicosis. Am Rev Respir Dis. 1984;129:767-771. 
45. Shen GQ, Ojo-Amaize EA, Agopian MS, Peter JB. Silicate antibodies in women with silicone breast implants: development of an assay for detection of humoral immunity. Clin Diagn Lab Immunol. 1996;3:162-166.

46. Kossovsky N, Gornbein JA, Zeidler M, et al. Self-reported signs and symptoms in breast implant patients with novel antibodies to silicone surface associated antigens [anti-SSAA(x)]. J Appl Biomater. 1995;6:153-160.

47. Zandman-Goddard G, Blank M, Ehrenfeld M, Gilburd B, Peter J, Shoenfeld Y. A comparison of autoantibody production in asymptomatic and symptomatic women with silicone breast implants. J Rheumatol. 1999;26:73-77.

48. Varga J, Schumacher HR, Jimenez SA. Systemic sclerosis after augmentation mammoplasty with silicone implants. Ann Intern Med. 1989;111:377-383.

49. Hajdu SD, Agmon-Levin N, Shoenfeld Y. Silicone and autoimmunity. Eur J Clin Invest. 2011;41:203-211.

50. Bennet RM, Jones J, Turk DC, Russel IJ, Matallana L. An internet survey of 2,596 people with fibromyalgia. BMC Musculoskelet Disord. 2007;9:8-27.

51. Borchers AT, Gershwin ME. Fibromyalgia: a critical and comprehensive review. Clin Rev Allergy Immunol. 2015;49(2):100-151.

52. Clauw DJ, Arnold LM, McCarberg BH. The science of fibromyalgia. Mayo Clin Proc. 2011;86:907-911.

53. Tuinder S, Baetens T, De Haan MW, Piatkowski de Grzymala A, Booi AD, Van Der Hulst R, Lataster A. Septocutaneous tensor fasciae latae perforator flap for breast reconstruction: radiological considerations and clinical cases. J Plast Reconstr Aesthet Surg. 2014;67(9):1248-1256.

54. Kasem A, Wazir U, Haedon H, Mokbel K. Breast lipofilling: a review in current practice. Ach Plast Surg. 2015;42:126-130.

55. Krastev T. Breast reconstruction with external pre-expansion and autologous fat transfer (BRAVA) versus standard therapy (BREAST) In: ClinicalTrials.gov. A service of the U.S. National Institutes of Health; 2015. https://clinicaltrials.gov/ct2/show/NCT02339779. Accessed 11 July 2016.

56. Sgarzani R, Negosanti L, Morselli PG, Vietti Michelina V, Lapalorcia LM, Cipriani R. Patient satisfaction and quality of life in DIEAP flap versus implant breast reconstruction. Surg Res Pract. 2015;2015:405163. 


\section{CHAPTER 5}

Subjective cognitive functioning in silicone breast implant patients: A cohort study
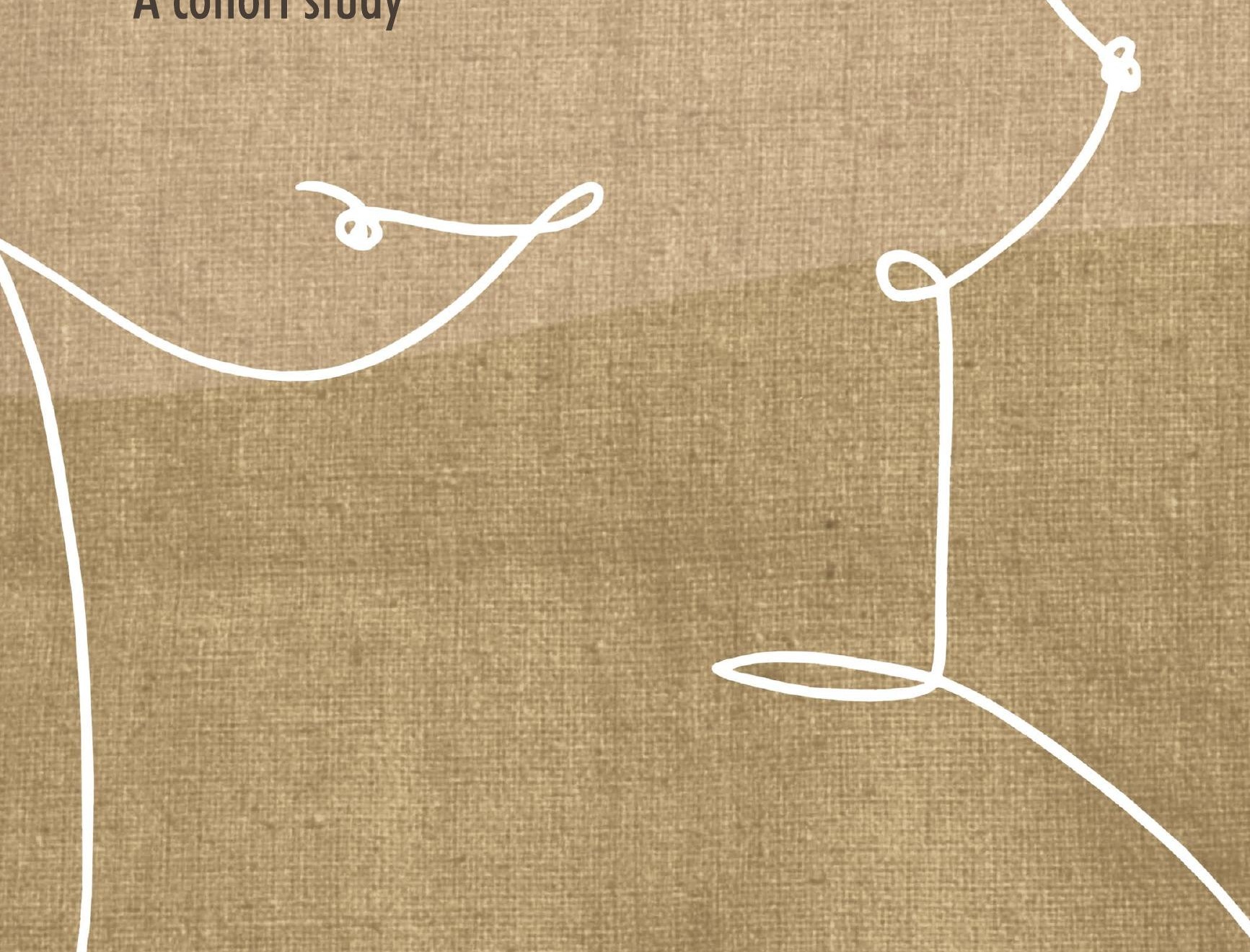


\section{Maartje JL Colaris Jan Willem Cohen Tervaert Rudolf WHM Ponds Johan W Wilmink René RWJ van der Hulst}

\section{Plast Reconstr Surg Glob Open. 2021 Feb;9(2):e3394.}




\section{ABSTRACT}

\section{Background}

Cognitive impairment is frequently reported by silicone breast implant (SBI) patients. The aim of our study is to investigate whether subjective cognitive failure indeed is more frequent in a cohort of SBI patients compared with healthy controls (HCs). Furthermore, the severity of this cognitive failure and a possible relation to other symptoms as well as the duration of SBI exposure was examined. In addition, we assessed the effect of ruptures and reinterventions on cognitive failure severity.

\section{Methods}

A cohort study was performed, including 376 women and consisting of 3 different groups of patients; $143 \mathrm{SBI}$ patients (group 1), 94 age- and sex-matched HC patients (group 2), and 139 women with SBI and health issues who registered themselves at a Dutch foundation for women with illness due to SBI (group 3). All patients filled in the Cognitive Failure Questionnaire (CFQ). The American College of Rheumatology Fibromyalgia Diagnostic Criteria (2010) were used to score other symptoms.

\section{Results}

Completed CFQ data from 222 patients were available for analysis: $n=79$ for group $1, \mathrm{n}=62$ for group 2, and $\mathrm{n}=81$ for group 3. SBI patients from group 3 had a significantly higher prevalence of subjective cognitive dysfunction (CFQ score $\geq 43$ ) compared with SBI patients from group 1 and HC (60.5\% versus $13.9 \%$ and $12.9 \%$; $p=0.000)$. Linear regression showed a statistically significant relation between subjective cognitive functioning scores and other symptoms ( $p=0.000)$. Implant duration as well as rupture rate and reinterventions were not found to significantly influence CFQ scores.

\section{Conclusion}

An increased risk of cognitive failure in consecutive SBI patients when compared with HCs could not be found. 


\section{INTRODUCTION}

Silicone breast implants (SBIs) may be associated with symptoms such as fatigue, arthralgias, myalgias, pyrexia, and sicca symptoms. ${ }^{1}$ In addition, patients may also complain that they develop cognitive impairment, characterized by memory loss, word finding problems, and concentration problems. Up until now, no studies have been performed to assess cognitive complaints in SBI patients compared with healthy controls (HCs).

In 1994, Shoaib and Patten ${ }^{2,3}$ first described a neurological disease in patients with SBIs with multiple sclerosis-like symptoms and/or atypical motor neuron disease. They reported 100 women with SBIs from which 84 patients underwent a magnetic resonance imaging of the brain. ${ }^{4}$ Nineteen of these 84 women showed multiple white matter lesions and 13 women showed multiple small ischemic lesions.

In 2011, Shoenfeld and Agmon-Levin ${ }^{5}$ proposed that above described (atypical) neurological symptoms may be due to adjuvant activity of SBIs. Later on, we and others described large cohorts of patients with SBI that were diagnosed as suffering from "Autoimmune/Inflammatory Syndrome Induced by Adjuvants" (ASIA-syndrome). ${ }^{6-8}$ Next to cognitive impairment, these patients also frequently report fatigue, arthralgias, myalgias, dry eyes, dry mouth, pyrexia, stroke, and/or multiple sclerosis-like symptoms. ${ }^{1}$ The prevalence of ASIA, due to silicone incompatibility or so called breast implant illness, and also the pathogenesis, however, at present are unknown. ${ }^{9}$ In the last decade, over 5000 Dutch women with SBIs made their complaints public online on the World Wide Web and registered themselves at a Dutch foundation for women with illness due to breast implants. ${ }^{10}$

The aim of this cohort study is to investigate the prevalence of cognitive failure in a cohort of SBI patients compared with control patients, as well as to evaluate the severity of this cognitive failure. Furthermore, we evaluated the existence of a possible relation between cognitive failure severity and the presence of other symptoms that are frequently reported in SBI patients as well as the duration of SBls exposure. At last, we assessed the effect of patients reported ruptures and reinterventions on cognitive failure severity. 


\section{PATIENTS AND METHODS}

\section{Patients and controls}

The study included 376 women consisting of 3 different groups of patients. Group 1 consisted of 143 SBI patients that had been operated between 1997 and 2004 in the Maastricht University Medical Center, Maastricht, the St. Anna Hospital, Geldrop or the Maxima Medical Center, Eindhoven, The Netherlands. Patients were detected by archived surgery reports of the participating hospitals. The time span for the period of breast implantation from 1997 to 2004 was chosen based on our previous study, in which we reported the occurrence of onset of clinical symptoms after a median period of 4 years after time of breast implantation and a diagnosis of ASIA after a median period of 13 years after breast implantation. ${ }^{7}$ Group 2 consisted of 94 age- and sex-matched HC friends of the patients of group 1, which were selected according to the following exclusion criteria: (history of) SBIs and/or (history of) breast cancer. Group 3 consisted of 139 women with $\mathrm{SBI}$ and health issues who registered themselves at a Dutch foundation for women with illness due to breast implants (in Dutch: Steunpunt voor Vrouwen met Siliconen implantaties), matched for the period of breast implantation to patients of group 1. All women who were registered with known address details and had been operated between 1997 and 2004 were contacted and invited. All subjects were invited by post to complete a questionnaire after signing the informed consent form. The questionnaire consisted of a general questionnaire, the Dutch version of the 2010 American College of Rheumatology Fibromyalgia Diagnostic Criteria, and the Cognitive Failure Questionnaire (CFQ). Paper questionnaires were distributed by the clinical researcher (M.J.L.C.). They were coded with a unique number in advance to anonymize obtained data. Written informed consent for participation in this study was obtained from all subjects. The study was approved by the local Medical Ethics board of the Maastricht University Medical Center, The Netherlands.

\section{Questionnaires}

The prevalence of self-reported cognitive failure was assessed by filling in the CFQ, completed by all patients between July 2016 and July 2017. The CFQ, developed by Broadbent et $\mathrm{al}^{11}{ }^{11}$ is a self-report questionnaire consisting of 25 items assessing 
impairment in attention, perception, memory, and motor functioning in everyday life. In addition to these 25 items, all participants indicated on a 5-point Likert scale if they had experienced an increase in cognitive failures in the past 5 years (termed "increase," ranging from "no increase" score 1, to "very strong increase" score 5), and to what extent these cognitive impairments affected their daily life, ranging from "no hindrance at all" (score 1) to "very much hindrance" (score 5), how worried they were about these cognitive failures, ranging from "not worried at all" (score 1) to "very much worried" (score 5) and finally how annoying they found their cognitive failure, ranging from "not annoying at all" (score 1) to "very much annoying" (score 5). The total CFQ score was calculated by summing up all items. A high CFQ score is defined as a score $\geq 43$, based on reference data from healthy volunteers ( $n=1357$ ) who participated in the Maastricht Aging Study. ${ }^{12}$ Cognitive failure severity is defined as the mean of the total CFQ scores, measured for all the participants in the group.

The somatic symptoms from the SS Scale score of the American College of Rheumatology Fibromyalgia Diagnostic Criteria (2010) were used to score other symptoms (range 0-6). ${ }^{13}$ These symptoms included: arthralgia, myalgia, fatigue/unrefreshed sleep, cognitive difficulties (e.g., memory loss, concentration problems), sicca (e.g., dry eyes and/or dry mouth), and pyrexia. A clinical score was calculated by summing up the total amount of symptoms (range 0-6).

Rupture rates were identified by the patient's questionnaires respectively selfreporting. Duration of silicone exposure is counted from the year of implantation to year of explantation (mean in years \pm SD).

\section{Statistical analysis}

Continuous variables were reported as mean and SD and percentages were reported for categorical variables. Differences in mean CFQ scores between 2 groups were compared using Student's $t$ test for independent samples or the Mann-Whitney $U$ test and differences in mean scores between more than two groups were compared using analysis of variance. Comparisons among groups were performed by the Chi-square or the Fisher's exact tests for categorical variables. Pearson's correlation and (unadjusted and adjusted) linear regression coefficients were used to estimate the crude and adjusted associations between the clinical score of other symptoms, age and duration of silicone exposure of breast implant(s) in relation to total CFQ scores. Statistical analyses were 
performed using SPSS (version 22.0). All statistical tests were 2-tailed, and a significance level of $p \leq 0.05$ was used as indicated statistical significance.

\section{RESULTS}

Of the 376 patients, 231 (61.4\%) returned the questionnaires. Because of incomplete data, 9 patients had to be excluded. In total from 222 patients, CFQ data were completed and available for analysis: $n=79$ (55\%) for group $1, n=62$ (66\%) for group 2 and $n=81$ (58\%) for group 3. The demographic characteristics of the included SBI patients from the consecutive cohort (group 1) and from the cohort with previous reported health issues (group 3) are summarized in Table 5.1. The mean age of the HC patients was $43.01( \pm 14.29)$ years.

Table 5.1 Demographic characteristics of Included SBI patients with (Group 3) and without (Group 1) previously reported health issues.

\begin{tabular}{|c|c|c|c|}
\hline Variable & $\begin{array}{c}\text { SBI Patients } \\
\text { Group 1 } \\
(n=79)\end{array}$ & $\begin{array}{l}\text { SBI Patients } \\
\text { Group } 3 \\
\text { (n= }=81 \text { ) }\end{array}$ & $P$ (2-sided) \\
\hline Age, mean in years $\pm S D$ & $57.77 \pm 10.18$ & $53.89 \pm 9.36$ & $0.015^{*}$ \\
\hline \multicolumn{4}{|l|}{ Reason of breast implantation, $\mathrm{n}(\%)$} \\
\hline Cosmetic & $52(65.8)$ & $62(76.6)$ & 0.134 \\
\hline Reconstruction after breast cancer & 25 (31.6) & $15(18.5)$ & \\
\hline BRCA mutation & $12(15.2)$ & $4(4.9)$ & \\
\hline Other & $2(2.6)$ & $4(4.9)$ & \\
\hline \multicolumn{4}{|l|}{ Reintervention, $\mathrm{n}(\%)$} \\
\hline Yes & $53(67.1)$ & $69(85.2)$ & $0.007^{*}$ \\
\hline No & $26(32.9)$ & $12(14.8)$ & \\
\hline \multicolumn{4}{|l|}{ Rupture rate of breast implant(s), $n(\%)$} \\
\hline Yes & $21(26.6)$ & $24(29.6)$ & 0.668 \\
\hline No & $58(73.4)$ & $57(70.4)$ & \\
\hline Duration of silicone exposure, mean in years $\pm S D$ & $16.2 \pm 10.2$ & $15.4 \pm 7.2$ & $0.004^{*}$ \\
\hline Clinical score, ${ }^{+}$mean \pm SD & $2.4 \pm 1.7$ & $4.1 \pm 1.4$ & $0.008^{*}$ \\
\hline
\end{tabular}

*Statistical significant results $(p<0.05)$. +Clinical score: amount of other symptoms (range $0-6)$.

In group 3 (i.e., SBI patients with previous reported health issues), a significantly higher prevalence of subjective cognitive dysfunction (CFQ score $\geq 43$ ) was observed compared to SBI patients from group 1 (consecutive patients) and HCs $(60.5 \%$ versus $13.9 \%$ and $12.9 \% ; p=0.000)$ (Figure 5.1 ). No difference in the prevalence of subjective cognitive dysfunction could be found for SBI patients from group 1 compared with HCs (13.9\% versus $12.9 \% ; p=1.000)$. 


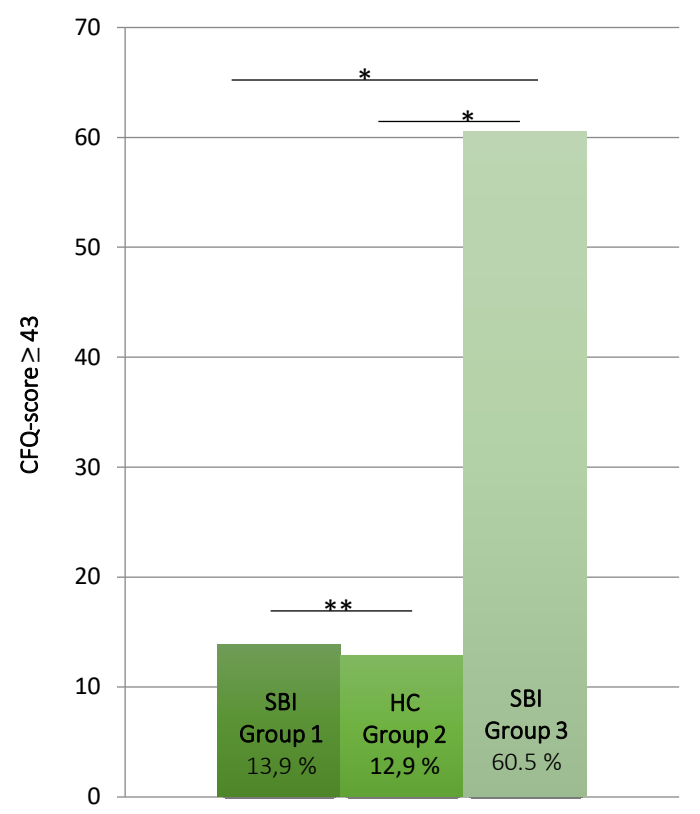

Figure 5.1 Prevalence of cognitive failure. ${ }^{*}$ Statistical significant results $(p<0.05) .{ }^{* * N S}$.

SBI patients from group 1 had CFQ scores comparable to CFQ scores of HC, but significantly lower than $\mathrm{SBI}$ patients from group $3(p=0.000)$ (Figure 5.2). SBI patients from group 3 experienced significantly higher increases in cognitive failures in the past 5 years and were more impaired, annoyed, and worried about these cognitive failures compared with $\mathrm{HCs}$ and $\mathrm{SBI}$ without previous reported health issues (all $p=0.000$ ).

Total CFQ scores are positively correlated with the clinical score of other symptoms in SBI patients from either group 1 and/or group 3 ( $p=0.000$ ) (Figure 5.3). Also after adjustment for age, a correlation between total CFQ scores and the total clinical score remained present $(p=0.004)$ (Table 5.2). Total CFQ scores are not correlated with duration of silicone exposure itself in $\mathrm{SBI}$ patients from either group 1 or group $3(p=0.596)$. 


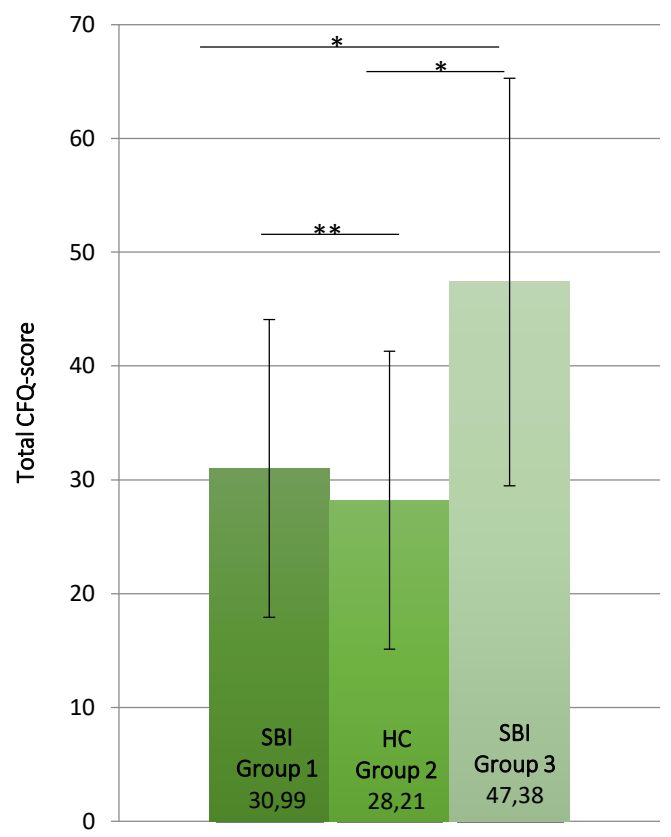

Figure 5.2 Severity of cognitive failure. * Statistical significant results $(p<0.05) .{ }^{*}$ NS.

Self-reported ruptures of SBIs do not influence CFQ scores of SBI patients from group $1(p=0.211)$ as well as CFQ scores of SBI patients from group $3(p=0.991)$ (Table 5.3). Moreover, CFQ scores were not found to be influenced by reintervention of the SBIS in SBI patients from group $1(p=0.850)$ as well as in SBI patients from group $3(p=0.504)$ (Table 5.4). 


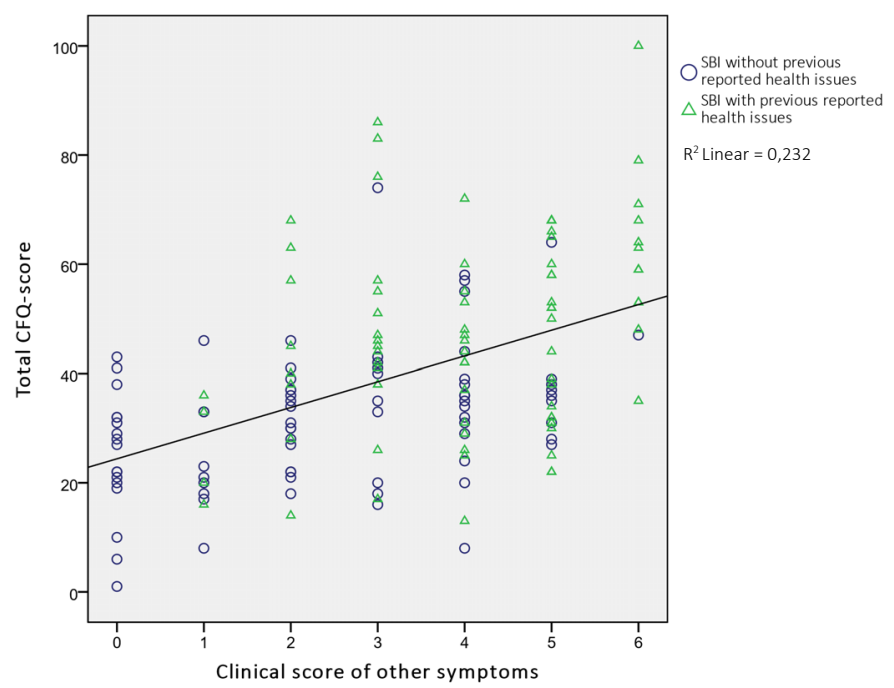

Figure 5.3 Relationship between total CFQ-scores and other clinical symptoms in SBI patients. Linear regression: the $y$ axis represents the value of the CFQ-scores, values range from 1 to 100: a high CFQ-score was defined as a score $\geq 43$. The $x$ axis represents the clinical score, which was calculated by summing up the amount of other symptoms (range $0-6$ ). The blue circles in the scatterplot represent the SBI patients without previous reported health issues (group 1), and the green triangles represent the SBI patients with previous reported health issues (group 3). The black line is the linear regression with a regression coefficient of $4.698 \pm 0.68$ and an $R^{2}$ of $0.232 \pm 15.32(p=0.000)$.

Table 5.2 Pearson's correlation and crude and adjusted linear regression coefficients of clinical scores and age in relation to total CFQ-Scores

\begin{tabular}{llccccc}
\hline & & \multicolumn{5}{c}{ Crude } \\
Independent & Dependent & $\mathbf{R}$ & $\mathbf{R}^{\mathbf{2}}$ & $\mathbf{B}$ & $\mathbf{C l}$ & $\boldsymbol{P}$ \\
\hline Clinical score* & Total Cognitive Failure Score & 0.481 & 0.232 & 4.698 & $3.354-6.043$ & 0.000 \\
Age & Total Cognitive Failure Score & -0.248 & 0.062 & -0.422 & -0.685 to -0.158 & 0.002 \\
\hline Independent & Dependent & \multicolumn{5}{c}{ Adjusted } \\
\hline Clinical scoret & Total Cognitive Failure Score & 0.527 & 0.277 & 4.381 & $3.092-5.670$ & 0.004 \\
\hline
\end{tabular}

$\mathrm{B}$, regression coefficient; $\mathrm{Cl}$, confidence interval. ${ }^{*}$ Clinical score: amount of other symptoms (range 0-6). tAdjusted for age.

Table 5.3 Mean total CFQ-Scores in SBI patients with (Group 3) and without (Group 1) ruptures of their SBIs.

\begin{tabular}{|c|c|c|c|c|c|c|}
\hline \multirow[b]{2}{*}{ Rupture of SBI } & \multicolumn{3}{|c|}{$\begin{array}{c}\text { SBI Patients } \\
\text { Group } 1 \\
\text { (n= 79) }\end{array}$} & \multicolumn{3}{|c|}{$\begin{array}{c}\text { SBI Patients } \\
\text { Group } 3 \\
(n=81)\end{array}$} \\
\hline & $\begin{array}{c}+ \\
(n=21)\end{array}$ & $\begin{array}{c}- \\
(n=58)\end{array}$ & $\begin{array}{c}P \\
\text { (2-sided) }\end{array}$ & $\begin{array}{c}+ \\
(n=24)\end{array}$ & $\begin{array}{c}- \\
(n=57)\end{array}$ & $\begin{array}{c}P \\
\text { (2-sided) }\end{array}$ \\
\hline $\begin{array}{l}\text { Total CFQ scores, } \\
\text { mean } \pm \text { SD }\end{array}$ & $34.57 \pm 16.76$ & $30.50 \pm 10.89$ & 0.211 & $47.42 \pm 17.86$ & $47.37 \pm 18.10$ & 0.991 \\
\hline
\end{tabular}


Table 5.4 Mean Total CFQ Scores in SBI Patients with (Group 3) and without (Group 1) Reintervention of Their SBIs.

\begin{tabular}{|c|c|c|c|c|c|c|}
\hline \multirow[b]{2}{*}{ Reintervention of SBI } & \multicolumn{3}{|c|}{$\begin{array}{c}\text { SBI Patients } \\
\text { Group } 1 \\
\text { (n= 79) }\end{array}$} & \multicolumn{3}{|c|}{$\begin{array}{c}\text { SBI Patients } \\
\text { Group } 3 \\
\text { (n= 81) }\end{array}$} \\
\hline & $\begin{array}{c}+ \\
(n=53)\end{array}$ & $\begin{array}{c}- \\
(n=26)\end{array}$ & $\begin{array}{c}P \\
\text { (2-sided) }\end{array}$ & $\begin{array}{c}+ \\
(n=69)\end{array}$ & $\begin{array}{c}- \\
(n=12)\end{array}$ & $\begin{array}{c}P \\
\text { (2-sided) }\end{array}$ \\
\hline $\begin{array}{l}\text { Total CFQ scores, } \\
\text { mean } \pm \text { SD }\end{array}$ & $31.77 \pm 13.46$ & $31.19 \pm 11.28$ & 0.850 & $47.94 \pm 18.33$ & $44.17 \pm 15.59$ & 0.504 \\
\hline
\end{tabular}

\section{DISCUSSION}

This cohort study was aimed at exploring the prevalence and severity of subjective cognitive dysfunction in SBI patients compared with controls. Our data showed that consecutive SBI patients from group 1 have the same amount (CFQ score $\geq 43$ ) and severity of cognitive difficulties (mean of total CFQ score) as measured with the CFQ compared to sex- and age-matched HCs (13.9\% versus $12.9 \%$ and 30.99 versus $28.21 ; p>0.05$ ). Furthermore, these SBI patients have less frequent and less severe cognitive failure than SBI patients who registered themselves at a Dutch foundation for women with illness due to breast implants $(60.5 \%$ and $47.38 \%$; $p=0.000$ ). Our study raises awareness that SBI patients who made their complaints public are a selected group of patients with multiple symptoms including higher cognitive failure scores. The higher frequency and severity of cognitive failure in these latter silicone breast patients suggests that in these patients similar psychological mechanisms are operative as in conditions characterized by so-called central sensitizations such as fibromyalgia and/or chronic fatigue syndrome. A major difference with chronic fatigue syndrome and fibromyalgia, however, is that under these conditions reversibility has only infrequently been described, whereas cognitive difficulties and other symptoms may improve and/or disappear after explantation of the breast implants. , $^{1,14}$

Silicone can migrate outside the outer shell after SBI rupture, but also migration with an intact shell, the so-called gel bleed have been described. ${ }^{1}$ Also, the duration of silicone breast implantation time is positively correlated to the rupture rate or leakage of the SBIs. ${ }^{15-17}$ In previous studies, it is postulated that implant rupture and aging can be an important factor for an inflammatory response or triggering of the immune system as reaction to migration of silicone particles 
throughout the body. ${ }^{18}$ In our study, however, no relation of cognitive failure severity with self-reported rupture rate and/or duration of silicone implant exposure was found. Therefore, the results of this study imply that rupture of SBIs and leakage of silicone exposure are not responsible for the cognitive difficulties that SBI patients experience.

The results of our study clearly show that cognitive failure occurred more frequently in the group of SBI patients with other self-reported symptoms. We admit that a statistical difference between group 1 and group 3 could be previously expected because of the selection bias of group 3. Due to this selection bias, we cannot conclude that there is an increased risk to develop cognitive failure after $\mathrm{SBI}$ in general. In fact, in the group of SBI patients without other self-reported symptoms, which represents the general SBI population the most, an increased risk to develop cognitive failure could not be found at all in comparison to HCs. We can conclude that the selected SBI patients, with previously self-reported symptoms, cannot represent the overall general SBI patients. In SBI patients with other selfreported symptoms, chronic reactions of the immune system, however, may have resulted in the symptoms of cognitive failure. Otherwise, social media may have an influence suggesting that the concerns that these patients are sharing with each other may have contribute to the development of symptoms of cognitive failure. ${ }^{19}$ This is the first study that measures subjective cognitive failure in consecutive SBIs patients compared with controls. A limitation of this cohort study is that a subjective screening instrument is used for the assessment of cognitive dysfunction. Subjective cognitive functioning is, however, not equal to objective cognitive functioning. ${ }^{20}$ Broadbent et al. ${ }^{11}$ described "cognitive failure" as a cognitive error that occurs during the performance of a task that a person normally would execute successfully. Beliefs about cognitive changes are strongly influenced by self-efficacy beliefs, personality, vitality, and coping styles. ${ }^{21}$ Zuckerman et al. ${ }^{22}$ reviewed the literature about the link between breast implants and self-esteem, quality of life and the risk of suicide suggesting that breast implants are related to risks to mental health. Without studying cognitive function before implants, it is, however, not possible to make firm conclusions. Depression and fatigue are both important issues regarding cognition. 


\section{CONCLUSION}

Subjective cognitive failure is a substantial problem in SBI patients that registered themselves with a patient organization. In the current study, we could not find an increased risk of cognitive failure in consecutive SBI patients, without previously self-reported symptoms, when compared with HCs. Implant duration, rupture rate, and reinterventions were not found to be related to CFQ scores in all of the patients that we studied. Prospective cognitive function studies should be performed, in which cognitive function will be measured before SBI and after longterm follow-up before definitive conclusions can be drawn. 


\section{REFERENCES}

1. Cohen Tervaert JW, Colaris MJ, van der Hulst RR. Silicone breast implants and autoimmune rheumatic diseases: myth or reality. Curr Opin Rheumatol. 2017;29:348-354.

2. Shoaib BO, Patten BM. An atypical motor neuron disease syndrome in patients with breast implants. Can J Neurol Sci. 1994;1:64-69.

3. Shoaib BO, Patten BM. An MS-like syndrome in women with silicone breast implants or silicone fluid injections in breast. Neurology. 1994;44:37-44.

4. Shoaib BO, Patten BM, Calkins DS. Adjuvant breast disease: an evaluation of 100 symptomatic women with breast implants or silicone fluid injections. Keio J Med. 1994;43:79-87.

5. Shoenfeld Y, Agmon-Levin N. "ASIA" - autoimmune/inflammatory syndrome induced by adjuvants. J Autoimmun. 2011;36:4-8.

6. Cohen Tervaert JW, Kappel RM. Silicone implant incompatibility syndrome (SIIS): a frequent cause of ASIA (Shoenfeld's syndrome). Immunol Res. 2013;56:293-298.

7. Colaris MJL, de Boer M, van der Hulst RR, et al. Two hundreds cases of ASIA syndrome following silicone implants: a comparative study of 30 years and a review of current literature. Immunol Res. 2017;65:120-128.

8. Maijers MC, de Blok CJ, Niessen FB, et al. Women with silicone breast implants and unexplained systemic symptoms: a descriptive cohort study. Neth J Med. 2013;71:534-540.

9. Healing Breast Implant Illness. Breast implant safety. 2020. Available at: http://healingbreastimplantillness.com/breastimplant-safety. Accessed April 18, 2017.

10. Meldpunt Klachten Siliconen. Dutch foundation for women with illness due to breast implants. Available at: https://www.meldpuntklachtensiliconen.com. Accessed February 06, 2020.

11. Broadbent DE, Cooper PF, FitzGerald $\mathrm{P}$, et al. The cognitive failures questionnaire (CFQ) and its correlates. Br J Clin Psychol. 1982;21:1-16.

12. Ponds $R$, van Boxtel $M$, Jolles J. De "cognitive failure questionnaire"als maat voor subjectief functioneren. Tijdschrift voor neuropsychologie. 2006;1:37-42.

13. Wolfe F, Clauw DJ, Fitzcharles MA, et al. The American College of Rheumatology preliminary diagnostic criteria for fibromyalgia and measurement of symptom severity. Arthritis Care Res (Hoboken). 2010;62:600-610.

14. de Boer M, Colaris M, van der Hulst RRWJ, et al. Is explantation of silicone breast implants useful in patients with complaints? Immunol Res. 2017;65:25-36.

15. Peters W, Keystone E, Smith D. Factors affecting the rupture of silicone-gel breast implants. Ann Plast Surg. 1994;32:449-451.

16. Holmich LR, Friis S, Fryzek JP, et al. Incidence of silicone breast implant rupture. Arch Surg. 2003;138:801-806.

17. Seigle-Murandi F, Lefebvre F, Bruant-Rodier C, et al. Incidence of breast implant rupture in a 12-year retrospective cohort: evidence of quality discrepancy depending on the range. J Plast Reconstr Aesthet Surg. 2017;70:42-46.

18. Nesher G, Soriano A, Shlomai G, et al. Severe ASIA syndrome associated with lymph node, thoracic, and pulmonary silicone infiltration following breast implant rupture: experience with four cases. Lupus. 2015;24:463-468.

19. Tang SYQ, Israel JS, Afifi AM. Breast implant illness: Symptoms, patient concerns, and the power of social media. Plast Reconstr Surg. 2017;140:765e-766e.

20. Walitt B, Čeko $M$, Khatiwada $M$, et al. Characterizing "fibrofog": subjective appraisal, objective performance, and task-related brain activity during a working memory task. Neuroimage Clin. 2016;11:173-180.

21. Ponds RW, Commissaris KJ, Jolles J. Prevalence and covariates of subjective forgetfulness in a normal population in The Netherlands. Int J Aging Hum Dev. 1997;45:207-221.

22. Zuckerman DM, Kennedy CE, Terplan M. Breast implants, selfesteem, quality of life, and the risk of suicide. Womens Health Issues. 2016;26:361-365. 
CHAPTER 6 Summary, general discussion and future perspectives 


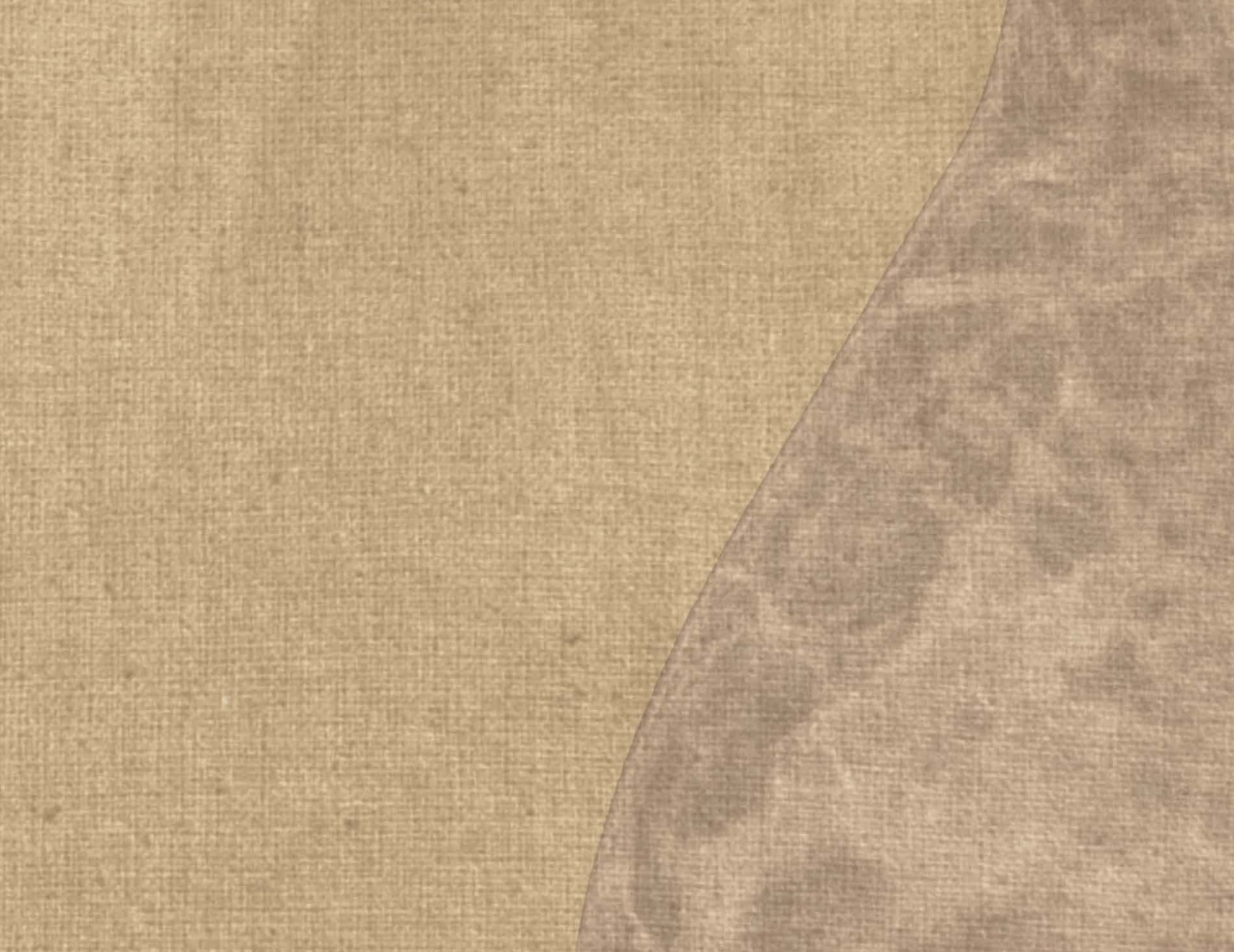





\section{SUMMARY AND GENERAL DISCUSSION}

Many women worldwide undergo breast surgery with the use of silicone implants in aesthetic and reconstructive surgeries, i.e., after mastectomy. ${ }^{1,2} \mathrm{~A}$ group of patients with implants (SBI) started reporting medical complaints, known as "Silicone Breast Implant IIIness" (SBII). ${ }^{3}$ SBII is a not well-defined collective name for a widespread cluster of nonspecific symptoms, allocated by SBI patients as being caused by their breast implants. Currently, there have been thousand articles on this phenomenon and more than fifty different symptoms have been described during the years. The most commonly symptoms SBI patients are reporting are fatigue, arthralgia and/or myalgia, brain fog, memory loss and concentration problems, dry eyes and/or dry mouth, pyrexia and various autoimmune diseases. ${ }^{4,5}$ SBI women often present themselves to surgeons with a self-diagnosis of SBII and in some cases, requesting explantation. ${ }^{6}$ Three hypotheses have been postulated for the development of these symptoms in SBI patients: 1) 'adjuvant' hypothesis: activation of the immune system by silicones that are leaked (known as silicone 'bleeding') and/or spread into the body after rupture of the implant, 2) 'silicon toxicity' hypothesis: cell death induced by apoptotic processes exposed to toxic silicone compounds, and 3) 'psychosomatic illness' hypothesis: mental health issues where SBI act as a nociceptive stimulator. 7,8

The 'adjuvant' hypothesis: The activation of the immune system is driven by monocytes, which differentiate into M1 macrophages in contact to SBI. They perform silicone phagocytosis and secrete pro-inflammatory cytokines (TNF- $\alpha$, IFN- $\gamma$, IL-6), stimulated by denatured plasma proteins., ${ }^{9,10}$ IL-6 is produced during the inflammatory response and induces the development of Th17 cells with the leading cytokines IL-8, IL-17, IL-6 and IFN- $\gamma .{ }^{11} \mathrm{M} 1$ Macrophages could mediate silicone-induced adverse responses, such as foreign body reaction and fibrous encapsulation. They develop into foreign body giant cells and cause the recruitment of fibroblasts, which isolate the SBI from the surrounding tissue by depositing collagen and the fibrous capsule mediated by the profibrotic cytokine TGF- $\beta .^{12}$ The migration of the silicone particles throughout the body is accompanied by lymph node and thoracic silicone infiltration, with giant-cell granulomas and small silicone vacuoles found in lymph node biopsies. ${ }^{7,13}$ In this hypothesis, the SBI acts as an 'adjuvant' to the immune system. ${ }^{5}$ 
The 'silicon toxicity' hypothesis: Polydimethylsiloxane, the most common silicone in $\mathrm{SBI}$, is, by migrating throughout the body after leaving the SBI by gel 'bleed' and/or rupture of the implant, adhering to plasma membrane lipids as well as accumulates preferably in adipocytes because of its lipophilic character. ${ }^{14}$ Exposure of cultured human cells (Jurkat cells and HeLa cells) to low molecular weight methylcyclosiloxanes, the smallest cyclic silicone oligomer octamethylcyclotetrasiloxane (D4) and the larger decamethylcyclopentasiloxane (D5), can induce cell death by apoptotic processes such as cleavage of caspase substrates and DNA fragmentation. ${ }^{14}$ The induction of the apoptotic processes by silicones, known as 'silicon toxicity', seems to be depending on the amount and the size of the silicone molecules and also the cell sensitivity to the toxic silicone compounds seems to differ due to cell type. ${ }^{14}$ In addition, textured implant surfaces increase cell apoptosis and down-regulates IL-8 release in cultured human breast derived fibroblasts (BDFs) when compared to cells on smooth implant surfaces. ${ }^{15}$

The 'psychosomatic illness' hypothesis: It has also been postulated that SBI patients with symptoms are suffering from a "psychosomatic" illness. Patients have mental issues and are worried by their SBI. At present, mainstream media and social media are exploding with laymen's discussions about SBII. ${ }^{16}$ Many of the SBII patients share their experience, seek support, and express frustration on social media with discussions about SBII. ${ }^{17}$ It has been postulated that the concerns that these patients are sharing with each other on social media, have a contributable influence on their psychological fixation on SBII, especially of common symptoms ${ }^{16,18,19}$ and that this affects their quality of life and daily function. Indeed, stress, cognitive and emotional mechanisms may affect many physical symptoms and sensations and may activate the immune system as well. ${ }^{19}$ SBII patients may experience anxiety with elevated anxiety scores demonstrated on testing. ${ }^{18}$ Published data on outcomes following SBI explantation show improvement of symptoms in more than half of the explanted SBI patients. ${ }^{20-22}$ Whether the relief of these symptoms is directly related to the removal of the implant or that the improvement may have been the result of other factors is questionable. ${ }^{23}$ It is imaginable that explantation of the SBI causes relief of the psychological fixation on SBII. ${ }^{22}$ However, in about one third of the investigated explanted cases, symptoms do not improve. ${ }^{20,22}$ This seems particularly in those who have developed a well-defined autoimmune disease such as rheumatoid arthritis or Sjögren Syndrom. ${ }^{22}$ 


\section{Critical Appraisal of the studies}

In chapter one, as part of the introduction, the available evidence to the existence of Silicone Breast Implant IIIness (SBII) is analyzed by performing an overview. During the last few years, the concept that SBII is due to an adjuvant effect of migrated silicones has been further worked-out. Due to either SBI rupture or gelbleed, silicones may migrate through the body into tissues and the central nervous system. Furthermore, these silicones can induce a chronic inflammatory process that may ultimately result in (an increase of) allergies, autoimmune diseases, immune deficiency and/or lymphomas. It is concluded that larger adjusted epidemiological studies are needed to obtain better evidence. Such a study was recently performed in Israel indicating an $45 \%$ increased risk of autoimmune diseases in patients with silicone breast implants when compared to women without implants. ${ }^{24}$ Despite the large sample size of the study, the presented evidence is not fully unbiased.

In chapter two, we compared a cohort of one hundred silicone breast implant patients diagnosed with ASIA in 2014 in Maastricht, the Netherlands, with a cohort of one hundred historical patients with adjuvant breast disease diagnosed in the Baylor College of Medicine, Houston, USA, between 1985 and 1992. Similarities and differences between these two cohorts were identified to determine whether the spectrum of silicone-related disease changed during the last 30 years. We concluded that a great similarity in clinical manifestations exists with actually an unchanged spectrum between the two cohorts as well as in all of the other 18 reviewed cohort studies during all these years. Especially, the most commonly symptoms SBI patients report are present throughout all identified cohorts. Our study showed that the materials used for the breast implants did not influence the pattern of complaints. Despite major improvements in implants used, no differences were found between the cohorts who had surgery more than 30 years ago and the cohort were implants were placed more recently.

In chapter three, a cohort study on vitamin D as a risk factor for the development of autoimmunity resulting in the formation of autoantibodies in SBII patients is described. Furthermore, a review of the literature on vitamin $\mathrm{D}$ levels and the presence and/or titer levels of autoantibodies in different autoimmune diseases was performed. A substantial proportion of SBII patients had a deficient humoral immune system. Vitamin D may act as a regulatory agent of the immune system. Vitamin D deficiency was found to be related to the presence of autoantibodies in 
patients with SBII. The main critical limitation to this finding is that a control group is lacking. Whether vitamin D deficiency is also related to the presence of autoantibodies in SBI patient without complaints as well as healthy control women remains therefore unknown. Randomized, controlled trials must be performed to elucidate whether vitamin D supplementation is beneficial as preventive therapy in patients with silicone breast implants to inhibit the development of autoantibodies.

In chapter four, a systematic review of the existing literature reflecting the results of explantation of silicone breast implants in patients with silicone-related complaints and/or autoimmune diseases. After explantation of the SBI, the complaints improve in $75 \%$ of the patients; whereas in patients with a developed autoimmune disease, improvement only occurs when explantation is combined with immunosuppressive therapy. In more recent research of our group, SBII was found to be the fifth most common indication for explantation (11.2\%) in a cohort of 197 patients (303 breast implants). ${ }^{20}$ A recent study on the topic of explantation in a large cohort of 752 patients also demonstrated significant immediate and sustained improvement of symptoms after explantation. ${ }^{21}$

In chapter five, a cohort-study on subjective cognitive functioning in silicone breast implant patients compared to controls was performed. Our data showed that SBI patients have the same cognitive score as measured with the CFQ (13.9\% vs. $12.9 \%$ and 30.99 vs. $28.21 ; p>0.05$ ) compared to sex- and age matched healthy controls. These SBI patients have less frequent and less severe cognitive failure than SBI patients who registered themselves at a Dutch foundation for women with illness due to breast implants $(60.5 \%$ and $47.38 \% ; p=0.000)$. No relation of cognitive failure severity with self-reported rupture rate and/or duration of silicone implant exposure could be found. This is the first study that measures subjective cognitive failure in consecutive silicone breast implants patients compared to controls. A limitation of this case control study is that a subjective screening instrument is used for the assessment of cognitive dysfunction. Objective cognitive functioning could be investigated in future research by measuring before SBI implantation and after long-term follow-up, e.g., using functional MRI (fMRI). 


\section{FUTURE PERSPECTIVES}

Breast Implant IIIness is still a poorly understood phenomenon. A retrospective study on the prevalence of self-reported health complaints in women with SBI compared to women without breast implants (controls) showed, after adjustment for potential confounders (e.g. age, smoking, and comorbidities), that the prevalence of SBII symptoms was only higher in the group of the self-reported women. ${ }^{25}$ The adjusted prevalence in women with SBIs without self-reported health complaints did not differ from women without breast implants. There were no significant differences in the prevalence of SBII based on the reason for implantation (cosmetic vs. reconstructive) within groups. It is unknown if health complaints were pre-existing before the implantation of the SBIs. Comorbidities were defined as having a self-reported chronic disease, such as allergy, irritable bowel syndrome (IBS), chronic fatigue syndrome (CFS) or fibromyalgia (FM). A significantly higher prevalence of having a chronic disease, allergy, and IBS was found in self-reported SBII women, but not in SBI women without self-reported complaints. However, CFS and FM were reported significantly more frequently in women with SBIs compared to controls. Our results suggest that women who registered themselves as SBII are selected patients which differ from women with SBI that do not suffer from SBII. Further studies are needed to investigate whether CFS/FM are preexistent or induced by SBI.

The main difficulty in assessing the incidence of SBII is a lack of studies that investigated the incidence of above mentioned symptoms in patients with SBI. Since the PIP debacle, the importance of large prospective registration studies and post-market surveillance for medical devices by implant registries has been frequently emphasised. ${ }^{26}$ A report of the Dutch Institute of National Health showed a lack of compliance of breast implant producers to CE requirements, in which two out of ten implants producers were based on a different medical silicone gel not reported to the Notified Body. ${ }^{27}$ The urgently need for an optimal, prospective method to monitor performance of breast implants over time, resulted in the Netherlands in the introduction of the Dutch Breast Implant Registry (DBIR) in 2015. This independent national implant registry system is unique in its sort as an opt-out system without the need for informed consent. ${ }^{28}$ An estimated $1-3 \%$ of all Dutch women have breast implants and it is estimated that around 30.000 implants are annually inserted. ${ }^{2}$ Monitoring of breast implants by the DBIR opens 
the opportunity to perform long-term epidemiologically research on a quality dataset regarding implant issues as SBII. To increase the total number of implant procedures in the dataset, registry data can be pooled globally with internationally agreed quality indicators as standardized patient reported outcome measures developed by the International Collaboration of Breast Registry Activities (ICOBRA). ${ }^{26}$

To get more insight in the phenomenon of SBII, firstly the suggested codetermining psychosomatic aetiology has to be elucidated, by performing studies comparing subgroups of SBI patients pre- and post-implantation with controls onto anxiety and depression (e.g., Hospital Anxiety and Depression Scale (HADS)), selfefficacy (e.g., Dutch General Self-Efficacy Scale), personality (e.g., Eysenck Personality Questionnaire (EPQ)) and body imaging (e.g., Body Image Concern Inventory $(\mathrm{BICl})$ ) and analyzing a possible relation with the development of SBII herein. Secondly, it has been suggested that silicone related complaints do not resemble a new disease and that silicone-related complaints cannot be differentiated from 'idiopathic' fibromyalgia. ${ }^{29}$ So studies comparing idiopathic fibromyalgia with SBII have to be performed. Thirdly, to gain more insight in the neurophysiological basis and nociceptive system of symptomatic SBII patients, functional neuroimaging studies are planned in the near future at our department. Processing of harmless tactile stimuli in SBII patients during fMRI could possible lead to better understanding of the nociceptive system (and possibly other involved disturbed pain related brain areas) and the effect of how brain changes reflect and even maintain persistent pain and other complaints in these patients. Fourthly, to investigate the effect of explantation of silicone breast implants on brain regions, $\mathrm{fMRI}$ could be performed pre- and postoperatively. Fifthly, we should take a closer look on the foreign body host response of SBII. A proinflammatory response with fibrous encapsulation of the implant locally as well as systemically, driven by an inflammatory immune-mediated mechanism is described. ${ }^{30}$ However, the effect of silicones on numerous physiological processes of the surrounding soft-tissue and the cellular responses after leakage (e.g., gel 'bleeding' or implant rupture) has actually hardly been investigated. The available in vitro studies and evidences on the interactions of silicone with different human cell phenotypes remain limited. A restriction for experimental research is to develop an environment that sufficiently simulates - in vivo - the environment of the silicone breast prosthesis. Furthermore, in vitro models are an over 
simplification of in vivo environmental conditions and the physical property of silicone gel (e.g., hydrophobicity, lower density, stickiness) makes its application to culture medium difficult. The differences of implant surfaces (e.g., texturing, size, shape), the production process of the implant, and the droplet size of the silicone gel are other variables that have to be considered, when trying to identify pathological outcomes when studying an inflammatory and/or immune response.

\section{My personal perspective}

In my opinion, until long-term longitudinal prospective studies are performed and sufficient data is present (i.e., DBIR), research has to focus on experimental study designs with due consideration of the previously quoted limitations of current clinical research (e.g., adequate powering, adjusting for confounders, SBII diagnosis by a physician and representing control groups). Furthermore, for the clinical practice, it is important that SBII patients have to be taken seriously in their experienced health complaints. Informing, listening, acknowledging, clarifying and an individual approach to move forward are the main themes to gain trust of the patient. ${ }^{31}$ For pre-implanted patients initial consultation should focus on potential risks of SBII. Subsequently after better understanding of an acknowledged phenomenon of SBII and its pathophysiology, structured treatment protocols and guidelines have to be developed to optimize management of SBII. In conclusion, SBII is a notable symptom complex worthy of further study. 


\section{REFERENCES}

1. The American Society for Aesthetic Plastic Surgery (ASAPS). The American Society for Aesthetic Plastic Surgery's Cosmetic Surgery National Data Bank: Statistics 2018. Aesthet Surg J. 2019;39:1-27.

2. de Boer M, van Middelkoop M, Hauptmann M, et al. Breast Implant Prevalence in the Dutch Female Population Assessed by Chest Radiographs. Aesthet Surg J. 2020;40(2):156-164.

3. Magnusson MR, Cooter RD, Rakhorst H, McGuire PA, Adams WP, Jr., Deva AK. Breast Implant Illness: A Way Forward. Plast Reconstr Surg. 2019;143(3S A Review of Breast Implant-Associated Anaplastic Large Cell Lymphoma):74S-81S.

4. Shoenfeld Y, Agmon-Levin N. 'ASIA' - autoimmune/inflammatory syndrome induced by adjuvants. J Autoimmun. 2011;36(1):4-8.

5. Cohen Tervaert JW, Kappel RM. Silicone implant incompatibility syndrome (SIIS): a frequent cause of ASIA (Shoenfeld's syndrome). Immunol Res. 2013;56(2-3):293-298.

6. Jewell ML, Jewell HL. Breast Implant-Associated Illness: Medicine by Belief, So Says Dr. Google. Aesthet Surg J. 2019;39(4):NP87-NP89.

7. Colaris MJL, de Boer M, van der Hulst RR, Cohen Tervaert JW. Two hundreds cases of ASIA syndrome following silicone implants: a comparative study of 30 years and a review of current literature. Immunol Res. 2017;65(1):120-128.

8. Nesher G, Soriano A, Shlomai G, et al. Severe ASIA syndrome associated with lymph node, thoracic, and pulmonary silicone infiltration following breast implant rupture: experience with four cases. Lupus. 2015;24(4-5):463-468.

9. Rhie J, Han S, Byeon J, Ahn S, Kim H. Efficient in Vitro Model for Immunotoxicologic Assessment of Mammary Silicone Implants. Plastic and Reconstructive Surgery. 1998(1):73-77.

10. Naim JO, van Os CJ, Ippolito KML, et al. In vitro activation of human monocytes by silicones. Colloids and Surfaces B: Biointerfaces. 1998;11(1-2):79-86.

11. Wolfram D, Rabensteiner E, Grundtman C, et al. T regulatory cells and TH17 cells in peri-silicone implant capsular fibrosis. Plast Reconstr Surg. 2012;129(2):327e-337e.

12. Bachour Y, Verweij SP, Gibbs S, et al. The aetiopathogenesis of capsular contracture: A systematic review of the literature. J Plast Reconstr Aesthet Surg. 2018;71(3):307-317.

13. Kappel RM, Boer LL, Dijkman H. Gel Bleed and Rupture of Silicone Breast Implants Investigated by Light-, Electron Microscopy and Energy Dispersive X-ray Analysis of Internal Organs and Nervous Tissue. Clin Med Rev Case Rep. 2016;3(1):1-9.

14. Onnekink C, Kappel RM, Boelens WC, Pruijn GJM. Low molecular weight silicones induce cell death in cultured cells. Sci Rep. 2020;10(1):9558.

15. Kyle DJ, Oikonomou A, Hill E, Bayat A. Development and functional evaluation of biomimetic silicone surfaces with hierarchical micro/nano-topographical features demonstrates favourable in vitro foreign body response of breast-derived fibroblasts. Biomaterials. 2015;52:88-102.

16. Tang SY, Israel JS, Afifi AM. Breast Implant IIIness: Symptoms, Patient Concerns, and the Power of Social Media. Plast Reconstr Surg. 2017.

17. Adidharma W, Latack KR, Colohan SM, Morrison SD, Cederna PS. Breast Implant Illness: Are Social Media and the Internet Worrying Patients Sick? Plast Reconstr Surg. 2020;145(1):225e-227e.

18. Ahern M, Smith M, Chua H, Youssef P. Breast implants and illness: a model of psychological illness. Ann Rheum Dis. 2002;61(7):659.

19. Dush DM. Breast implants and illness: a model of psychological factors. Ann Rheum Dis. 2001;60(7):653-657.

20. Misere RML, van der Hulst R. Self-Reported Health Complaints In Women Undergoing Explantation of Breast Implants. Aesthet Surg J. 2020.

21. Wee CE, Younis J, Isbester K, et al. Understanding Breast Implant Illness, Before and After Explantation: A Patient-Reported Outcomes Study. Ann Plast Surg. 2020;85(S1 Suppl 1):S82-S86.

22. de Boer $M$, Colaris M, van der Hulst RRWJ, Cohen Tervaert JW. Is explantation of silicone breast implants useful in patients with complaints? Immunol Res. 2017;65(1):25-36.

23. Lachmansingh DA. Breast implant illness and psychiatric implications. Ir J Psychol Med. 2019:1-2. 
24. Watad A, Rosenberg V, Tiosano S, et al. Silicone breast implants and the risk of autoimmune/rheumatic disorders: a real-world analysis. Int J Epidemiol. 2018;47(6):1846-1854.

25. Miseré RML, Colaris MJL, van der Hulst RRWJ. The Prevalence of Self-Reported Health Complaints and Health-Related Quality of Life in Women With Breast Implants. Aesthet Surg J. 2020.

26. Hopper I, Ahern S, Nguyen TQ, et al. Breast Implant Registries: A Call to Action. Aesthet Surg J. 2018;38(7):807-810.

27. Keizers P, Drongelen Av, Jong $\mathrm{Wd}$, et al. Silicone breast implants in the Netherlands: a market surveillance study. RIVM Letter report. 2016.

28. Rakhorst HA, Mureau MAM, Cooter RD, et al. The new opt-out Dutch National Breast Implant Registry Lessons learnt from the road to implementation. J Plast Reconstr Aesthet Surg. 2017;70(10):13541360.

29. Wolfe F. "Silicone related symptoms" are common in patients with fibromyalgia: no evidence for a new disease. J Rheumatol. 1999;26(5):1172-1175.

30. Cohen Tervaert JW. Autoinflammatory/autoimmunity syndrome induced by adjuvants (ASIA; Shoenfeld's syndrome): a new flame. Autoimmun Rev. 2018;17:1259-1264.

31. Steve AK, Temple-Oberle C, Yeung JK, Lafreniere AS, Harrop AR. "You Helped Create This, Help Me Now": A Qualitative Analysis of Patients' Concerns about Breast Implants and a Proposed Strategy for Moving Forward. Plast Reconstr Surg. 2021;147(1):16e-24e. 


\section{CHAPTER 7}

Dutch Summary | Nederlandse samenvatting
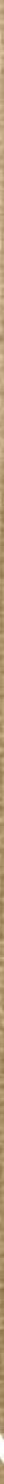


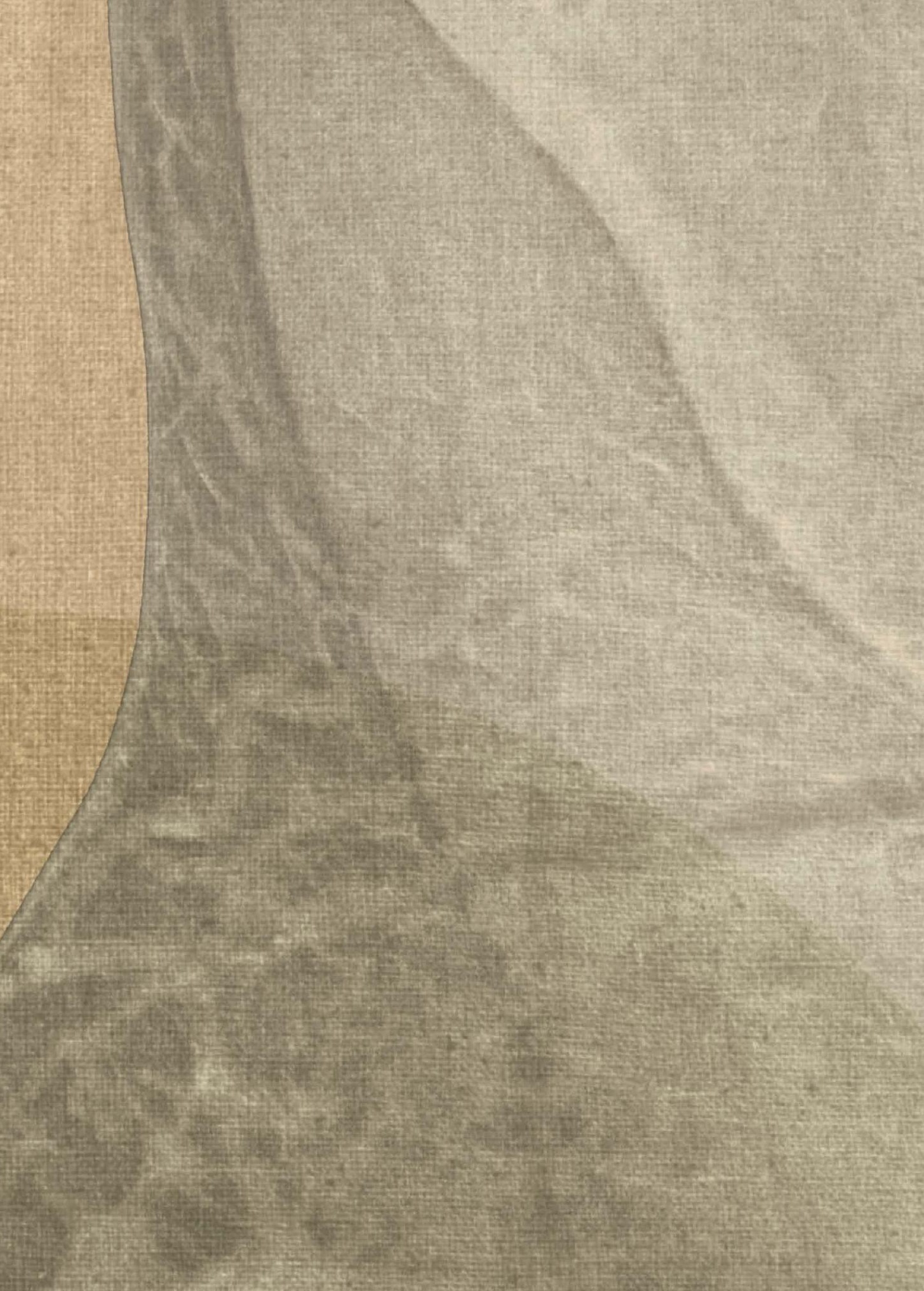





\section{DUTCH SUMMARY | NEDERLANDSE SAMENVATTING}

Wereldwijd ondergaan een groot aantal vrouwen een borstoperatie vanwege cosmetische of reconstructieve reden, waarbij siliconen borstimplantaten worden geplaatst. Een geselecteerde groep vrouwen ontwikkeld een spectrum aan onverklaarbare lichamelijke symptomen na het implanteren van borstimplantaten. Of deze lichamelijke klachten een direct gevolg zijn van de siliconen borstimplantaten staat na decennia aan wetenschappelijk onderzoek tot op heden nog steeds ter discussie. Welke vrouwen en hoeveel vrouwen lijden aan deze lichamelijke symptomen alsmede aan auto-immuun ziekten, is onduidelijk. Dit fenomeen staat in de literatuur bekend als, siliconen borstimplantaatziekte' (in het Engels: Silicone Breast Implant Illness (SBII)). In Nederland hebben nationaal ongeveer 6000 vrouwen hun zorgen en gezondheidsklachten online gerapporteerd bij de Nederlandse vereniging Meldpunt Klachten Siliconen (MKS), een vereniging voor vrouwen die hun klachten beoordelen als een direct gevolg van hun siliconen borstimplantaten. Wetenschappelijk onderzoek heeft inmiddels aangetoond dat vrouwen met borstimplantaten meer kans hebben op borstimplantaatgeassocieerd anaplastisch grootcellig lymfoom (BIA/ALCL), een zeldzaam type nonhodgkinlymfoom.

Het doel van dit proefschrift was om inzicht te krijgen in de (systemische) gezondheidsklachten waar patiënten met siliconen borstimplantaten over klagen en om inzicht te krijgen in welke en hoeveel siliconen borstimplantaat patiënten deze gezondheidsklachten ervaren. Op basis van dit proefschrift hebben we het spectrum van gezondheidsklachten bij vrouwen met siliconen borstimplantaatziekte kunnen bepalen en hebben we vastgesteld dat dit spectrum in de loop van de jaren in grote lijnen ongewijzigd is gebleven. De meest bekend beschreven symptomen die vrouwen met siliconen borstimplantaatziekte ontwikkelen zijn vermoeidheid, gewrichtspijnen en/of spierpijnen, brain fog, oftewel moeite met concentreren en geheugenverlies, droge ogen en/of een droge mond, koorts en verschillende auto-immuunziekten.

In hoofdstuk 1 wordt als onderdeel van de inleiding van het proefschrift, een overzicht van de bestaande literatuur aangaande het bestaan van siliconen borstimplantaatziekte weergegeven. Daarbij wordt het concept dat de laatste jaren 
gesuggereerd wordt, dat siliconen borstimplantaatziekte een gevolg is van migratie van siliconen partikels door het lichaam, verder uitgewerkt. De studie beschrijft dat zowel door rupturen als ook het 'zweten' van siliconen borstimplantaten (het lekken van kleine siliconen gel-druppeltjes door een intact omhulsel van het implantaat), siliconen door het lichaam kan verplaatsen en in weefsel kan opstapelen. In de beschreven studies wordt een mogelijk verband gelegd tussen allergieën, auto-immuun ziekten en andere afwijkingen. Aanvullend epidemiologisch en basaal onderzoek van voldoende grootte en kwaliteit zal nodig zijn om bewijs te genereren tussen migratie en (auto)inflammatoire processen.

In hoofdstuk 2 wordt een cohortstudie beschreven, waarbij een groep van honderd vrouwen met siliconen borstimplantaten gediagnosticeerd met borstimplantaatziekte in 2014 in Maastricht, wordt vergeleken met een groep van honderd vrouwen gediagnosticeerd met borstimplantaatziekte in de Baylor College of Medicine (Houston, USA) tussen 1985 en 1992. Andere beschreven cohortstudies uit de literatuur werden eveneens geanalyseerd en beschreven aangaande de lichamelijke symptomen die door borstimplantaat patiënten worden gerapporteerd. Geconcludeerd kan worden dat er een grote overeenkomst bestaat in het spectrum van lichamelijke symptomen dat de twee onderzochte groepen, alsook in de andere 18 geanalyseerde cohort studies, wordt beschreven. Deze studie bewijst dat de verschillende aanpassingen en materialen die gedurende de jaren gebruikt zijn voor de ontwikkeling van siliconen borstimplantaten, geen invloed hebben op het spectrum van klachten die door de vrouwen beschreven worden.

In hoofdstuk 3 wordt een cohort studie naar het vitamine D-gehalte als risicofactor voor het ontwikkelen van auto-antistoffen in siliconen borstimplantaat patiënten beschreven. Daarnaast wordt de literatuur naar vitamine D-gehalten en de aanwezigheid en/of titer waarden van auto-antistoffen in andere autoimmuunziekten systematisch weergegeven. Vitamine D-tekort bleek gerelateerd te zijn aan de aanwezigheid van auto-antilichamen bij patiënten met siliconen borstimplantaatziekte. Een kanttekening van deze studie is het ontbreken van een controle groep: of vitamine $D$ deficiëntie derhalve ook gerelateerd is aan de aanwezigheid van auto-antilichamen bij patiënten zonder siliconen borstimplantaten is onbekend. Vitamine D kan fungeren als een regulerend middel 
van het immuunsysteem. Gerandomiseerd, gecontroleerd wetenschappelijk onderzoek moet worden uitgevoerd om uit te zoeken of vitamine D-suppletie als preventieve therapie gebruikt kan worden om het ontwikkelen van autoantistoffen bij patiënten met siliconen borstimplantaten te reduceren.

In hoofdstuk 4 wordt een systematische review van de literatuur naar het effect van explantatie van siliconen borstimplantaten bij patiënten met lichamelijke symptomen en/of auto-immuunziekten beschreven. Na explantatie van siliconen borstimplantaten, blijkt dat bij ca. $75 \%$ van de patiënten de lichamelijke symptomen subjectief verbeteren en/of verdwijnen. In patiënten die reeds een auto-immuunziekte ontwikkeld hebben, is verbetering van de lichamelijke symptomen alleen te zien in combinatie met aanvullende immunosuppressieve therapie. Een meer recente studie van onze studiegroep in een cohort van 197 patiënten (met in totaal 303 borstimplantaten) laat zien dat siliconen borstimplantaatziekte de $5^{\mathrm{e}}$ meest voorkomende indicatie is voor het verwijderen van de borstprothesen (11.2\%).

In hoofdstuk 5 wordt een cohortstudie naar het subjectief cognitief functioneren van patiënten met siliconen borstimplantaten in vergelijking met gezonde controles gepresenteerd. Om dit cognitief functioneren te meten, wordt gebruik gemaakt van de CFQ-vragenlijst ('Cognitive Failure Questionnaire'), waarbij de frequentie van alledaagse cognitieve vergissingen wordt nagegaan als maat voor cognitieve competentie of belastbaarheid. Het onderzoek laat zien, dat patiënten met siliconen borstimplantaten hetzelfde cognitief scoren in vergelijking met gezonde controle patiënten. Patiënten met siliconen borstimplantaten in het algemeen hebben minder frequent en minder ernstige cognitieve vergissingen in vergelijking met patiënten met siliconen borstimplantaten die hun lichamelijke symptomen kenbaar maakten bij de Nederlandse vereniging MKS. Er kon geen relatie worden gevonden tussen de ernst van het cognitief functioneren met de aanwezigheid van rupturen van de borstimplantaten en/of de duur van siliconen blootstelling. Een beperking van deze studie is, dat er een subjectief screeningsinstrument wordt gebruikt voor de beoordeling van cognitieve disfunctie. Objectief cognitief functioneren zou in toekomstig wetenschappelijk onderzoek uitgevoerd kunnen worden met behulp van functioneel MRI-onderzoek 
vóór en na implantatie van siliconen borstprothesen met voldoende follow-up duur.

\section{Conclusie}

Siliconen borstimplantaatziekte blijft als buitengewoon symptoomcomplex tot heden een beperkt begrepen fenomeen. Lange-termijn uitdagingen zullen liggen in het voorkomen van het ontwikkelen van lichamelijke symptomen na implantatie van siliconen borstimplantaten. Identificatie van een bepaald risicoprofiel kan specifieke vrouwen selecteren en bijdragen aan betere voorlichting. Vrouwen met uitgebreide allergieën en/of reeds bestaande auto-immuunziekten moeten extra gewezen worden op mogelijke effecten van siliconen borstimplantaten. Alternatieve borstvergrotingsprocedures, bijvoorbeeld door lipofilling of autologe reconstructies, zijn onderwerp van toekomstig onderzoek en kunnen specifiek worden aangeboden aan vrouwen met risico op borstimplantaatziekte. Aanvullend bewijs vanuit experimenteel (lab)onderzoek is nodig voor een beter begrip van de pathofysiologie van siliconen borstimplantaatziekte. 

CHAPTER 8 Impact Paragraph 


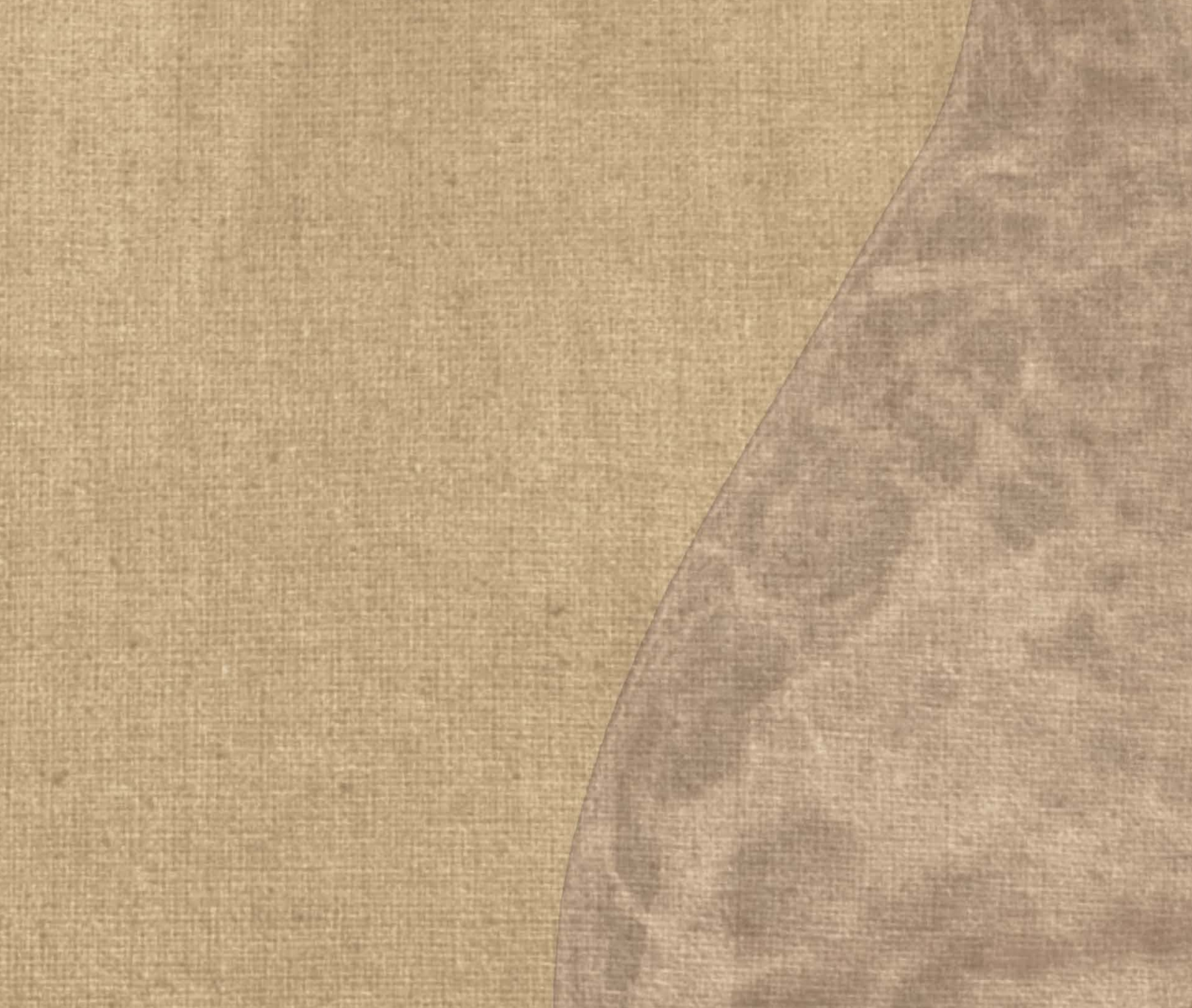





\section{IMPACT PARAGRAPH}

The safety and adverse effects of Silicone Breast Implants (SBI) are still a matter of debate. There are women around the whole world that claim a widespread spectrum of health complaints after implantation of silicone breast implants. During recent years, these health complaints are referred to as Silicone Breast Implant Illness (SBII). Previously, it was also reported in the literature as Autoimmune/Inflammatory Syndrome Induced by Adjuvants (ASIA). In the Netherlands, about 6000 women made their concerns and health complaints public on the World Wide Web by the Dutch Foundation for Women with Illness due to Breast Implants (Meldpunt Klachten Siliconen [MKS]). Which women are at risk and how many women actually suffer from silicone breast implants is still not known.

The research conducted in this thesis has a high clinical significance and social impact. The main aim of this thesis was to determine insight in the (systemically) health complaints that silicone breast implant patients are complaining about as well as to determine insight in which and how many SBI patients experience these health complaints. From this thesis, we were able to determine the spectrum of health complaints in women with SBII and found that this spectrum is broadly unchanged during the years. The most commonly symptoms SBII patients are reporting are fatigue, arthralgia and/or myalgia, brain fog, memory loss and concentration problems, dry eyes and/or dry mouth, pyrexia and autoimmune diagnosis. Having knowledge of the symptoms silicone breast implant patients may have is clinically relevant, not only for plastic surgeons, but also for doctors of other specialisms (e.g. internist, rheumatologist, immunologist) as well as the general practitioner to whom these women can report.

Women with concerns about the potential risks of their breast implants are frequently misunderstood and unheard from doctors where they report their complaints. In the last decade, national attention has been drawn to the concerns in various ways. Especially in the media extensive attention have been paid, several times by the Dutch television program ,Radar', more known from their international research in 2018 named ,The Implant Files', as well as for example the more recent petition ,Calm Your Tits' of Jamie Crafoord in cooperation with the Dutch Foundation for Women with Illness due to Breast Implants (Meldpunt Klachten Siliconen [MKS]). We cannot determine whether the concerns of SBII 
patients are exacerbated by media reports. However, the general concerns of women about the potential risks of their breast implants are nationally and internationally acknowledged by plastic surgeons. In the Netherlands, the Dutch Breast Implant Registry (DBIR), introduced in 2015, has included SBII as part of the registry. In 2017, the National Institute of Public Health and the Environment (RIVM) was commissioned by the Dutch Health and Youth Care Inspectorate to investigate the health complaints of women with silicone breast implants.

This thesis showed that SBI patients have less frequent and less severe cognitive failure than SBI patients who made their complaints public (SBII). No difference could be found in subjective cognitive functioning between SBI patient without self-reported compared to healthy control patients. Other research performed by our research group on the prevalence of self-reported health complaints in woman with SBI compared to controls also showed that, after adjustment for potential confounders (e.g. age, smoking, and comorbidities), the prevalence of clinical symptoms was only higher in the group of the self-reported women who made their complaints public. The adjusted prevalence in women with SBIs without selfreported health complaints did not differ from women without breast implants. The fact that complaints of implants are mainly seen in a selected self-reporting group of SBI patients, suggests that only a selected group of patients suffers from SBII and that adverse effects of implants is not generalizable for the whole SBI population. However we also observed that after explantation of the SBI, the complaints remarkably improved in about $75 \%$ of the patients. In patients with a developed autoimmune disease, improvement only occurred when explantation is combined with immunosuppressive therapy. If explantation should be used as a standard therapy option for SBII patients should be further studied in prospective research studies with longer follow-up.

The contribution of the results of this thesis further enlighten the complex issue of SBII. Non-selected SBI patients should be studied preferably in a prospective way and compared to matched representative control patients. To help the current group of SBII patients, the Dutch Healthcare Authority (NZa) already agreed that reimbursement of explantation of SBI should be given by health insurers once the diagnose of SBII is made by a medical specialist. Importantly, SBII patients have to be taken seriously in their health complaints. Women who consider breast augmentation with silicone breast implants have to be informed with clear and honest information by physicians about the risks known until now. Furthermore, 
information should be accessible and have to be handed out by plastic surgeons as an information folder during the consultation. Doctors who treat these women should have awareness about SBII. In the Netherlands, the Dutch plastic surgery society has introduced an extensive package leaflet, which has to be given to all patients before implant surgery takes place.

The long-term societal challenges will be to prevent health complaints after implantation of silicone breast implants. Identification of a particular risk profile can discourage specific women to take silicone breast implants. Women with extensive allergies and/or pre-existent autoimmune diseases should be discouraged to take SBI. Moreover, alternative augmentation procedures (e.g., thru fat transfer or autologous reconstruction) are subject of future research, which may be especially offered to women at risk for SBII. 


\section{CHAPTER 9 Addendum}
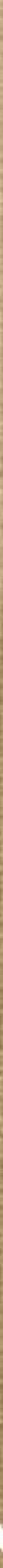


\section{Acknowledgements | Dankwoord}




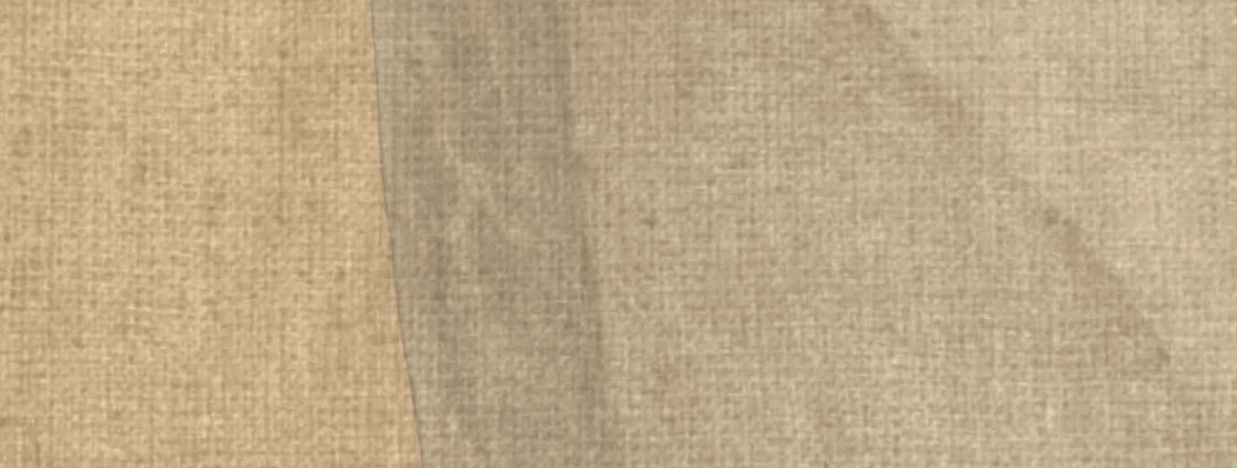

(2)

(1)

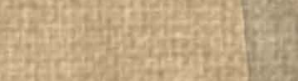

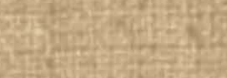

(5)

-

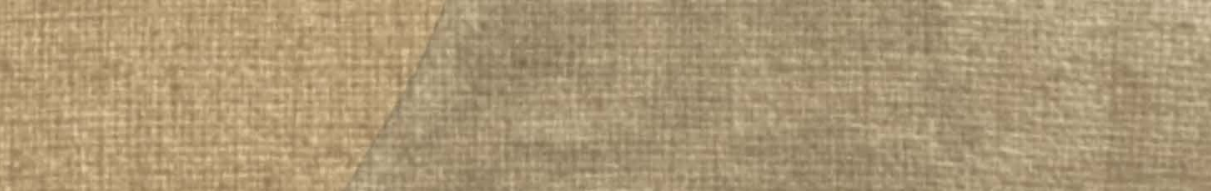

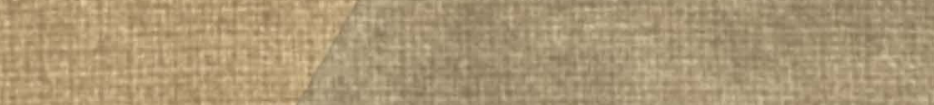

(2)

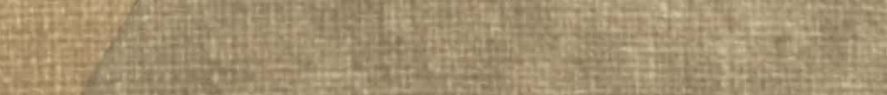

14. 



\section{ACKNOWLEDGEMENTS | DANKWOORD}

Wat begon als interesse in 'een kijkje nemen' in onderzoek, groeide uit in een promotie en dit proefschrift. Uiteraard was dit alles niet mogelijk geweest zonder hulp en steun van allemaal individueel bijzondere mensen om mij heen, die ik hier dan ook in het bijzonder wil bedanken.

Als eerst bedank ik mijn promotoren.

Professor dr. van der Hulst, mijn eerste promotor; $u$ bent degene die mij introduceerde in het onderwerp van dit proefschrift toen ik enkele jaren geleden bij $u$ aanklopte voor 'een kijkje' in onderzoek binnen uw afdeling. $U$ liet mij kennismaken met het vak waar ik altijd van droomde, plastische chirurgie. U liet mij kennismaken met de wereld van de wetenschap, die voor mij destijds nog volledig groen was. $U$ liet mij kennismaken met mijn inmiddels tweede promotor. Ik wil u bedanken voor uw vertrouwen in mij en dit promotietraject. Het onderwerp van dit proefschrift is en blijft een wetenschappelijke uitdaging, die $u$ al reeds enkele jaren ten volste gesteund heeft en ook toekomstig zal blijven steunen. Ik wil u bijzonder bedanken voor uw geduld en begrip op de momenten dat ik een stap terug moest doen. $U$ heeft mij weten te begeleiden als een volwaardig promotor tot het eind. René, bedankt!

Professor dr. Cohen Tervaert, mijn tweede promotor; Als hoogleraar in de interne geneeskunde/ immunologie wist u als een van de weinige specialisten in Nederland een aanspreekpunt te zijn voor de Bll patiënten. Met uw luisterend oor voelden zij zich ten alle tijden gehoord. Ik dank $u$, dat ik uw series patiënten mocht benaderen voor onderzoek uit dit proefschrift. Ik dank $u$, voor de wekelijkse besprekingen en begeleiding, vooral in de beginfase van mijn promotietraject. Ik dank $u$, voor uw selectief nakijkwerk en correcties van de manuscripten. Eveneens toen u naar Canada emigreerde, wist u de begeleiding van mijn promotietraject ook op deze afstand tot het eind te voltooien. Jan Willem, bedankt!

Geachte leden van de promotiecommissie; professor dr. Tjan-Heijnen, professor dr. Boonen, dr. Rakhorst, dr. van Bastelaar en professor dr. van Koeveringe. Ik dank jullie voor jullie kritische blik en positieve beoordeling van dit proefschrift. Een persoonlijke dank aan professor Boonen, voor het prompt inspringen als 
waarnemend voorzitter voor de beoordeling van mijn proefschrift. Dr. Rakhorst, dank voor de inspiratie die ik heb gekregen van uw eigen onderzoeken. Het door u ontwikkelde en geïmplementeerde Nederlands Borstimplantatenregister (DBIR), is niet alleen een unicum voor Plastisch Chirurgie Nederland, maar in het bijzonder van groot belang voor de kwaliteit en veiligheid van de borstimplantaat patiënten en toekomstig wetenschappelijk onderzoek in deze.

Ik wil mijn dank betuigen aan alle deelnemende ziekenhuizen, collega plastisch chirurgen en alle patiënten die bereid zijn geweest voor hun deelname en medewerking aan het onderzoek als onderdeel van dit proefschrift. Zonder jullie was dit proefschrift niet mogelijk geweest.

Secretariaat van de afdeling Plastische Chirurgie van het MUMC+; bedankt voor het in goede banen leiden van de hoeveelheden post die in en uit gingen voor mijn onderzoek. Zonder jullie zijn er gelukkig geen brieven verloren gegaan.

Geachte mede-auteurs; dank voor jullie input en medewerking aan de afsluitende studie van dit proefschrift. In het bijzonder mijn dank aan professor $d r$. Ponds; met uw aanbevolen en ontwikkelde vragenlijst, de 'Cognitive Failure Questionnaire', hebben we de basis voor de laatste studie kunnen leggen en een beeld kunnen krijgen van het subjectief cognitief functioneren van Bll patienten. Hopelijk mogen ook uw andere aanbevelingen toekomstig nog tot uitvoering gebracht worden en van meerwaarde zijn om een beter beeld te krijgen van het complexe fenomeen 'Silicone Breast Implant Ilness'.

Amanda Kaas; je was altijd vriendelijk en toegankelijk om ideeën uit te wisselen over de studieopzet van onze fMRI-studie. Je vertelde gepassioneerd over je eigen ervaringen in het wetenschappelijk onderzoek naar o.a. somatosensorische waarneming en pijn binnen de afdeling Cognitive Neuroscience (FPN) en kwam met waardevolle input. Amanda, helaas blijven onze gesprekken nu slechts een herinnering, ik zal uw ambitie en enthousiasme meenemen als drijfveer in mijn toekomstige carrière.

Renée Miseré; mijn opvolgster in onderzoek naar het thema van deze thesis 'Breast Implant IIIness (BII)'. Renée, ik dank jou dat je mijn data niet verloren hebt laten gaan en verder aan de kar hebt getrokken. Ik dank je in het bijzonder, dat je de belangrijke fMRI-studie tot uitvoering hebt weten te brengen. Jong en gedreven 
ben je ervoor gegaan en inmiddels ook in de afrondingsfase van je promotie. Chapeau! Ik wens je alle geluk en succes met je nieuwe uitdaging in de kliniek als ANIOS Plastische Chirurgie in het Zuyderland Medisch Centrum.

Jean en Tiny; de vormgeving van dit proefschrift was zonder jullie hulp niet geworden wat het nu is. Dank Tiny, voor iedere keer weer de aanpassingen door te voeren die ik van u vroeg. Jean, bedankt voor het eindresultaat van het design waarin je het ontwerp van mijn zus hebt opgenomen. Je hebt mijn ideeën nóg mooier weten om te zetten dan ik zelf had kunnen wensen.

Herr Professor Beier; ich danke Ihnen, dass Sie mir die Möglichkeit gegeben haben, bei Ihnen die Facharztausbildung Plastische Chirurgie an der Uniklinik RWTH Aachen ausüben zu dürfen. Ich möchte mich auch dafür bedanken, dass Sie mir die Möglichkeit geben experimentelle Forschung bzw. Tissue Engineering unten Leitung von Herrn Ruhl in unserem Labor zu lernen und durchzuführen und ich freue mich schon auf das neue Labor.

Jörg und Astrid; ich danke euch, für die herzliche und warme Aufnahme in eures kleines, sympathisches Team der Plexus- und peripheren Nervenchirurgie. Astrid; du hattest und hast auch noch immer ein offenes Ohr für mich. Du bist ein menschen-Mensch, bleib so wie du bist. Jörg; Ich danke dir für deine MentorenGespräche; nicht nur professionell, sondern auch privat warst und bist du mir im vergangenen Jahr eine große Stütze. Ich bewundere ihre Art von Medizin praktizieren, besonders mit den kleinsten und jüngsten Patienten die wir haben. Du bist ein Vorbild für mich. Vielen Dank, dass ich diese Erfahrung mit dir machen und genießen durfte.

Naast promoveren is er natuurlijk meer in het leven. Uiteraard wil ik ook mijn familie en vrienden bedanken voor hun steun langs de zijlijn van het gehele promotietraject. Alle familie en vrienden die hieronder niet apart vernoemd zijn, dank ik uiteraard ook.

Sarah und Francesco; ihr seid mehr als nur Kollegen, ihr seid Freunden, die ich nicht aus den Augen verlieren werde. Gemeinsam sind wir die drei Musketiere der 
Plastischen Chirurgie des Uniklinikums Aachen. Die Kaffees (nicht zu vergessen die Eiskaffees), Hamburger, gemeinsamen Polikliniken, OPs und all die Momente, in denen wir miteinander 'quatschen' können, sind für mich Gold wert. Besondere Erinnerungen sind die Abendessen und Ausflugsabende zu Hause in Maastricht, aber auch jetzt in meiner neuen Heimat Geetbets, sind nicht zu vergessen. Ihr Süßen, ihr seid großartig!

Lieve Lieke, Suus, Max, Elke, Ashley en Mintsje; Een dag niet geflaneerd of geëscaleerd, is voor ons een dag niet geleefd. Helaas gooit Covid-19 roet in ons levensmotto, maar we kijken gezamenlijk uit naar nieuwe avontuurlijke borrelavonden in de Koestraat in Maastricht of op het strand in Zeeland of Den Haag bij ons Suus.

Maxie, dank voor je Rotterdamse nuchterheid en altijd eerlijke mening. Ik mis onze McDonalds cravings, want alleen jíj begrijpt deze verslaving als tijdsinvulling voor een break. Elke, leeve, dank voor er te zijn voor mij. Ook met weinig woorden begrijpen wij elkaar. Onze laate en zaate carnavalsdagen in Maastricht op ons favoriet plekje in de Koestraat staan in mijn hart gekerfd en er zullen nog velen volgen. Met jou wil ik, danse tot t morgeleech'! Ashke, wat ben ik trots op je! Je dromen achterna en nog even en dan is het zover, niet meer met twee. Jij gaat dat fantastisch doen samen met Tom. Ik verheug me jullie kleine te mogen komen bewonderen. Minteke, van onderzoekspartners en collega's naar vriendinnetjes. Nu we beiden onze promotie hebben afgerond, is het hoog tijd onze borrelavonden weer op te pakken. Wie weet mogen we als toekomstig plastisch chirurgen weer samen op OK staan!

Suus en Liek; waar moet ik beginnen? Ik citeer Suus: "dankjewel Liek, Suus en Basilica". Daar zit zeker de kern van waarheid als het gaat over ons, maar ik zal toch proberen persoonlijke woorden op papier te zetten. Onze jaren in Maastricht en jullie steun zijn niet samen te vatten in een paar regels. Wij waren met 3 personen 1, ieder z'n eigen plekje, maar tóch altijd bij elkaar. Ik koester deze mooie momenten, die neemt niemand ons meer af. Ook nu we verder van elkaar wonen, houdt dat ons niet tegen dagelijks op de hoogte te zijn van elkaars levens met bijbehorende ups en downs. Jullie wijze woorden houden mij tot de dag van vandaag bij de les, wanneer ik weer eens verzink in mijn laptop; "Maart, een dag heeft maar 24 uur", "Pas je op.." en "Papa zou zeggen dat...". Lieverds, ik dank jullie altijd klaar te staan. Weet dat jullie een 
bijzonder plekje hebben bij mij. Ik zal het hier afronden, want als het aan mijn whisky ligt, dan wordt het een veel te sentimentele bedoeling en denk ik opeens ook als Suus romans te kunnen schrijven.

Fabian; dank voor de borrels, zowel thuis als bij Thiessen. Ons gesprek in 'Salle Thiessen' gaf mij nieuwe input de schouders er verder onder te zetten mijn promotie af te ronden. Nu er een oppas is én mijn promotie is afgerond, ga ik wel op meer avonden met jullie rekenen. Onze wijnkelder is vanavond nog aangevuld ;)

Paranimfen Eugenie en Eva; onze vriendschap gaat al heel wat jaren terug toen we ons leerden kennen in de verpleegkunde opleiding. Jullie beiden zijn sindsdien nooit van mijn zijde weg gegaan en ik dank jullie daarvoor. Jullie zijn een enorme steun geweest op mooie momenten, op moeilijke momenten of wanneer er belangrijke beslissingen genomen dienden te worden.

Liefste Evie; toen ik je vroeg als paranimf wist je nog niet wat er op je afkwam. Al snel kreeg ik je bericht dat je je oprecht vereerd voelt dat ik je vroeg deze rol op je te nemen. En dat is ook niet onterecht. Je was en bent er altijd voor mij op belangrijke momenten; oprecht, eerlijk, behulpzaam en betrouwbaar. Gewoon zoals je bent. Bedankt dat je ook nu, ondanks alles, naast me wilt staan. Ik waardeer dat enorm en beloof je dat ook ik, als vriendin van jou, je ten alle tijden zal steunen waar je me nodig hebt. Bedankt voor je betrokkenheid lieve Evie!

Liefste Eugenie; voor jou kent vriendschap letterlijk geen grenzen. Het is niet de eerste keer dat je een belangrijke reis omboekt om aan mijn zijde te kunnen staan en je weet hoe ik dat waardeer. Wat wij samen hebben is niet in woorden uit te drukken. Of het nu om nieuwe mooie levenservaringen gaat, of de helaas harde lessen uit ons leven, jij bent er altijd! Lieve Eugenie, jij bent mijn vriendin die mij het best kent en begrijpt. Je bent onvoorwaardelijk steunend, dank daarvoor. Uiteraard mocht jij dan ook niet in de rol als paranimf ontbreken. Ik dank je, dat ook hier bij jou geen enige twijfel over mogelijk was. Ik dank je, voor je begrip en de vrijheid die je me gegeven hebt de afgelopen tijd om 'belangrijke zaken af te ronden'. Ik beloof je, dat wij deze tijd dubbel en dik gaan inhalen. Ik kan niet wachten, dank je lieve Eug! 
Liefste Matilda; friemel. Bedankt voor het opbrengen van je geduld en begrip voor mijn drukke werk, van huis zijn tijdens de dienst, slapen na de dienst of als ik wederom geen tijd had met je een spelletje te spelen. Ik waardeer je nu al grote interesse in dat wat ik doe en de kritische vragen die je me stelt. Dat belooft wat. Wij gaan nog vele mooie herinneringen maken samen met jouw papa, thuis, op vakantie, en niet te vergeten op onze boot Vaiana. Ik kijk ernaar uit!

Liefste mama, Femke, Jo, Mathis, Line en ..., Guido en Anaïs, Bram en Svetlana; wat hebben we bewogen jaren achter de rug. Onze uiteenlopende persoonlijkheden maakt dat we ieder zijn en staan waar we nu zijn, met ieder zijn eigen manier van het tot uiting brengen van onze gemeenschappelijke factor 'Colaris power'. Ik wil jullie bedanken dat jullie er, ondanks de afstanden, allen zijn om de verdediging bij te wonen. Fem; ik wil jou bijzonder bedanken voor de tijd die je hebt vrijgemaakt naast je drukke buitenlandse werkopdrachten, om de mooie illustraties van mijn proefschrift te ontwerpen. Met één woord weet je als zus altijd precies wat ik bedoel en kun je weer iets moois tevoorschijn toveren. Ik ben trots op je werken en weet dat papa dat ook zal zijn!

Liefste Papa; wat is het moeilijk woorden op papier te zetten voor jou. Er gaat geen dag voorbij dat ik niet aan je denk. Je woorden "altied kump alles good"' en "het venijn zit hem in de staart" zijn woorden waaraan ik vaak heb gedacht tijdens het afronden van mijn promotie. Ik mis je steunende gesprekken en interesse in wat ik doe. Ik zou wensen dat je erbij kon zijn; maar papa, ik weet dat je meekijkt en trots zult zijn. Zoals ik beloofd heb, zal ik mijn droom om plastisch chirurge te worden waarmaken. Papa, ik zal jou nooit vergeten en koester onze waardevolle herinneringen "met een gouden randje".

Allerliefste Steven; ik dank je, te zijn wie je bent. Ik dank je, voor altijd naast me te staan. Ik dank je, voor al je steun en onvoorwaardelijke liefde. Ik dank je, voor je geloof in mij en ons. Ik dank je, mij iedere keer weer in de realiteit te houden. Ik dank je, voor het geluk dat jij me geeft. Ik dank je, dat wij samen durven dromen en verheug me op onze toekomst. Ik hou van jou! 



\section{Author's list of publications}





\section{AUTHOR'S LIST OF PUBLICATIONS}

\section{Published}

David PR, Dagan A, Colaris MJL, de Boer M, Cohen Tervaert JW, Shoenfeld Y. ChurgStrauss Syndrome: Singular or Silicone (or both?). Isre Med Assoc J. 2016 MarApr;18(3-4):168-70.

Colaris MJL*, de Boer $\mathrm{M}^{*}$, van der Hulst RRWJ, Cohen Tervaert JW. Two hundreds cases of ASIA syndrome following silicone implants: a comparative study of 30 years and a review of current literature. Immunol Res. 2017 Feb;65(1):120-128. I ${ }^{*}$ Contributed equally

De Boer M, Colaris MJL, van der Hulst RRWJ, Cohen Tervaert JW. Is explantation of silicone breast implants useful in patients with complaints? Immunol Res. 2017 Feb;65(1):25-36.

Colaris MJL, van der Hulst RRWJ, Cohen Tervaert JW. Vitamin D deficiency as risk factor for the development of autoantibodies in patients with ASIA and silicone breast implants: a cohort study and review of the literature. Clin Rheumatol. 2017 May;36(5):981-993.

Cohen Tervaert JW, Colaris MJL, van der Hulst RRWJ. Silicone breast implants and autoimmune rheumatic disseases: myth or reality. Curr Opin Rheumatol. 2017 Jul;29(4):348-354.

Colaris MJL, Cohen Tervaert JW, Ponds RWHM, Wilmink JW, van der Hulst RRWJ. Subjective Cognitive Functioning in Silicone Breast Implant Patients: A Cohort Study. Plast Reconstr Surg Glob Open. 2021 Feb;9(2):e3394.

Miseré RML, Colaris MJL, van der Hulst RRWJ. The Prevalence of Self-Reported Health Complaints and Health-Related Quality of Life in Women With Breast Implants. Aesthet Surg J. 2021 May;41(6):661-668. 


\section{Submitted}

Colaris MJL, RuhI T, Beier JP. Effects of Silicone Breast Implants on human cell types in vitro: A closer look on host and implant.

\section{Manuscripts in preparation}

Miseré RML, Rutten S, van den Hurk J, Colaris MJL, van der Hulst RRWJ. Neuroimaging in Breast Implant Illness: an fMRI pilot study.

Colaris MJL, Ruhl T, Beier JP. The effect of Silicone Breast Implants on viability and differentiation of human cell types: an experimental in vitro study.

\section{SCIENTIFIC MEETINGS}

The $3^{\text {rd }}$ International congress on controversies in rheumatology \& autoimmunity, March 12-14, 2015, Sorrento, Italy.

Colaris MJL, de Boer M, Cohen Tervaert JW. How many clinical manifestations need to be present to diagnose 'Autoimmune/Inflammatory Syndrome Induced by Adjuvants' (ASIA) following silicone breast implants?

The $10^{\text {th }}$ International congress on autoimmunity, April 6-10, 2016, Leipzig, Germany.

Colaris MJL, de Boer M, van der Hulst RRWJ, Cohen Tervaert JW. Vitamin D deficiency as a risk factor for immunodeficiency and autoimmunity in patients with ASIA due to silicone breast implants.

The $4^{\text {th }}$ International congress on controversies in rheumatology \& autoimmunity, March 9-11, 2017, Bologna, Italy.

Colaris MJL, de Boer M, Wilmink J, van der Hulst RRWJ, Cohen Tervaert JW. Everyday cognitive impairment in ASIA patients with silicone breast implants. 
The $7^{\text {th }}$ European Association of Plastic Surgeons (EURAPS) Research Council Meeting on May 16, 2018, Madrid, Spain.

Colaris MJL, Ponds RWHM, Wilmink JW, van der Hulst RRWJ, Cohen Tervaert JW. Everyday cognitive impairment in ASIA patients with silicone breast implants.

\section{GRANT}

Brains Unlimited Pioneer Fund, July 2016 | Subsidy for the use of hours on the MR system at the MRI scanning facility of Scannexus. Board of the University Fund Limburg/SWOL. 


\section{About the author}




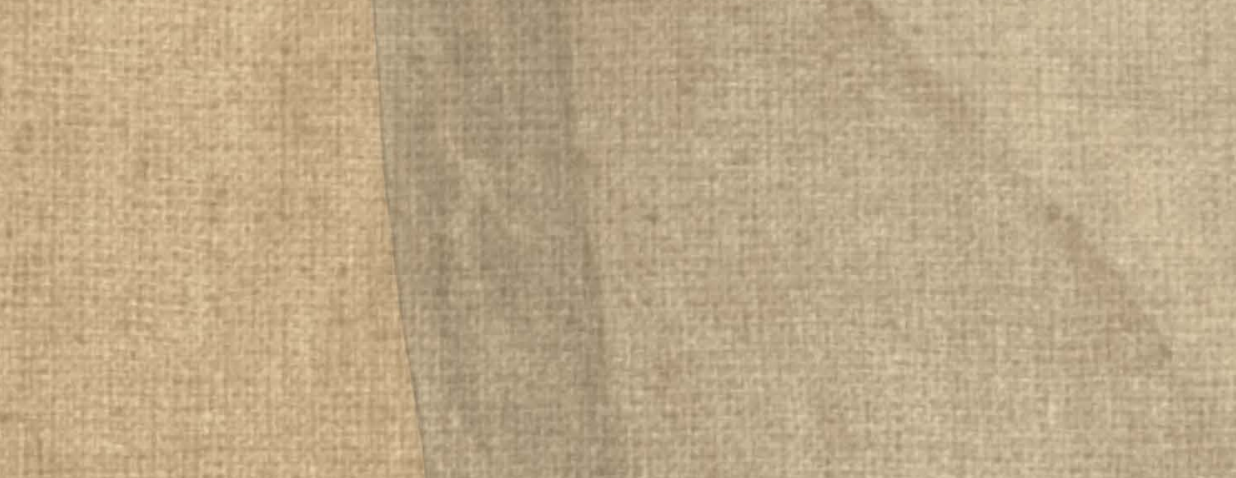

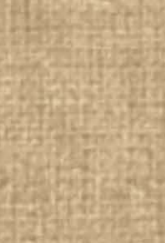

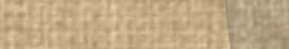

$x^{2}=x^{2}$

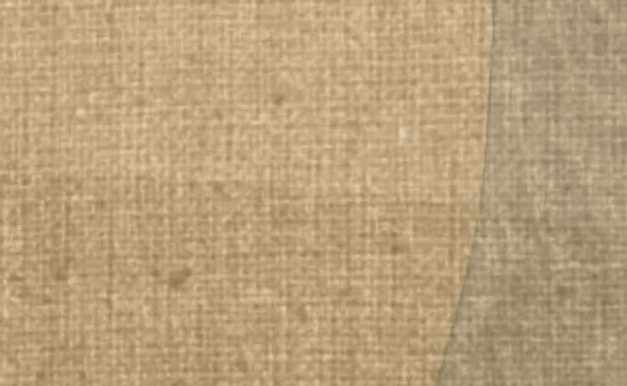

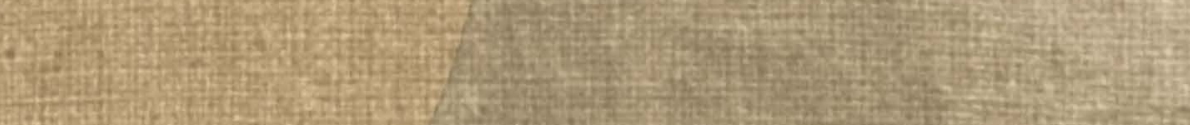

(14t)

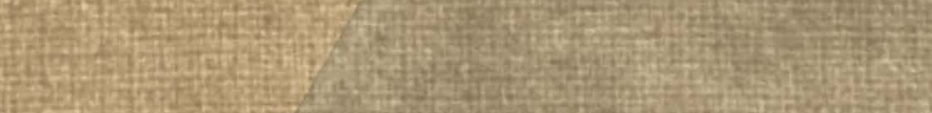

(15)

9.

C.5.

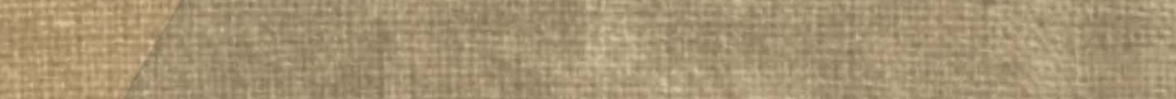

(1)

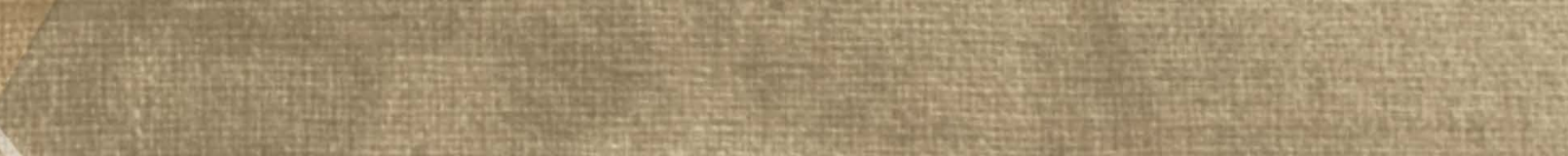
and

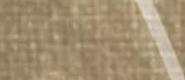

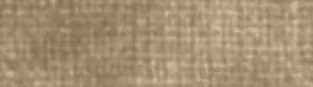

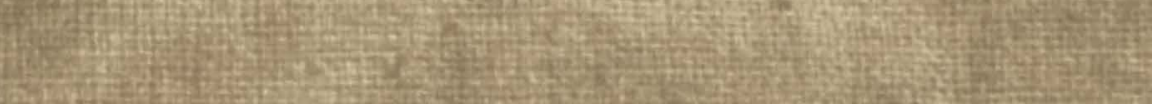





\section{ABOUT THE AUTHOR}

Maartje Josephine Lambertina Colaris was born as the second child of four on May 14 ${ }^{\text {th }}, 1987$ in Meerssen, the Netherlands. In 2009, she obtained her Bachelor of Nursing (BN) and started as an Emergency Nurse at the Emergency Department of the Maastricht University Medical Center.

Her dream of becoming a plastic surgeon was already raised during her work experience as a nurse in the surgery departments, which was confirmed during her working years at the Emergency Department of the Maastricht University Medical Center. In 2013, she took the step to study medicine at Maastricht University to make this dream come true.

During her medical studies, she gained the opportunity in 2014 to start scientific research at the department of Plastic, Reconstructive and Hand

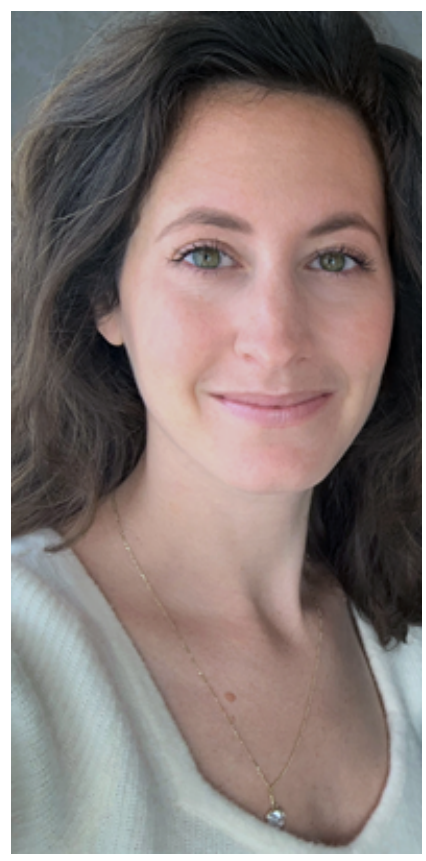
Surgery of the Maastricht University Medical Center under the supervision of Professor dr. René RWJ van der Hulst on the topic of Silicone Breast Implant Illness (SBII). Throughout her medical studies and extracurricular doctoral research, she worked as an Emergency Nurse. In her final year of medical school, she completed a four-month international internship at the Department of Plastic Surgery, Hand and Burn Surgery at the University Hospital RWTH Aachen, Germany. After completing her medical studies in February 2018, she started as a resident not in Training (ANIOS) at the department of Plastic, Reconstructive and Hand Surgery at the Maastricht University Medical Center.

In July 2018, she started as a resident in training (AIOS) at the Department of Plastic Surgery, Hand and Burn Surgery at the University Hospital RWTH Aachen, Germany. She now lives in Belgium and is in her $4 \mathrm{t}^{\text {h }}$ year of residency as a plastic surgeon. Besides her work, she performs experimental in vitro research - tissue engineering - in the laboratory of the Department of Plastic Surgery, Hand and Burn Surgery at the University Hospital RWTH Aachen, Germany. 
